\title{
A Biomechanical Investigation into Force, Power and Bone Morphology
}

Owen, Nicholas J.

How to cite:

Owen, Nicholas J. (2018) A Biomechanical Investigation into Force, Power and Bone Morphology. Doctoral thesis, Swansea University.

http://cronfa.swan.ac.uk/Record/cronfa49070

Use policy:

This item is brought to you by Swansea University. Any person downloading material is agreeing to abide by the terms of the repository licence: copies of full text items may be used or reproduced in any format or medium, without prior permission for personal research or study, educational or non-commercial purposes only. The copyright for any work remains with the original author unless otherwise specified. The full-text must not be sold in any format or medium without the formal permission of the copyright holder. Permission for multiple reproductions should be obtained from the original author.

Authors are personally responsible for adhering to copyright and publisher restrictions when uploading content to the repository.

Please link to the metadata record in the Swansea University repository, Cronfa (link given in the citation reference above.)

http://www.swansea.ac.uk/library/researchsupport/ris-support/ 


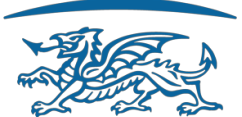 \\ a. \\ 䢗要 \\ Prifysgol Abertawe Swansea University}

A Biomechanical Investigation into Force, Power and Bone Morphology

Nicholas John Owen

Submitted to Swansea University in fulfilment of the requirements for the Degree of Doctor of Philosophy

Swansea University

2018 


\begin{abstract}
Force $(F)$, produced by the neuromuscular system and transmitted by bones, is necessary for locomotion. Performance in activities of daily living and sport requires effective production and use of $(F)$ for optimal outcomes. Quantifying neuromuscular performance, with $F$ and force derived variables, allows monitoring of the effectiveness of training. Strength $(\mathrm{S})$, power $(P)$ and rate of force development $(R F D)$ are important neuromuscular variables (NV) for predicting physical performance, which can be measured using a force platform $(F P)$. This corpus comprises of 5 papers that examine different aspects of force in terms of human performance. Paper 1, investigated using postactivation potentiation $(P A P)$, that may increase $P$ temporarily, on international swimmers and the effect on start time compared to a traditional warm-up. There was no difference in start time although $P$ was enhanced. PAP could be a useful alternative to a traditional warm-up. Paper 2, examined the relationship between isometric $F$ variables and dynamic performance using new method of $F$ analysis. Correlations were found between $R F D$, peak $F$ and $F$ at $100 \mathrm{~ms}$ vs. $10 \mathrm{~m}$ sprint times and jump height. Paper 3, reported the first published criterion method for determining peak mechanical $P(P p)$ in a countermovement jump (CMJ), measured by a $F P$, with an accuracy $<1 \%$. Paper 4, reported $P p$ normative values, which could be used to measure coordination and bone health in children, 7 to 11 years old, as existing, subjective measures are unreliable. Athletes' bones experience high forces, causing changes in their shape and composition. The Mary Rose skeletal collection comprises of 97 skeletons, some of which were elite athletes (archers). Paper 5 reports a valid and reliable method measuring periosteal cross sectional areas to accuracies of $<1 \%$ essential for identification of occupational activity and bone health measurement. NVs are useful metrics for assessing human performance and bone health. Morphometrics of bone health and NVs need to be optimised for validity and reliability in order to derive maximum performance and clinical benefit.
\end{abstract}




\section{Declarations and Statements}

1. I, Nicholas John Owen, hereby declares that the work presented in this thesis has not previously been accepted in substance for any degree and is not being concurrently submitted in candidature for any degree.

2. I, Nicholas John Owen, hereby declares that the thesis is the result of my own investigations, except where otherwise stated and that other sources are acknowledged by footnotes giving explicit references and that a bibliography is appended.

3. I, Nicholas John Owen, hereby gives consent for the thesis, if accepted, to be available for photocopying and for inter-library loan, and for the title and summary to be made available to outside organisations.

Signed: (candidate)

Date: October 2018 
Acknowledgements $\quad 5$

List of figure, tables and abbreviations $\quad 6$

$\begin{array}{ll}\text { List of published works } & 10\end{array}$

Copies of papers 12

Paper $1 \quad 13$

$\begin{array}{ll}\text { Paper } 2 & 20\end{array}$

Paper $3 \quad 27$

Paper $4 \quad 35$

Paper $5 \quad 37$

Critical review $\quad 42$

1 Introduction 43

1.1 A selected brief historical overview of biomechanics 43

1.1.1 Kinematics $\quad 45$

1.1.2 Kinetics $\quad 46$

1.1.3 Anthropometric science $\quad 49$

1.1.4 The effect of loading on human tissue (bone) 51

1.1.5 Methods of imaging bone 53

1.2 Background to the papers presented in this corpus 55

1.2.1 Forces and the process of forward dynamics $\quad 55$

1.2.2 Overview of papers $\quad 57$

$\begin{array}{ll}1.3 \text { Review of papers } & 60\end{array}$

1.3.1 Review of paper $1 \quad 61$

1.3.2 Review of paper $2 \quad 65$

$\begin{array}{ll}1.3 .3 \text { Review of paper } 3 & 70\end{array}$

$\begin{array}{ll}\text { 1.3.4 Review of paper } 4 & 75\end{array}$

$\begin{array}{ll}1.3 .5 \text { Review of paper } 5 & 80\end{array}$

1.4 Discussion $\quad 85$

$\begin{array}{ll}\text { Appendix 1. Substantiations statement by co-authors } & 87\end{array}$

References $\quad 96$ 
Acknowledgements

This thesis represents the culmination of many years of work within the field of biomechanics. However, without the inspiration and support of Eben and Marie-Pierre it would have been possible. Thank you both. Thanks also to Dr Camilla Knight for acting as my advisor, and who is now an honorary biomechanist. Finally, thanks to Professor Jim Watkins for setting me on the correct path many years ago and for remaining a good friend and advisor since that time. 


\section{List of figure, tables and abbreviations}

Figures

Page

Figure 1. A plate from Giovanni Borelli’s De Motu Animalium (1680)

44

Figure 2. Eadweard Muybridge's The Horse in Motion (Library of Congress, Prints \& Photographic Division [reproduction number

LC-DIG-PPMSCA-06607])

Figure 3. Time series trace produced from Carlet's pneumatic gait device representing the vertical component of the ground reaction force of normal gait (adapted from Sunderland, 2005)

Figure 4. A schematic diagram of Amar's Trottoir Dynamographique.

1. Side elevation; 2. Transverse section; B. Platform for the wounded to walk; L, L.

System of levers supporting the platform via part M; R. Coil springs; C. Clevis joint; P. Pneumatic bladder operating a diaphragm $\mathrm{T}$ and recorded on the cylinder S; A. Resting landing [figure adapted and translated from (Jules Amar, 1917)]

Figure 5. An example of Dempster's (1955) meticulous work, on human anthropometry and BSP, showing the distribution of body mass of a cadaver relative to its height. The weights (sic) of transverse saw-cut sections of one-inch thickness were plotted relative to height; the weights ( $\mathrm{sic}$ ) of bone, muscle, integument and organs in successive sections are shown also. Adapted from (Dempster, 1955)

Figure 6. A schematic diagram comparing the internal structure of a human femur (Fig. 1.) with that of a lamp bracket (Fig. 2.). Ward (1938) observed that strut $a$ in Fig. 2., experiences compression and a bending moment about its base and that strut $b$, which is in tension, helps support $a$, the two elements providing a stable and strong structure. The analogous structures of the femur correspond to $\mathbf{A}, \mathbf{B}$. The region marked $\mathbf{G}$ (Ward's triangle), corresponds to the void g, in Fig. 2., and represents an area of low density trabecular bone in the femur. The femur supports the weight, m.g and the bracket supports the weight of the lamp, mL.g. Adapted from (Ward, 1838)

Figure 7. One of the first images produced using x-rays, Röntgen (1895). The image is of Frau Röntgen's hand. (Mould, 1995)

Figure 8. Examples of images produced by different scanning methods. Image A shows internal and external renders of a $\mu \mathrm{CT}$ scan of human remains (radius) from the warship Mary Rose (1545), resolution $\sim 30 \mu \mathrm{m}$. Image B shows a laser surface scan of the same radius as in $\mathrm{A}$, resolution $\sim 40 \mu \mathrm{m}$. Images $\mathrm{C}$ show a transvers plane view of a tibia and fibula using MRI scanning, optimised to render bone but not soft tissue. Image $C$ adapted from (Singh et al., 2018).

Figure 9. Example of an isometric mid-thigh pull set-up showing the athlete standing on a force platform and pulling on a bar, fixed to a power rack. 
Figure 10. An example of a force/time history derived from an athlete performing an IMTP on a force platform. $\mathrm{BW}=$ body weight, $\mathrm{Fp}=$ maximum value of force during the pull (expressed as force above BW), $\mathrm{Tp}=$ pull initiation time, $\mathrm{F} 100=$ force $100 \mathrm{~ms}$ after Tp (above BW), F250 = force at $250 \mathrm{~ms}$ after Tp (above BW)

Figure 11. Two typical force/time histories of IMTP, showing the period prior to initiation of the pull and the start of the pull. 10A, illustrates examples of a stable period and an unstable period, prior to the initiation of the pull. 10B shows the corresponding $1^{\text {st }}$ derivative of $10 \mathrm{~A}$ determined from raw data. $10 \mathrm{C}$ shows the corresponding $1^{\text {st }}$ derivative of $10 \mathrm{~A}$ but determined from data filtered with a dual pass Butterworth low pass filter cut-off frequency $20 \mathrm{~Hz}$

Figure 12. Illustration of the relationship between VGRF (F), vertical velocity (V) and mechanical power $(\mathrm{P})$ for a subject performing a CMJ. The dotted line indicates $P p$ and its relationship with $\mathrm{V}$ and $\mathrm{F}$.

Figure 13. Power/time histories for 15 elite rugby players at the start of a CMJ. Positive power indicates an elevation of the $\mathrm{WCoG}$ and negative power indicates a lowering of the WCoG.

Figure 14. Distribution of $P p$ output in children in school years 3 to 6 .

Figure 15. Cross sectional area bowl. Each dot represents one measure of CSA, the lowest value of CSA is chosen as the correct value.

Figure 16. Limit of agreement plots for intra-rater reliability A, and inter-rater reliability B, of CSA of 40 radii. 
Table 1. Illustrates the specification for collecting and analysing $P p$ utilising the VGRF collected from a FP. Adapted from Owen, 2008

Table 2. An example of the specifications reported in the literature for the determination of $P p$ of a $C M J$ by analysing the $V G R F$.

Adapted from (Owen, 2008)

Table 3. Specifications, for the measurement of lower limb $P p$ in children, reported for studies using "Mechanography" adapted from Jones (2018) 77 


\section{List of abbreviations}

\begin{tabular}{ll} 
3-D & three dimensional \\
B.C. & before the common era \\
BSP & body segment parameter \\
BW & body weight \\
CMJ & countermovement jump \\
CoG & centre of gravity \\
CT & computed tomography \\
FP & force platform \\
Fp & peak strength (IMTP) \\
fps & frames per second \\
GRF & ground reaction force \\
IMTP & isometric mid-thigh pull \\
MRI & magnetic resonance imaging \\
N1 & Newton's 1st law of linear motion \\
N2 & Newton's 2nd law of linear motion \\
N3 & Newton's 3rd law of linear motion \\
P & mechanical power \\
PAP & postactivation potentiation \\
Pp & peak mechanical power of the whole body centre of gravity \\
RFD & rate of force development \\
S & strength \\
SI & Système Internationale d'Unités \\
Tp & pull initiation time for IMTP \\
VGRF & vertical component of the ground reaction force \\
WCoG & whole body centre of gravity \\
$\mu C T$ & micro computed tomography \\
F100 & force 100 ms after Tp in an IMTP \\
F250 & force 250 ms after Tp in an IMTP \\
E & energy \\
W & work \\
d & distance \\
Y & school year \\
FCS & fairly complete skeletons \\
MRT & Mary Rose Trust \\
XSA & cross sectional area \\
\hline
\end{tabular}




\section{List of published works to be submitted for $\mathrm{PhD}$ by publication}

\section{Paper 1}

\section{Effect of postativation potentiation on swimming starts in international sprint swimmers}

Liam P. Kilduff, Dan J. Cunningham, Nick J. Owen, Daniel J. West, Richard M. Bracken and Christian J. Cook.

Journal of Strength and Conditioning Research. 2011. 25(9)/2418-2423

Applicant's input

Development of methods for data collection and analysis, namely:

- Data collection protocols and data analysis methods for assessment of power in a countermovement jump.

- Development of method for measuring ground reaction force and its vertical and horizontal components for a swimming start with a force plate mounted on the starting block.

- Development of a video based kinematics measuring system for the measurement of swimming start times to 15 metres

Data collection and analysis of data. Writing key elements of the methods section and elements of the introduction.

\section{Paper 2}

Relationship between force-time characteristics of the isometric midthigh pull and dynamic performance in professional rugby league players

Daniel J. West, Nick J. Owen, Marc R. Jones, Richard M. Bracken, Christian J Cook, Dan J. Cunningham, David A. Shearer, Charlotte V. Finn, Robert U. Newton and Liam P, Kilduff.

Journal of Strength and Conditioning Research. 2011. 25(11)/3070-3075

Applicant's input

Development of methods for data collection and analysis, namely:

- Data collection protocols and data analysis methods for assessment of power in a countermovement jump.

- Development for the data collection of force-time characteristics for an isometric mid-thigh pull.

- Development of the method of analysis of the force-time characteristics of an isometric mid-thigh pull. Specifically, a reliable definition of time of initiation of the pull and methods for the determination of peak instantaneous rate of force development.

Data collection and analysis of data. Writing key elements of the methods section and elements of the introduction. 


\section{Paper 3}

Development of a criterion method to determine peak mechanical power output in a countermovement jump

Nick J. Owen, James Watkins, Liam P. Kilduff, Huw R. Bevan and Mark A. Bennett. Journal of Strength and Conditioning Research. 2014. 28(6)/1552-1558

Applicant's input

Development of methods for data collection and analysis, namely:

- Data collection protocols and data analysis methods for assessment of power in a countermovement jump.

- Development of methods of optimising key variables.

- Statistical analysis of resulting data.

Data collection and data analysis including statistical analysis. Writing the paper.

\section{Paper 4}

Normative data for lower limb peak mechanical power in children aged 7 to 11 years old

N.J. Owen, W. Griffiths \& J. Watkins. Journal of Comorbidity 2015; 5: 93.

Applicant's input

- Development of all methodology including testing protocols.

- Statistical analysis

- Writing the paper

\section{Paper 5}

A computational method of obtaining reliable measurement of periosteal crosssectional area of human radii from laser scans

P. Mahmoodi, S. Annan and N. Owen. Proceedings of the 23rd UK Conference of the Association for Computational Mechanics in Engineering 2015, Swansea. 73-76.

Applicant's input

- Development of original concept and principles of analysis

- Acquisition of resources

- Co-writing the paper

- Statistical analysis

Please see Appendix 1. for substantiating statements by co-authors for all papers. All co-authors had sight of this list. 
Copies of the papers 


\section{Paper 1}

Effect of postactivation potentiation on swimming starts in international sprint swimmers

Liam P. Kilduff, Dan J. Cunningham, Nick J. Owen, Daniel J. West, Richard M.

Bracken and Christian J. Cook. Journal of Strength and Conditioning Research. 2011. 25(9)/2418-2423 


\section{Effect of Postactivation Potentiation on Swimming Starts in InTernational Sprint SWIMMERS}

Liam P. Kinduff, ${ }^{1}$ Dan J. Cunningham, ${ }^{1}$ Nick J. Owen, ${ }^{1}$ Daniel J. West, ${ }^{1}$ Richard M. Bracken, ${ }^{1}$ and Christian J. CooK ${ }^{2}$

${ }^{1}$ Sport and Exercise Science Research Center, Sivansea University, Szvansea, United Kingdom; and ${ }^{2} U K s p o r t$ Bath University, Bath, United Kingdom

Abstract

Kilduff, LP, Cunningham, DJ, Owen, NJ, West, DJ, Bracken, RM
PVF: $1,462 \pm 280$ vs. $1,518 \pm 311 \mathrm{~N}, p=0.038$ ); however, time to $15 \mathrm{~m}$ was the same when both starts were compared

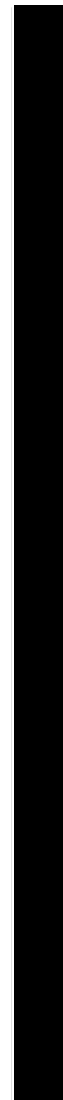

(1) 2011 National Strength and Conditioning Association

physiological condition, namely, postactivation potentiation

2418 Journal of Strength and Conditioning Research 
Joümal of Strength and Conditioning Research | www.rsca-jscorg

(PAP), with PAP defined as an acute enhancement of muscle function after a PAP stimulus (13).

The literature regarding an athlete's ability to harness PAP

TABLE 1. Physical characteristics of subjects at 


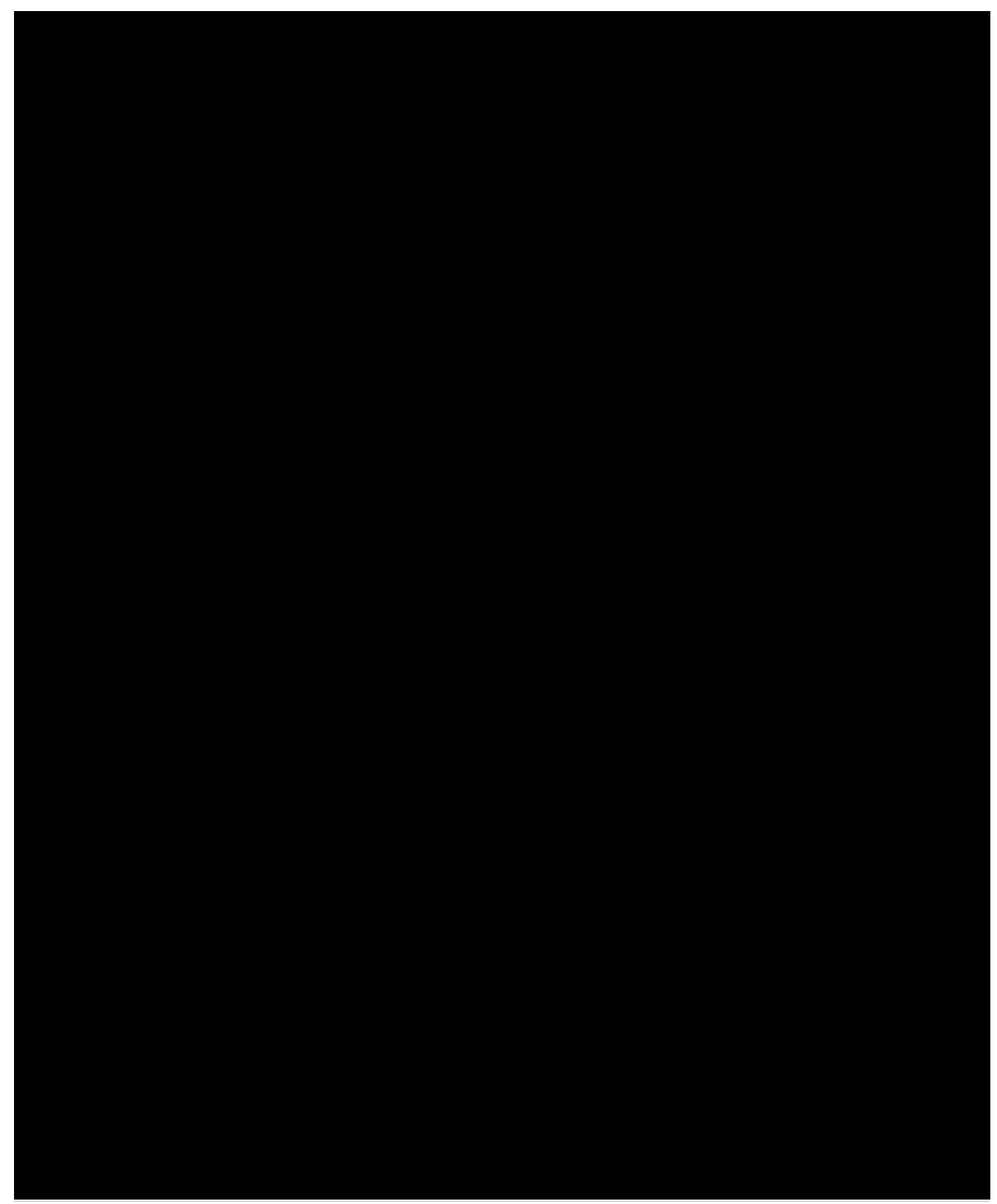


position, the subject was given verbal command take your

mark,' and shortly after the starting signal was sounded. The

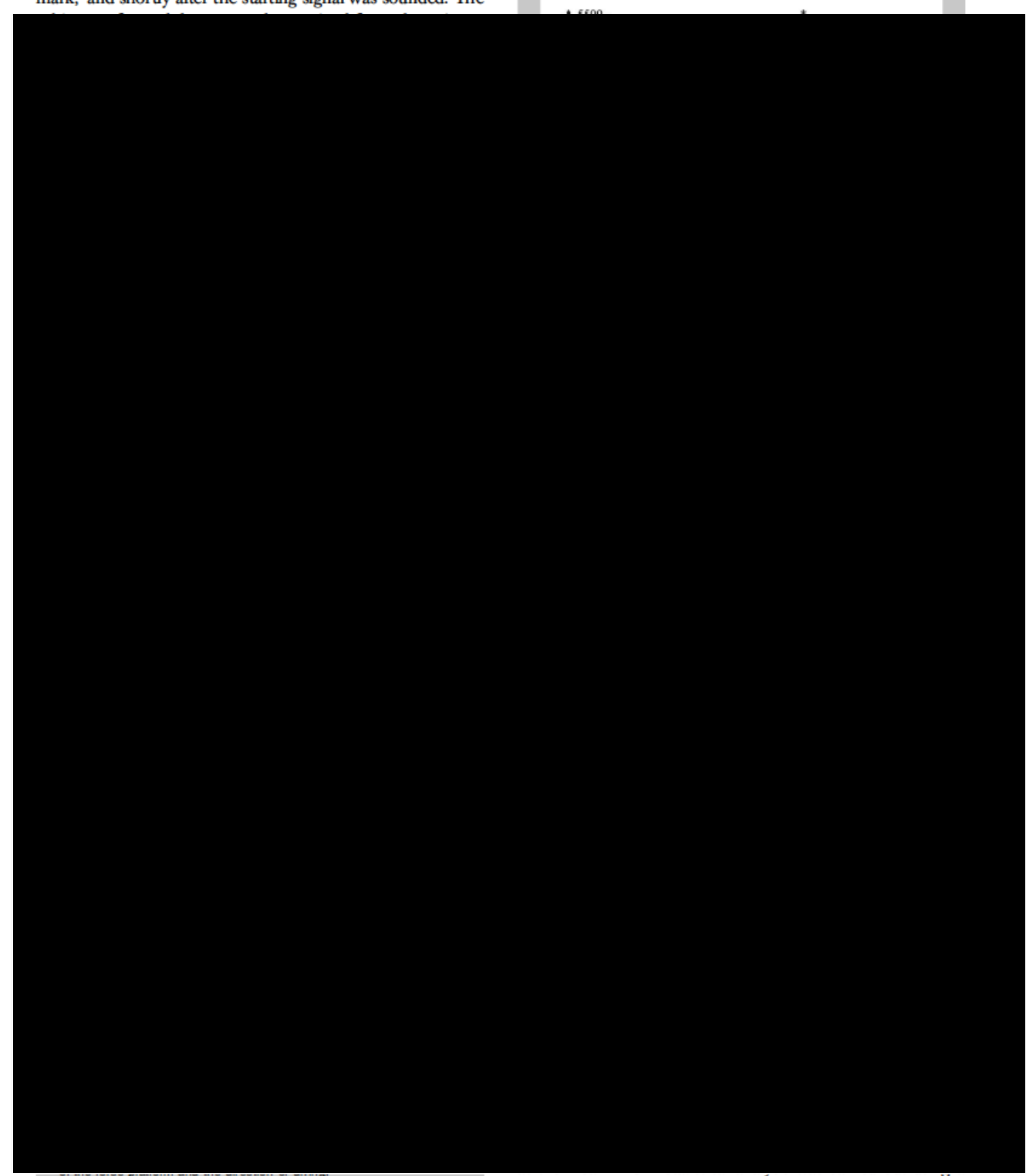

repeated measures 1-way ANOVÁ to determine whether $\mathrm{PO}$,

VOLUME 25 | NUMBER 9 | SEPTEMBER 2011 | 2421 


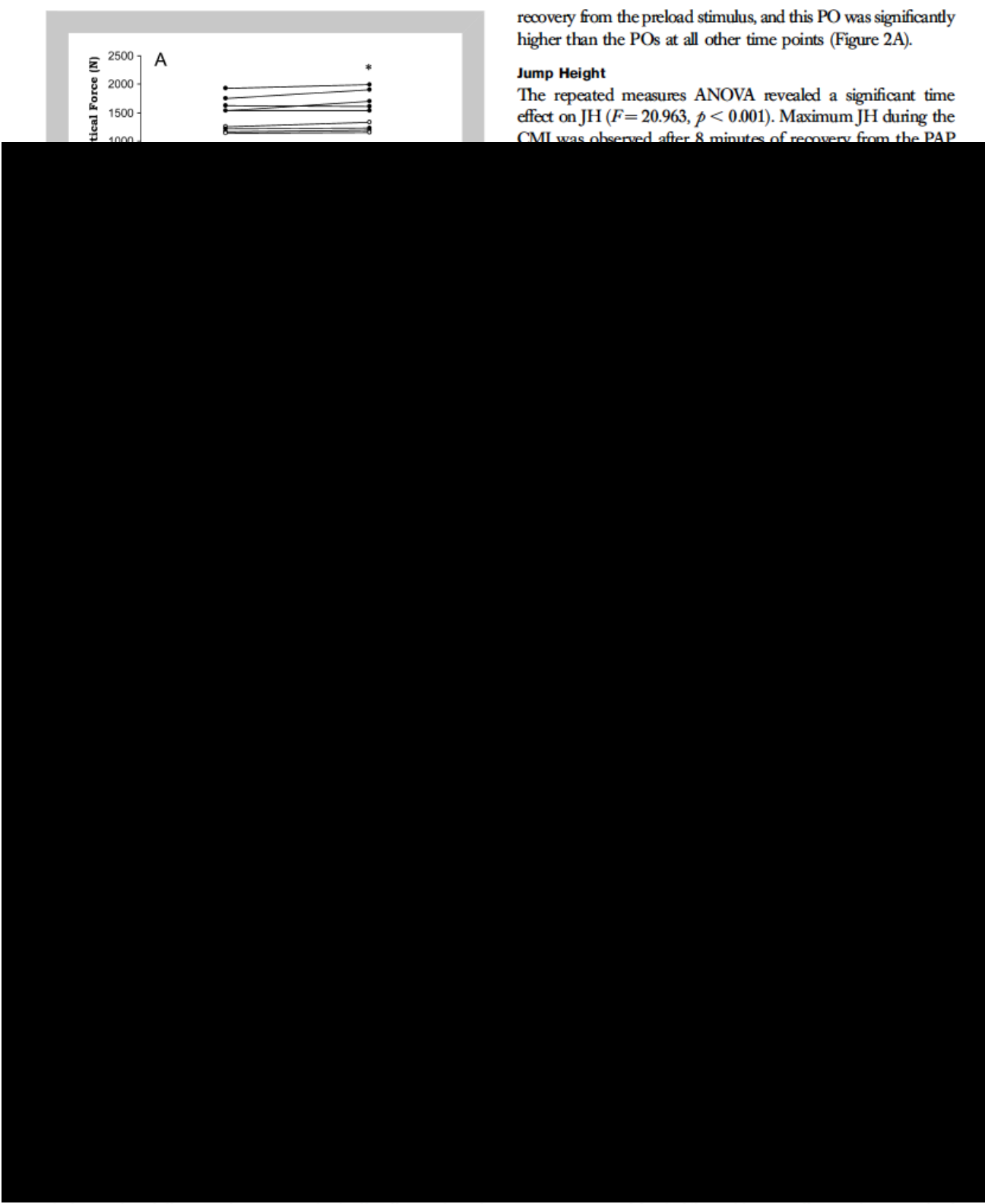

suay produced therr peak power output arter 8 minutes of up comprising of 1 set or 3 repetutions on the squat exercise lead 2422 Journal of Strength and Conditioning Research 
Joümal of Strength and Conditioning Research | www.nsca-jscrorg

to a similar dive start time compared to the swimmers traditional

2. Baechle, TR and Earle, RW. Resistance training and spotting

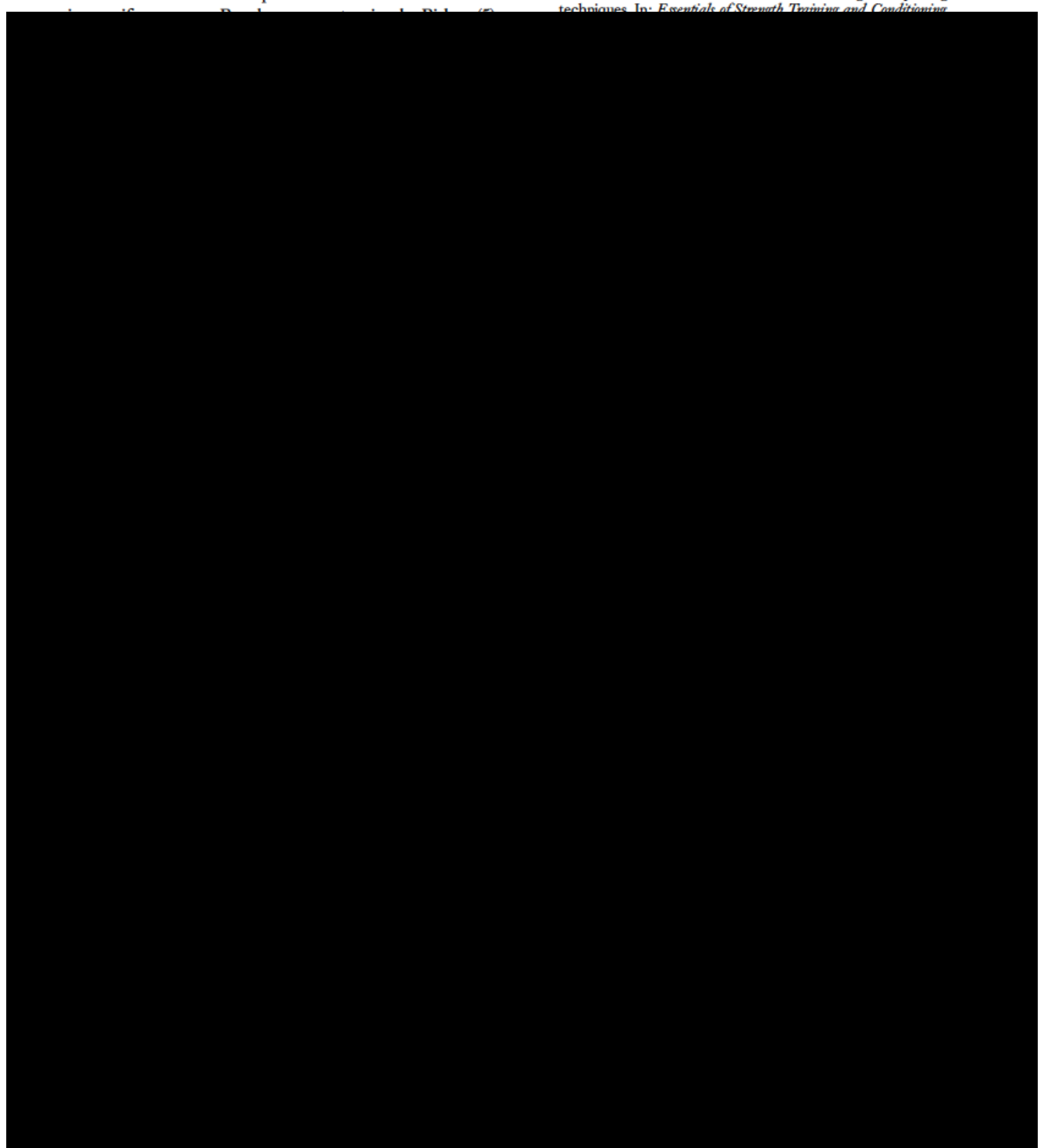

REFERENCES

sprint swimmers. J. Strength Cond. Res in press.

1. Aragon-Vargas, LF and Gross, MM. Kinesiological factors in vertical jump performance: differences among individuals. $J$ Appl Biomech
13: 24-44, 1997 .

21. Young, WB, Jenner, A, and Griffiths, K. Acute enhancement of power performance from heavy load squats. J Strength Cond Res

VOLUME 25 | NUMBER 9 | SEPTEMBER 2011 | 2423 


\section{Paper 2}

Relationship between force-time characteristics of the isometric midthigh pull and dynamic performance in professional rugby league players

Daniel J. West, Nick J. Owen, Marc R. Jones, Richard M. Bracken, Christian J Cook, Dan J. Cunningham, David A. Shearer, Charlotte V. Finn, Robert U. Newton and Liam P, Kilduff.

Journal of Strength and Conditioning Research. 2011. 25(11)/3070-3075 
Relationships Between Force-Time Characteristics of the Isometric Midthigh Pull and Dynamic Performance in Professional Rugby League Players

Daniel J. West, ${ }^{1}$ Nick J. Owen, ${ }^{1}$ Marc R. Jones, ${ }^{1}$ Richard M. Bracken, ${ }^{1}$ Christian J. Cook, ${ }^{2}$ Dan J. Cunningham, ${ }^{1}$ David A. Shearer, ${ }^{1}$ Charlotte V. Finn, ${ }^{1}$ Robert U. Newton, ${ }^{3}$ Blair T. Crewther, ${ }^{4}$ and Liam P. KildufF ${ }^{1}$

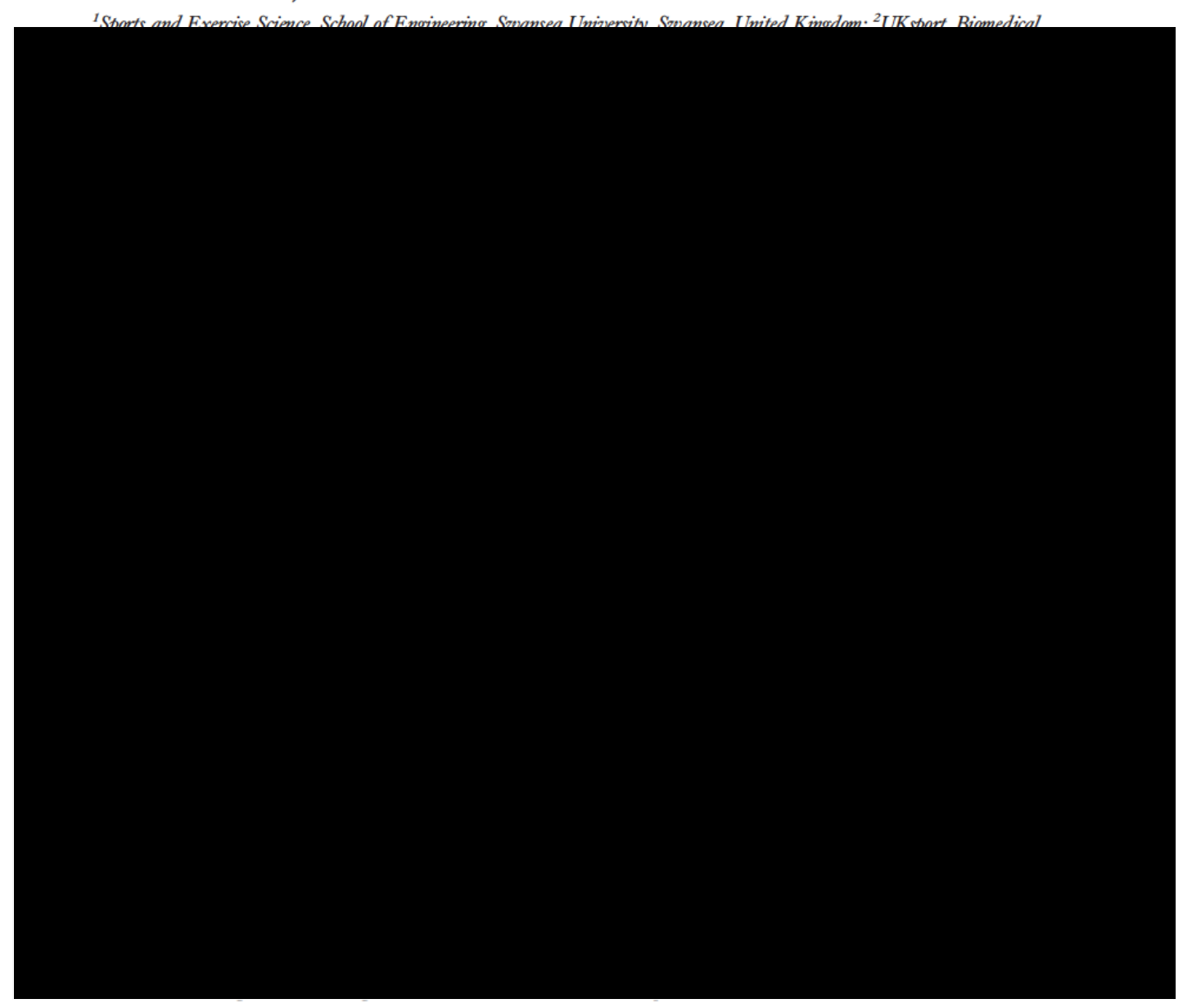

3070 Journal of Strength and Conditioning Research 
Journal of Strength and Conditioning Research $\mid$ wwwnsca-jsccorg

To date, there is no uniform agreement between researchers on the role isometric tests play in sports performance diagnosis with much of the discrepancies because of

TABLE 1. Physical characteristics of subjects at

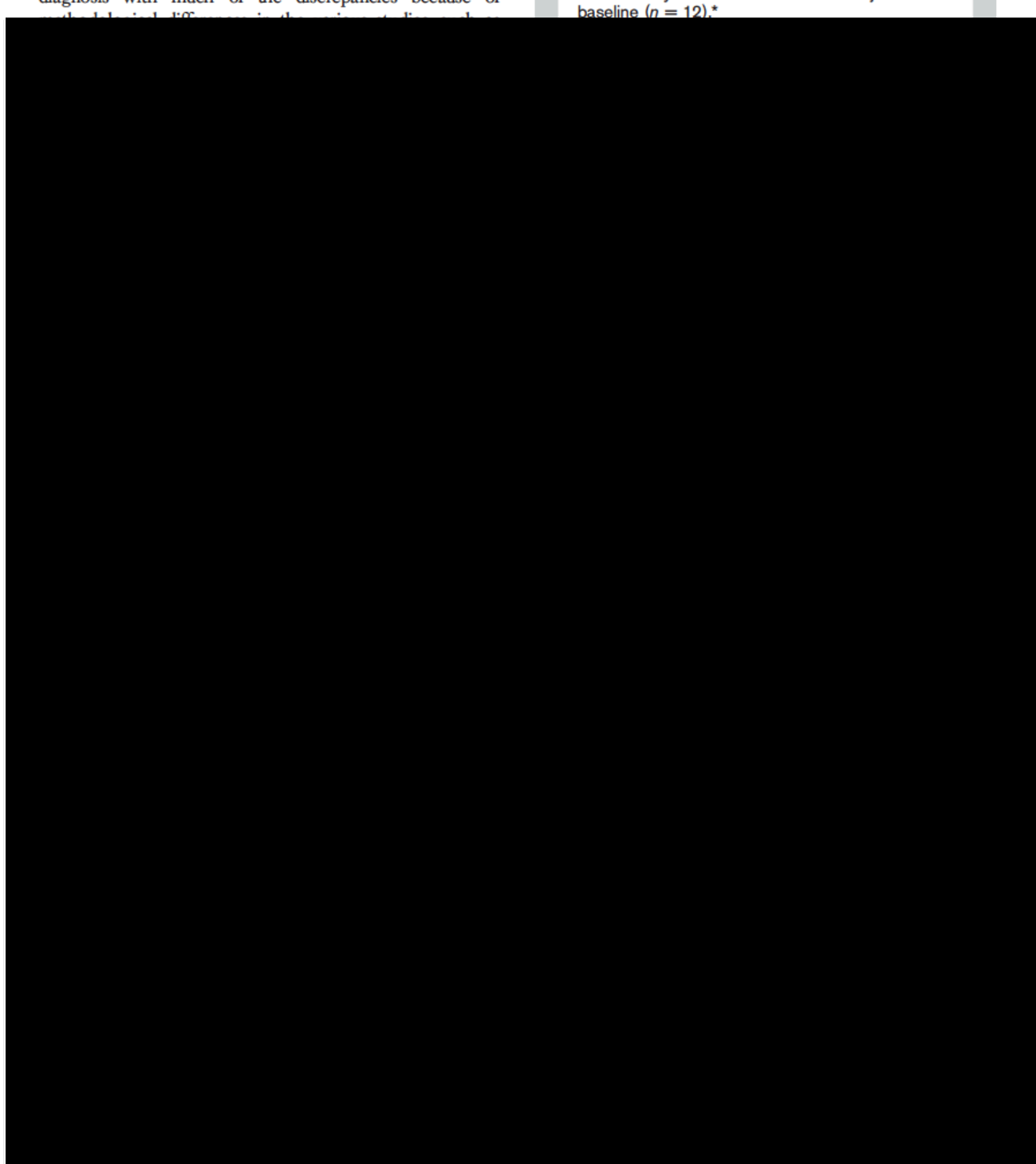

The IMTP testing was carried out with players standing on posttrigger phase and lasting for approximately 5 seconds. a portable force platform (type $92866 \mathrm{AA}$, Kistler Instruments The platform's calibration was checked before and after

VOLUME 25 | NUMBER 11 | NOVEMBER 2011 | 3071 
Isometric Midthigh Pull and Dynamic Performance

each testing session. During each trial, subjects were instructed to pull as hard and as fast as possible for a period of approximately 5 seconds. These commands were based on previous research indicating that the use of these instructions the trigger point. The start time $\left(T_{\mathrm{s}}\right)$ of the IMTP was then defined as the instant, after the trigger point, that the first derivative exceeded the mean value plus $5 S D$ s.

The $\mathrm{PF}$ was determined from the vertical component of the discarded to avoid the edge effects associated with digital filtering, and a mean and $S D$ were calculated for the remaining 1 second of quiet standing immediately before 3072

\section{Joürnal of Strength and Conditioning Researcti}

Instantaneous RFD was calculated from the first derivative of the vertical GRF. Before numerical differentiation, the vertical GRF was filtered using a dual-pass Butterworth filter 
Journal of Strength and Conditioning Researc" | wwwnsca.jsccorg

TABLE 2. Relationships between various force measures, obtained during the IMTP and dynamic performance.*

(Table 2). In addition, PRFD

VOLUME 25 | NUMBER 11 | NOVEMBER 2011 | 3073

Convright (O) National Strength and Conditioning Association Unauthorized renroduction of this article is prohibited. 
Isometric Midthigh Pull and Dynamic Performance

power, respectively (Table 2). Relative $\mathrm{F} 100 \mathrm{~ms}$ was highly correlated to $10-\mathrm{m}$ time and CMJ height (Table 2, Figure 1A, B)

Discussion researchers have based their conclusions on a limited sample size, and some studies reported findings from nonelite populations. In this study, we had a sample size of 39 elite rugby league players, which adds additional validity and

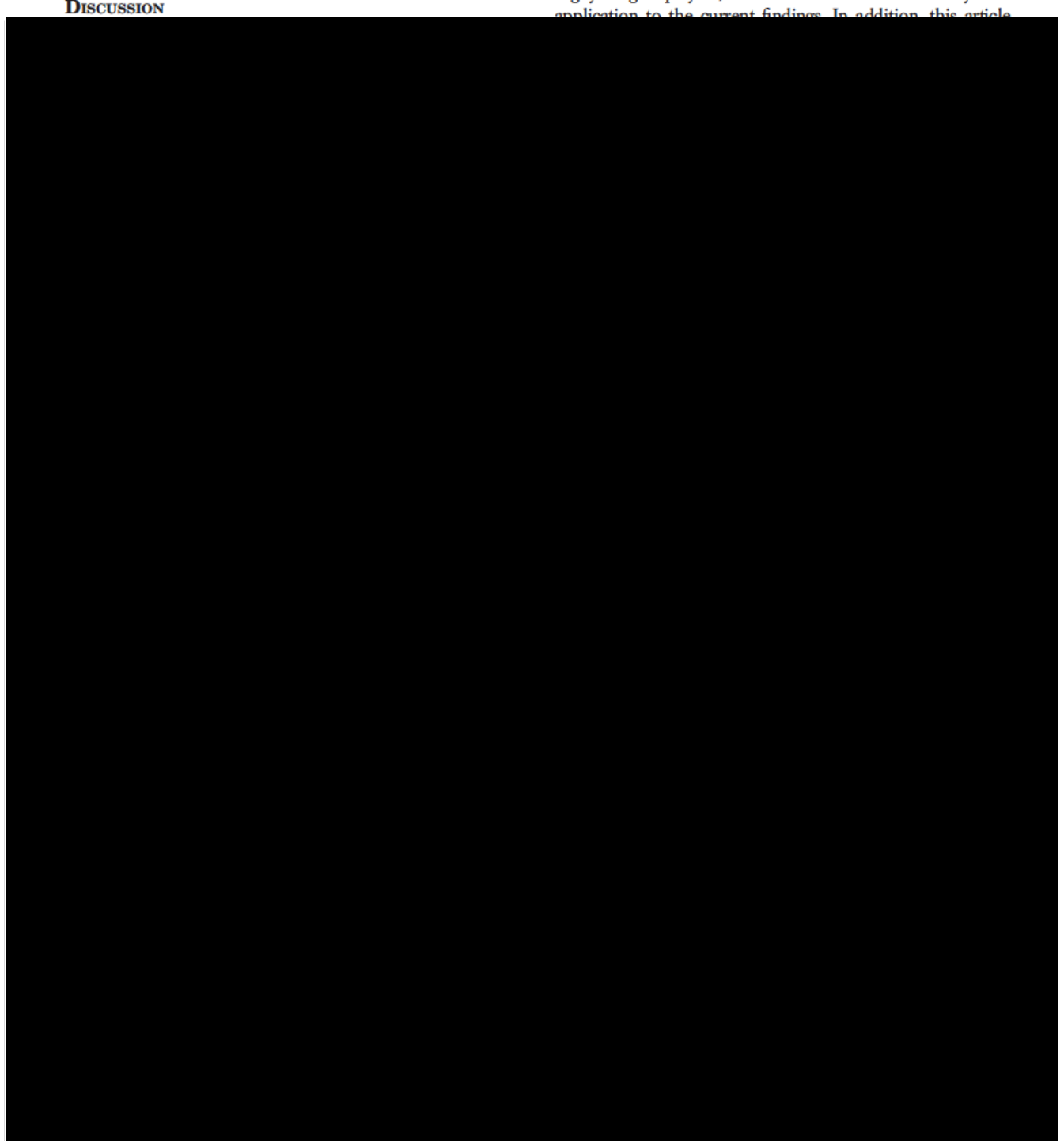

relation to dynamic sports. The majority of previous 1: 108-113, 2006. Journal of Strength and Conditioning Research 
Journal of Strength and Conditioning Researct | www.nscajsccorg

10. Murphy, AJ and Wilson, GJ. Poor correlations between isometric tests and dynamic performance: Relationship to muscle activation. Eur J Appl Physiol 73: 353-357, 1996.

11. Nuzzo, JL, McBride, JM, Comie, P, and McCaulley, GR Relationship between countermovement jump performance and multijoint isometric and dynamic tests of strength. $J$ Strength Cond Res 22: 699-707, 2008.

12. Requena, B, Gonzalex-Badillo, J, Saez Sael De Villareal, E, Ereline, J, Garcia, I, Gapeyeva, H, and Paasuke, MH, and Paasuke, M. Functional performance maximal strength, and power characteristics in isometric and dynamic actions of lower extremities in socer players. J Strength Cond Res 23: 1391-1401, 2009.
13. Stone, MH, Sands, WA, Carlock, J, Callan, S, Dickie, D, Daigle, K, Cotton, J, Smith, SL, and Hartman, M. The importance of isometric maximum strength and peak rate-of-force development in sprint cycling. J Strength Cond Res 18: 878-884, 2004.

14. Vanrenterghem, J, DeClercq, D, and Van Cleven, P. Necessary precautions in measuring correct vertical jumping height by means of force plate measurement. Ergonomics 44: 814-818, 2001.

15. Weyand, PG, Sternlight, DB, Bellizzi, MJ, and Wright, S. Faster top running speeds are achieved with greater ground forces not more rapid leg movements. J Appl Physiol 89: 1991-1999, 2000.

16. Wilson, GJ, Lyttle, AD, Ostrowski, KJ, and Murphy, AJ. Assessing dynamic performance: A comparison of rate of force development dynamic performance: A comparison of rate
tests. J Strength Cond Res 9: 176-181, 1995. 
Paper 3

Development of a criterion method to determine peak mechanical power output in a countermovement jump

Nick J. Owen, James Watkins, Liam P. Kilduff, Huw R. Bevan and Mark A. Bennett.

Journal of Strength and Conditioning Research. 2014. 28(6)/1552-1558 


\section{Development of a Criterion Method to Determine Peak Mechanical Power Output in}

a Countermovement Jump

Nick J. Owen, ${ }^{1}$ James Watkins, $^{1}$ Liam P. Kilduff, ${ }^{1}$ Huw R. Bevan, ${ }^{2}$ and Mark A. Bennett ${ }^{3}$

${ }^{1}$ Applied Sports Technology Exercise and Medicine Research Centr, College of Engineering, Szwansea University,

United Kingdom; ${ }^{2}$ The England and Wales Cricket Board, London, United Kingdom; and ${ }^{3} O$ ospreys Rugby,

Liberty Stadium, Swansea, United Kingdom

Abstract

Owen, NJ, Watkins, J, Kilduff, LP, Bevan, HR, and Bennett, MA.
INTRODUCTION

1 1 uscular power is widely considered to be a key

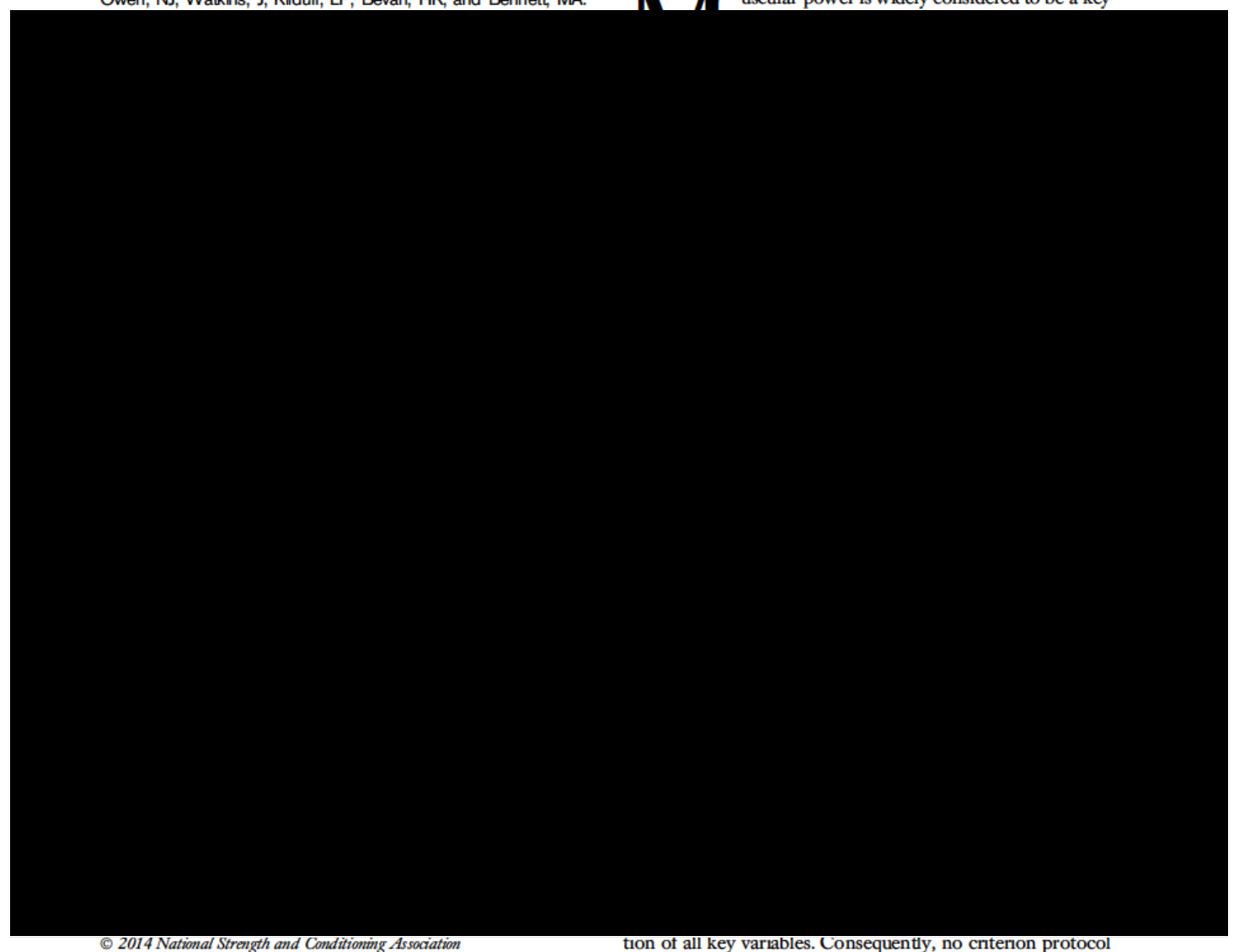

1552 Journal of Strength and Conditioning Research 
Journal of Strength and Conditioning Research $\mid$ wwwnsca.com

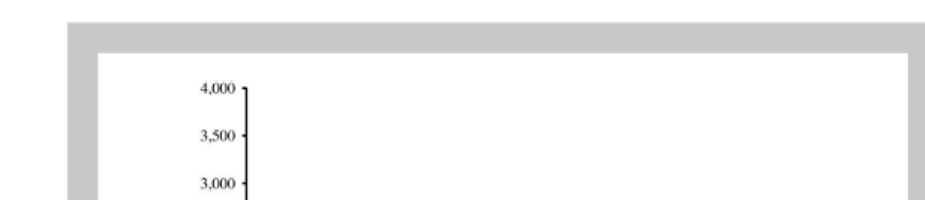

Body mass (BM) was determined from BW and taken to be BW $\cdot g^{-1}(\mathrm{~kg})$ with $g=$ acceleration due to gravity.

Subjects

The participants were 15 male

by $\mathrm{BM}$ to determine instantaneous velocity for time points VOLUME 28 | NUMBER 6 | JUNE 2014 | 1553 


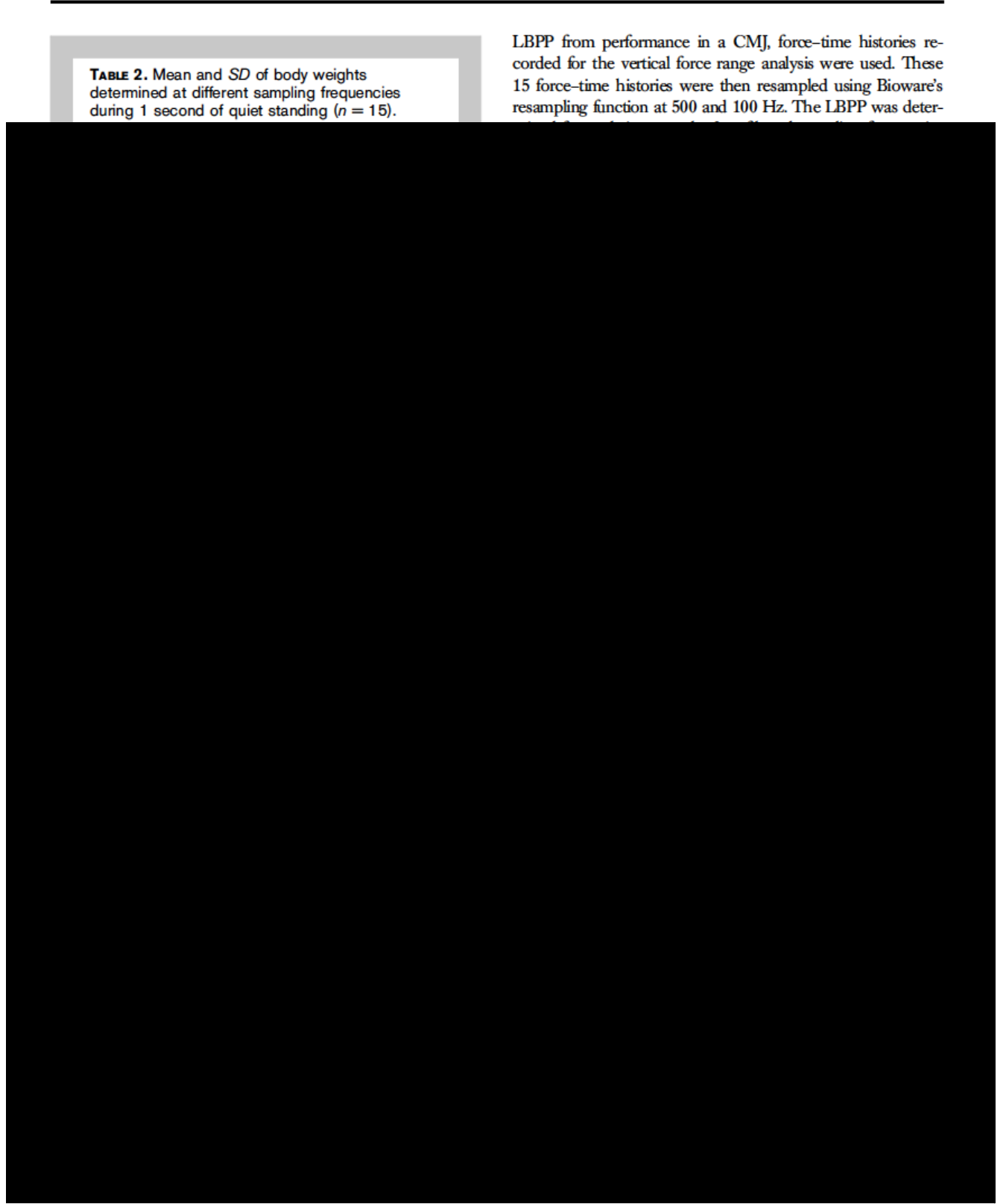

of the stance phase, will be in 
Joünal of Strength and Conditioning Research $\mid$ wwwnsa.com

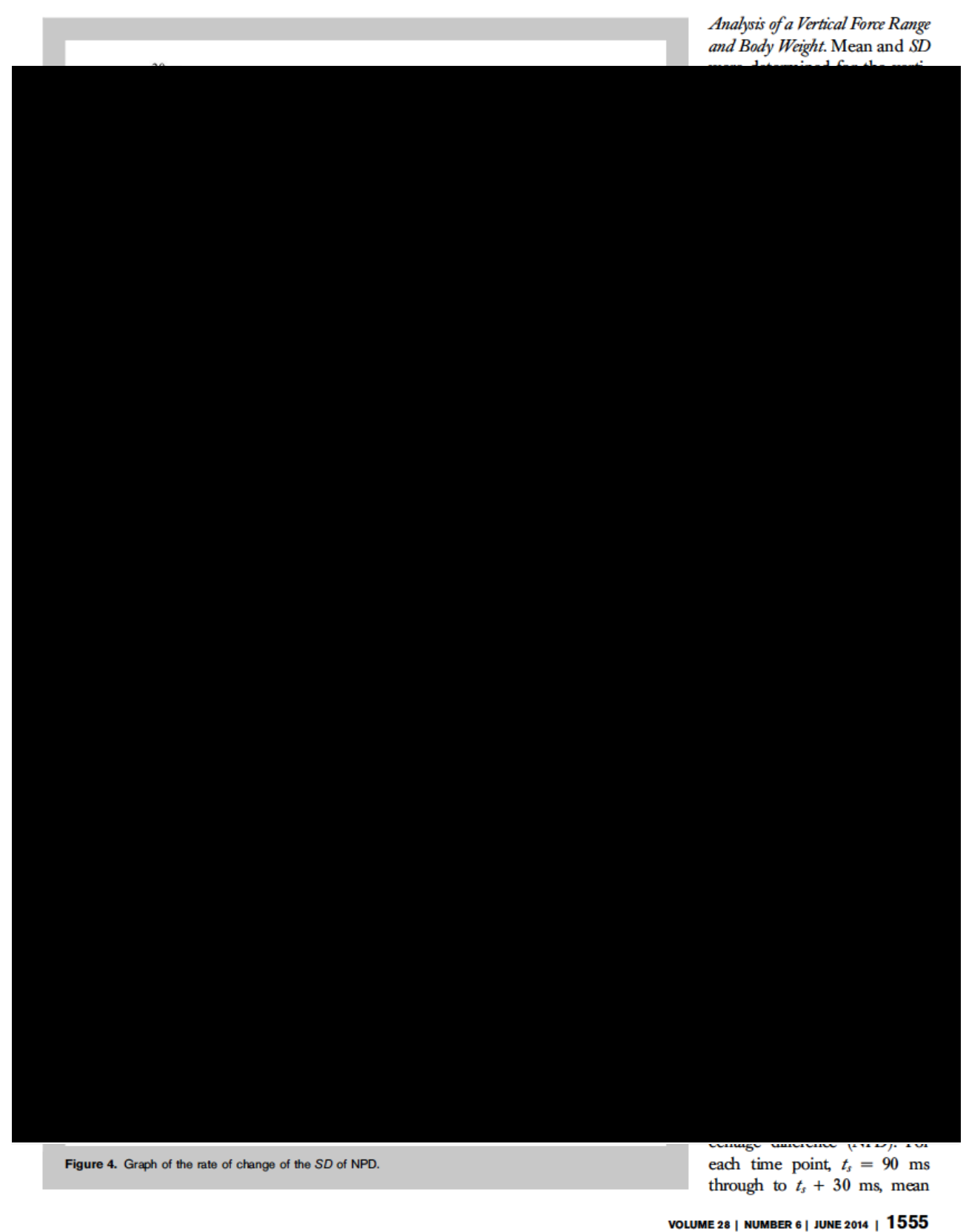

Copyright (c) National Strength and Conditioning Association Unauthorized reproduction of this article is prohibited. 
$\uparrow A$ specitication of $\mathrm{BW} \pm 5 \mathrm{SD}$ as opposed to a reduction in $\mathrm{BW}$ tor jump initation was necessary because generally approximately half of all jumpers start a CMJ by first raising their centre of gravity.

\section{Journal of Strength and Conditioning Research}


Joưrnal of Strength and Conditioning Research $\mid$ wwwnsca.com

and trapezoidal rule value) is plotted on the $x$ axis. The analysis resulted in a mean of the difference of $13 \mathrm{~W}$ and limits of agreement (mean $\pm 1.96 \times S D)$ of 6 and $19 \mathrm{~W}$ of interest in this study was the force-time history of a CMJ

Usually, Fourier's analysis is used to determine the highest frequency present in a signal, however a force-time history

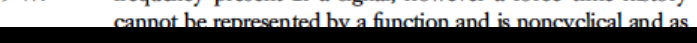

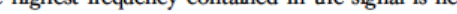
essary to ensure that none of the original signal is lost during the sampling process and also to prevent aliasing. The signal

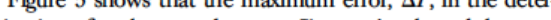
mination of peak power between Simpson's rule and the trapcaida rule would be, $\Delta \mathrm{P} \leq 0.13 \%$ (confidence interval $=95 \%$ ).

VOUUME 28 | NUMBER G | JUNE 2014 | 1557 
However, because it is unclear which of these methods of integration gives the more correct result, the best estimate
2. Bevan, HR, Owen, NJ, Cunningham, DJ, Kingsley, MIC, and Kilduff, LP. Complex training in professional rugby players:
Influence of recovery time on upper-body power output. J Strngnth

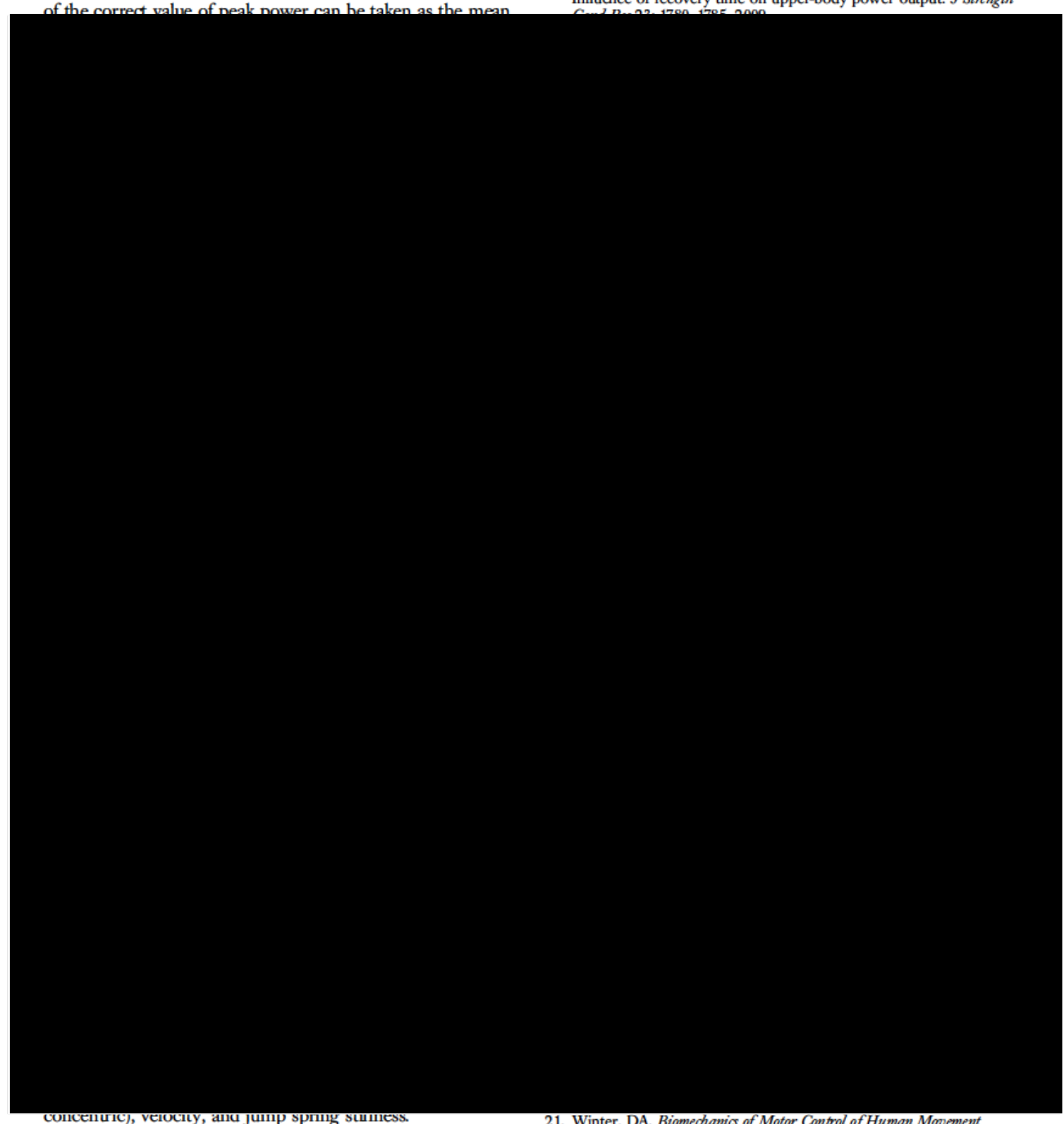

21. Winter, DA. Biomechanics of Motor Control of Human Movement (3rd ed.). Hoboken, NJ: John Wiley and Sons, 2005.

\section{REFERENCES}

1. Amonette, WE, Brown, LE, De Witt, KJ, Dupler, TL, Tran, TT, Tufano, J, and Spiering, BA. Peak vertical jump power estimations
in youths and young adults. J Strength Cond Res $26: 1749-1755,2012$.

22. Wright, GA, Pustina, AA, Mikat, RP, and Kernozet, TW. Predicting lower body power from vertical jump prediction equations for $J$ Strength Cond Res 26: 648-655, 2012.

1558

Journal of Strength and Conditioning Researct 
Paper 4

Normative data for lower limb peak mechanical power in children aged 7 to 11 years old

N.J. Owen, W. Griffiths \& J. Watkins. Journal of Comorbidity 2015; 5: 93. 
from similar research projects have indicated greater success in therapy when the children are actively involved in the therapeutic process and in determining the objectives of the treatment themselves and in cooperation with them. References:

Missiuna, C. \& Pollock, N. (2000). Perceived efficacy and goal setting in young children. Canadian Journal of Occupational Thenapy, 67, 101-109.

Rosenberg, L., Jarus, T. \& Bart, O. (2010). Development and initial validation of the Children Participation Questionnaire (CPQ). Disability and Rehabilitation, 32(20), 1633-1644.

Keywords: Daily routines; “Make my day"; Evaluation; Young children.

Normative data for lower limb peak mechanical power in children aged 7 to 11 years old

N.J. Owen ${ }^{1}$, w. Griffiths ${ }^{2} \&$ J. Watkins

${ }^{1}$ Applied Sports Technology, Exercise and Medicine Research Centrh, Swansea University, Swansea, SA2 8PP, UK. n.j.owen@swansea. ac.uk: ${ }^{2}$ Neath Port Talbot Education Authority, Civic Centre, Port Talbot, UK.

Aim: There are currently about 45 published instruments for the assessment of motor development in children. However, all of the tests lack robust evidence of reliability and validity'. A high levels of lower limb peak muscular power ( $\mathrm{Pmp}$ ) is widely considered a key determinant of athletic performance ${ }^{2}$; conversely it is reasonable to assume that poor physical performance, characterised by poor coordination, would be associated with low levels of Pmp. However there are currently limited valid data on normative values of Pmp in children. The aim of this study was to report valid normative data for Pmp in children.

Method: Children 7 to 11 years old $(n=791$, age $9.26 \pm 1.20$ decimal years, stature $=1.338 \pm 0.094 \mathrm{~m}$, body mass $=34.7 \pm 9.7 \mathrm{~kg}$ ) of mixed gender were randomly selected from schools in South Wales. Each child performed one countermovement jump (CMJ) off a force platform with performed one countermovement jump (CMJ) off a force platform with
their hand held on their hips to isolate the lower limbs. The ground reactheir hand held on their hips to isolate the lower limbs. The ground reaction force was recorded and the momentum impulse principle was used to A pilot study had shown good reliability for $\mathrm{Pp}$ in children in this age range (ICC > 0.92). Participants were grouped in school years ( $\mathrm{Y}$ ) and comparisons were made between genders and year groups for $\mathrm{Pp}$.

Results: There was no significant difference in $\mathrm{Pp}$ between genders for Results: There was no significant difference in $\mathrm{P} p$ between genders for
year group $(\mathrm{p}=0.05)$. Combined gender groups for each school year produced $\mathrm{P}_{\mathrm{P}}$ that were normally distributed and had the following values (mean Pp, standard deviation), Y3 $=905 \pm 191 \mathrm{~W}, \mathrm{Y} 4=1047 \pm 233 \mathrm{~W}, \mathrm{Y} 5$ $=1230 \pm 258 \mathrm{~W}, \mathrm{Y} 6=1367 \pm 326 \mathrm{~W}$. A significant difference in $\mathrm{P}$ p was found between successive mixed gender year groups $(p=0.01)$. Y3 $(n=$ $190)$ to $\mathrm{Y} 4(\mathrm{n}=182), \mathrm{t}=6.01, \mathrm{p}<0.001, \mathrm{Y} 4$ to $\mathrm{Y} 5(\mathrm{n}=215), \mathrm{t}=7.67, \mathrm{p}<$ $190)$ to $\mathrm{Y} 4(\mathrm{n}=182), \mathrm{t}=6.01, \mathrm{p}<0.001, \mathrm{Y} 4 \mathrm{t}$
$0.001, \mathrm{Y} 5$ to $\mathrm{Y} 6(\mathrm{n}=204), \mathrm{t}=3.94, \mathrm{p}<0.001$

Discussion: This study indicates that $\mathrm{P}_{\mathrm{p}}$ produced in a single-trial CMJ has the potential to provide information on the coordination of children aged 7-11 years, with a high level of discrimination. For example, in Y3 (aged 7-8 years) there is a 12\% increase in Pp between the 5th and 10th percentile. $\mathrm{Pp}$ as measured in a CMJ has the potential to augment test like Movement Assessment Battery for Children-2. However more study is needed regarding the potential benefits of allometric scaling of $\mathrm{P}_{\mathrm{p}}$ and further splitting school year groups into 3 month groups and comparison with other tests of physical ability.

References:

1. Brown, T., \& Lalor, A. (2009). The Movement Assessment Battery for Children - Second Edition (MABC-2): a review and critique. Physical \& Occupational Thenspy in Pediatrics, 29(1), 86-103.

2. Cronin, J. B., \& Hansen, K. T. (2005). Strength and power predictors of sports speed. Journal of Strength and Conditioning Research, 19, 349-357.

3. Owen, N. J., Watkins, J., Kilduff, L. P., Bevan, H. R., \& Bennett, M. A (2014). Development of a criterion method to determine peak mechanical power output in a countermovement jump. Journal of Strength and Conditioning Research, 28(6), 1552-1558.
Keywords: Power; Coordination; Vertical jumping; Children; Force platform

Specificity of motor abnormalities in DCD in the following children with Autism Spectrum Disorder using a standardized neuro-psychomotor assessment

A. Paquet ${ }^{1,3,4}$, B. Olliac ${ }^{4,5}$, B. Golsc ${ }^{2,3,6}$ \& L. Vaivre-Douret ${ }^{2,6,7}$ ${ }^{1}$ Department of Psychology, University of Paris Descartes, Sorbonne Paris City 75006, Paris. France aude.paquet@etu.parisdescartes.fr; ${ }^{2}$ Department of Medicine, University of Paris Descartes, Sorbonne Paris City, Paris, France; ${ }^{3}$ INSERM, UMR 1178, University of Paris Sud and Paris Descartes, Paris, France; ${ }^{4}$ University Pole of Psychiatry of the Child and the Teenager, Limoges, France; ${ }^{s} U M R$ 1094, University of Limoges, Limoges, France; 'Department of Child Psychiatry, AP-HP Necker-Enfants Malades University Hospital, IMAGINE affiliation, Paris, France; 'Department of Pediatrics, AP-HP Paris Center Port Royal-Cochin Hospital, Paris, France.

Aim: Decreased motor performance was described in Autism Spectrum Disorders (ASD) with a disturbance in walking, posture, coordination or arm movements. There is evidence in favour of comorbidity between Developmental Coordination Disorder (DCD) and ASD, including impairment of Cor show no decrease of the driving performance. Although there are difficulties in defining the DCD in the studies in children with ASD, it is estimated that there is a high prevalence of classic motor symptoms of DCD in these children. Objective: To highlight the semiology of movement disorders among children with ASD, using a neurodevelopmental assessment tool.

Method: Thirty-five children with ASD are recruited in a child psychiatry service (Limoges) and Autism Resource Centers (Bordeaux, Limoges, Toulouse). Evaluations of the first instances (psychiatric/ ADI; psychological/ KABC-II/ Rey's figure/ London tower; understanding/NEEL; psychomotor/ $\mathrm{M}-\mathrm{ABC}$ ) were supplemented by a standardized assessmen battery of neuro-developmental psychomotor functions (NP-MOT). Results: From the NP-MOT test, the tests of two-hand and finger praxis are largely failed $(33 \%$ and $60 \%)$. Manual and digital gnosopraxis are equilibrium tests $(60 \%)$ and dynamic $(53 \%)$. There is also the difficulties of coordination between the upper and lower limbs in $55 \%$ of children. We find a failure to the M-ABC (79\%). Spatial orientation is deficient in $47 \%$ and visuospatial structuring in $56 \%$ of cases. Children with Asperger's Syndrome (AS) were better on perceptual-visuo-spatial tests.

Discussion: We can emphasize in the light of the results of manual and digital gnosopraxis tests a planning deficit in children with autism. A gesdigital gnoso poor results in the tests of two-hand praxis NP-MOT, by failure to M-ABC tests despite the training of the child and by the visuospatial test. These planning and programming difficulties gesture increase a mixed type of dyspraxi (ideomotor/visiospatial and constructive) of this DCD in children with ASD. However it appears that children with AS have a better overall motor coordination and we did not notice any perceptual and visuospatial disorder in these children. And children with AS would present a particular type of ideomotor typology of DCD. The use of neurodevelopmental tool allows to refine the semiology of motor abnormalities in the DCD. References:

Paquet, A., Olliac, B., Golse, B., \& Vaivre-Douret, L. (2014). Etat des connaissances sur les troubles moteurs des enfants porteurs de Trouble du Spectre Autistique et apport de l'évaluation neuro-psychomotrice standardisée. Les Entretiens de Bichat, Paris

Vaivre-Douret, L. (2006). Batterie d'éuluation des fonctions neuro-psychomotrices de l'enfant. Paris: ECPA.

Vaivre-Douret, L. (2014). Developmental coordination disorders: State of art Neurophysiologie Clinique/Clinical Neurophysiology, 44(1), 13-23.

Keywords: Autism Spectrum Disorders; Motor skills; Neuro-psychomotor functions; Developmental Coordination Disorder. 


\section{Paper 5}

A computational method of obtaining reliable measurement of periosteal crosssectional area of human radii from laser scans

P. Mahmoodi, S. Annan and N. Owen. Proceedings of the 23rd UK Conference of the Association for Computational Mechanics in Engineering 2015, Swansea. 73-76. 


\section{A computational method of obtaining reliable measurement of periosteal cross-sectional area of human radii from laser scans}

P. Mahmoodi, S. Annan and *N. Owen

College of Engineering, Swansea University, Singleton Park, Swansea, SA2 8PP

*n.j.owen@swansea.ac.uk

\section{ABSTRACT}

The accurate quantification of bones cross-sectional geometry provides valuable information about mechanical properties of bones such as rigidity to torsional, bending and compressive loading and also reveals insights into habitual activities of humans in the past. However, the use of current methods can produce large errors between measured and true cross-sectional areas. In this study the minimum cross sectional area was calculated at midshaft for a unique collection of laser scanned radii bones, recovered from Mary Rose warship, using a novel technique. A computational method was used to measure multiple cross-sectional areas for different orientations to then determine a minimum. This was then taken to represent a reliable mid-shaft cross-sectional area. The reliability of the process was tested using Bland and Altman plots to analyse the agreement between measurement trials. The systematic bias between the two measurement trials was $0.06 \mathrm{~mm}^{2}(0.04 \%$ of the average cross-sectional area measurement) with $95 \%$ limits of agreement of $1.69 \mathrm{~mm}^{2}(1.13 \%)$ and $-1.57 \mathrm{~mm}^{2}$ $(1.05 \%)$. Consequently this method can be used as a reliable measure of periosteal cross-sectional area. The possibility also exists to transfer the methods described here to other imaging technologies for example, micro CT and magnetic resonance imaging. This would augment existing methods of computational analysis and produce accurate models

Keywords: computational modelling, bone topology, osteology, biomechanics

\section{Introduction}

The study of osteology and bone morphology refers to the detailed analysis of the form and structure of bone. The results of such analyses in human studies help science understand important areas of human development and health, such as habitual activities of humans in the past and evolutionary medicine [1,2]. The use of engineering theory, specifically beam analysis is increasingly used to analysis bones structurally. Recently the trend has been to use virtual bones derived from different imaging technologies for such studies [1]. The most common technologies used for creating dimensionally accurate virtual bones are laser scans [1], peripheral qualitative computed technology scan [2] and computed tomography scans [3]. However bones, when compared to manufactured objects, present certain challenges with regard to valid and reliable metrology. For example, it is common practice to align bones or limbs to be scanned with an external reference plane. Whilst this would provide a reliable position for repeated measurements of the same bone or limb, it would not necessarily allow reliable measurements of different bones due to inter-specimen/limb variation, that is, the same bone from different people vary considerably in shape and size. Consequently, the purpose of the current study is to develop a reliable method of measuring bone morphology, specifically mid-shaft cross-sectional area.

\section{Materials and Methods}

Human radii bones $(\mathrm{n}=10)$, recovered from Mary Rose warship provided by the Mary Rose Trust, were used in this study

All radii were scanned on a FARO three dimensional (3-D) laser scanner ( 7 axis, 10 foot Fusion model; FARO Technologies Inc., Florida, USA). MeshLab (v1.3.1; Visual Computing Lab, Pisa, Italy) was used toinput into MATLAB. 
The minimum cross-sectional areas (at mid-shaft) of scanned bones, with arbitrary orientations, were measured in three steps. Reference bony landmarks were first defined from which orthogonal reference axis lines were determined. In the second step all the bones' reference axes were rotated to align them with the global reference frame. In the last step a computational method was used to find the minimum cross sectional area of the bone at the mid-shaft position.

Three reference bony landmarks were used to align the bones with the global reference frame to enhanced the performance of the method. Figure 1 shows the location of the bony landmarks used to define the reference axes, they were: a) the furthest point of the styloid process (point 1), b) the centre of the concaved surface on the proximal radial head (point 2) and c) the mid-point between the corners of the distal articulating surface above the ulnar notch and point 1 (point 3 ). Orthogonal axes, $\vec{V}_{31}$ and $\vec{V}_{32}$, were then defined based on the coordinates of the bony landmarks. The desired orientation of bones was defined such that a vector connecting points 3 and $2\left(\vec{V}_{32}\right)$ is parallel to the global x-axis and $\vec{V}_{31}$ is located on a plane parallel to (x-y), Figure 1. The procedure of alignment of bones to the desire orientation consists of three stages. In the first stage the point cloud rotates about the y-axis by the angle of $\theta$. Stage two involved rotation of the point cloud about

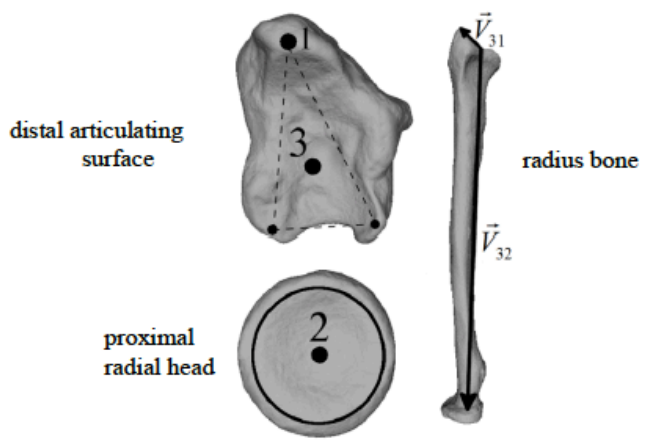

Figure 1: Position of reference bony landmarks and reference axes for each radius bone.

the z-axis by the angle of $\phi$ so that $\vec{V}_{32}$ became parallel to the x-axis Figure 2 . In the final stage new coordinates of the scanned bone rotate about its longitudinal vector $\left(\vec{V}_{32}\right)$ by the angle of $\psi$ so that $\vec{V}_{31}$ is located on a plane parallel to (x-y) Figure 2. Thus, the point cloud at each stage is given by:

$$
\left[\begin{array}{l}
x_{\theta} \\
x_{\varphi} \\
x_{\psi}
\end{array}\right]=\left[\begin{array}{c}
x_{1}+l_{\theta} \cos \left(\theta-\theta^{*}\right) \\
x_{1}+l_{\varphi} \cos \left(\varphi-\varphi^{*}\right) \\
x_{\varphi}
\end{array}\right],\left[\begin{array}{l}
y_{\theta} \\
y_{\phi} \\
y_{\psi}
\end{array}\right]=\left[\begin{array}{c}
y_{\text {initial }} \\
y_{1}+l_{\phi} \sin \left(\phi-\phi^{*}\right) \\
y_{1}+l_{\psi} \cos \left(\psi-\psi^{*}\right)
\end{array}\right],\left[\begin{array}{c}
z_{\theta} \\
z_{\phi} \\
z_{\psi}
\end{array}\right]=\left[\begin{array}{c}
z_{1}+l_{\theta} \sin \left(\theta-\theta^{*}\right) \\
z_{\theta} \\
z_{1}+l_{\psi} \sin \left(\psi-\psi^{*}\right)
\end{array}\right]
$$

Where $l_{\theta}, l_{\phi}$ and $l_{\psi}$ are the length of the projection of vectors connecting a point on the point cloud to the point 3 on planes (x-z), (x-y) and (y-z) respectively at each stage. The angles $\theta^{*}, \phi^{*}$ and $\psi^{*}$ are the initial angles between the projections of $\vec{V}_{32}$ on reference planes and axes. 


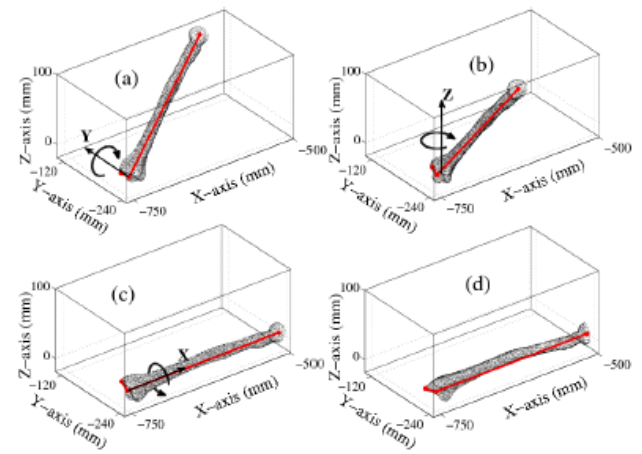

Figure 2: Rotation of the bone point cloud. $\mathrm{a}, \mathrm{b}$ and $\mathrm{c}$ show the rotation of the bone with respect to $\mathrm{y}$-axis, $\mathrm{z}$-axis and $\mathrm{x}$-axis or longitudinal reference line respectively. Final orientation of the bone is described in $\mathrm{d}$.

In order to find a minimum cross-sectional area, an initial cross section is defined as the intersection of a plane parallel to (y-z) plane (local plane), Figure 3, and the bone at mid-point of the longitudinal

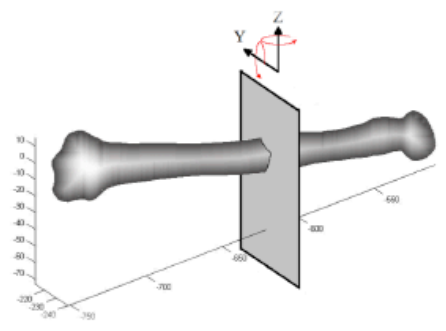

Figure 3. Local plane (y-z) used to define cross-sectional areas for different orientations

reference axes. In the second step a local coordinate system is defined such that its origin is located on the centre point of the initial cross section and its axes are parallel to the global coordinate system. In the next step, the minimum cross section area is determined by rotating the bone about the local y-axis and $z$-axis $\left( \pm 20^{\circ}, 1^{\circ}\right.$ steps) and measuring the intersection of the bone and the local coordinate system at each orientation, thus producing 1600 cross-section measurements. The minimum cross-sectional area was then chosen. The minimum cross-sectional area of each bone was measured twice with measurements derived from separate laser scans. The pairs of measurements were then statistically assess for agreement.

\section{Statistical Analysis}

The aim of the statistical analysis was to assess reliability (repeatability) of the method of measuring mid-shaft cross-sectional area. The test described by Band and Altman [5], measures the systematic bias between paired measurements of the same object and quantifies the $95 \%$ confidence limits of agreement (LOA)

\section{Results}

The systematic bias between the paired measurements was $0.06 \mathrm{~mm}^{2}$ with an upper LOA of 


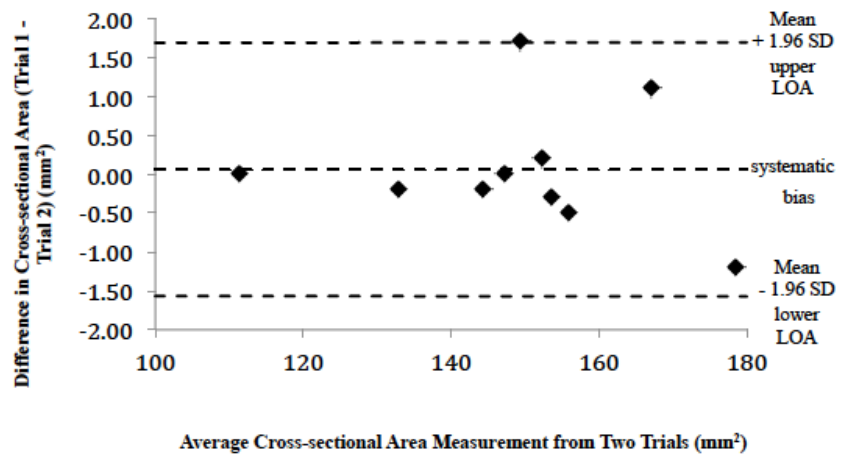

Figure 4. Bland and Altman plot of mid-shaft cross-sectional area

$+1.69 \mathrm{~mm}^{2}$ and a lower LOA of $-1.57 \mathrm{~mm}^{2}$, representing $0.04 \%, 1.13 \%$ and $-1.05 \%$, respectively, of the average cross-sectional area.

\section{Conclusion and Discussion}

The results of the study indicate that this method of assessing periosteal cross-sectional areas produces reliable and valid measurements within the range of the LOA. Analysis of bones for the assessment of occupational activity in humans increasingly uses engineering theory, specifically beam analysis. The current study provides quick and reliable method of providing metrics for such analyses. Future studies should increase the $\mathrm{n}$ number and determine the optimal orientation step and fan angle. Also, adaptation of this method for micro computed tomography and magnetic resonance imaging should be investigated, thus augmenting existing methodologies [6].

\section{References}

[1] T.G. Davies, C.N. Shaw, J.T. Stock. A test of a new method and software for the rapid estimation of crosssectional geometric properties of long bone diaphysis from 3D laser surface scans, Archaeological and Anthropological Sciences, 4, 277-290, 2012.

[2] H. Sievänen, V. Koskue, A. Rauhio, P. Kannus, A. Heinonen, I. Vuori. Peripheral Quantitative Computed Tomography in Human Long Bones: Evaluation of In Vitro and In Vivo Precision. Journal of Bone and Mineral Research, 13, 871-882, 1998

[3] H. Haapsalo, S.Kontulainen, H. Sievänen, P. Kannus, M. Järvinen, \& I. Vuori. Exercise-induced Bone Gain Is Due to Enlargement in Bone Size Without a Change in Volumetric Bone Density: A Peripheral Quantitative Computed Tomography Study of the Upper Arms of Male Tennis Players. Bone, 27 (3), 351 357,2005

[4] J.A.Rhodes and C.J. KnunselActivity-Related Skeletal Change in Medieval Humeri: Cross-Sectional and Architectural Alterations. American Journal of Physical Anthropology, 128, 536-882, 2005.

[5] J. M. Bland, \& D. G. Altman, D.G. Statistical Methods for Assessing Agreement between Two Methods of Clinical Measurement. The Lancet, 327 (8476): 307-310, 1986.

[6] P.Young, T. Beresford-West, S. Coward, B. Notarberardino, B. Walker, A. Abdul-Aziz, An efficient approach to converting three-dimensional image data into highly accurate computational models, Philosophical transactions. Series A, Mathematical, physical, and engineering sciences, 366, 3155-73, 2008 
Critical review 


\section{Introduction}

The following introduction is intended to provide an overview of the areas that are important for this corpus. It is neither intended to be comprehensive nor complete, but to provide a background and historical context to the papers included herein. As such, it will demonstrate the linking themes between studies.

\subsection{A selected brief historical overview of biomechanics}

Biomechanics is the study of the structure and function of biological systems by means of the methods of mechanics (Hatze, 1974). Clinical and sports biomechanics refer to applying mechanical principles to human subjects and can trace its roots to the ancient Egyptians in as much as they are considered to be the originators of anatomical investigation (Cave, 1950; Elhadi et al., 2012). Cave (1950) considered their interest in anatomy as limited to that which was necessary to embalm individuals, as opposed to a curiosity about the function or structure of the human body. However, more recent research has determined that as long ago as 3100 before the common era (B.C.), Egyptian physicians had an interest in and knowledge of medicine and anatomy. For example, two works titled Practical Medicine and Anatomical Book were written by Dier or Athothis around 300 B.C.. These works may be the first practical and systematic studies of human anatomy (Elhadi et al., 2012).

Nevertheless, it was not until several centuries B.C. that the Greek philosophers started considering the mechanisms behind human function and movement (Cooper, 1983). Galileo Galilie (1560 - 1642) and Sir Issac Newton (1642-1727) both provided the foundations of modern dynamics (Cooper, 1983). Galileo, through his work on falling bodies and Newton through his establishment of his laws relating to motion (I. Newton, 1687).

In terms of modern biomechanics, the studies by Giovanni Borelli's (1608 - 1679), a student of Galileo, of human movement are normally considered to be the first in the field (Maquet, 1989; Pope, 2005; Thurston, 1999). His studies demonstrated a clear understanding of both anatomy and mechanics of movement (Figure 1). Figure 1. clearly illustrate Borelli's understanding of several key principles of biomechanics through a series of individual figures. For example, Borelli's Fig 3, illustrates 
functional muscle mechanics in terms of lower leg extension and Borelli's Fig 5, illustrates the principle of balance and the line of gravity remaining within the base support. However, although Borelli was able to relate muscular movement to mechanical principles, he lacked the experimental tools to investigate his keen observations and, as such, he is considered one of the theoreticians (Cooper, 1983).

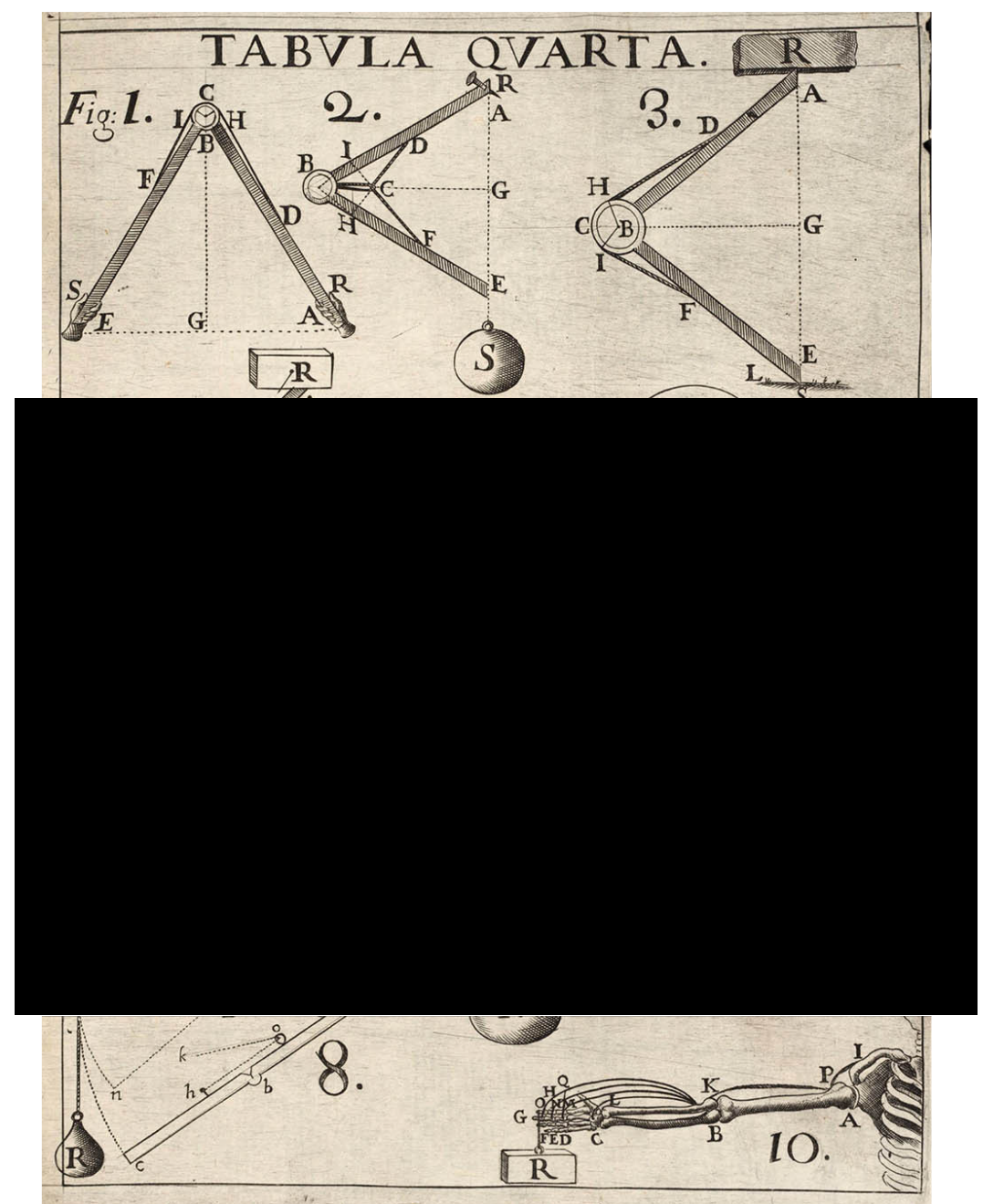

Figure 1. A plate from Giovanni Borelli's De Motu Animalium (1680) 


\subsubsection{Kinematics}

Kinematics is the study of motion based on position (spatial) and time (temporal) data, without recourse to the cause of the motion (Watkins, 2014). In terms of experimental kinematics, the Weber brothers, Eduard (1806-1871) and Heinrich (1795-1878) were considered to be the first to record experimental locomotive data based on both observation and some basic measurements (Thurston, 1999). However, Eadweard Muybridge (1830-1904) was the first to use the concept of successive photographic images, and a scaled backdrop, to study the locomotion of horses (1878 Figure 2).

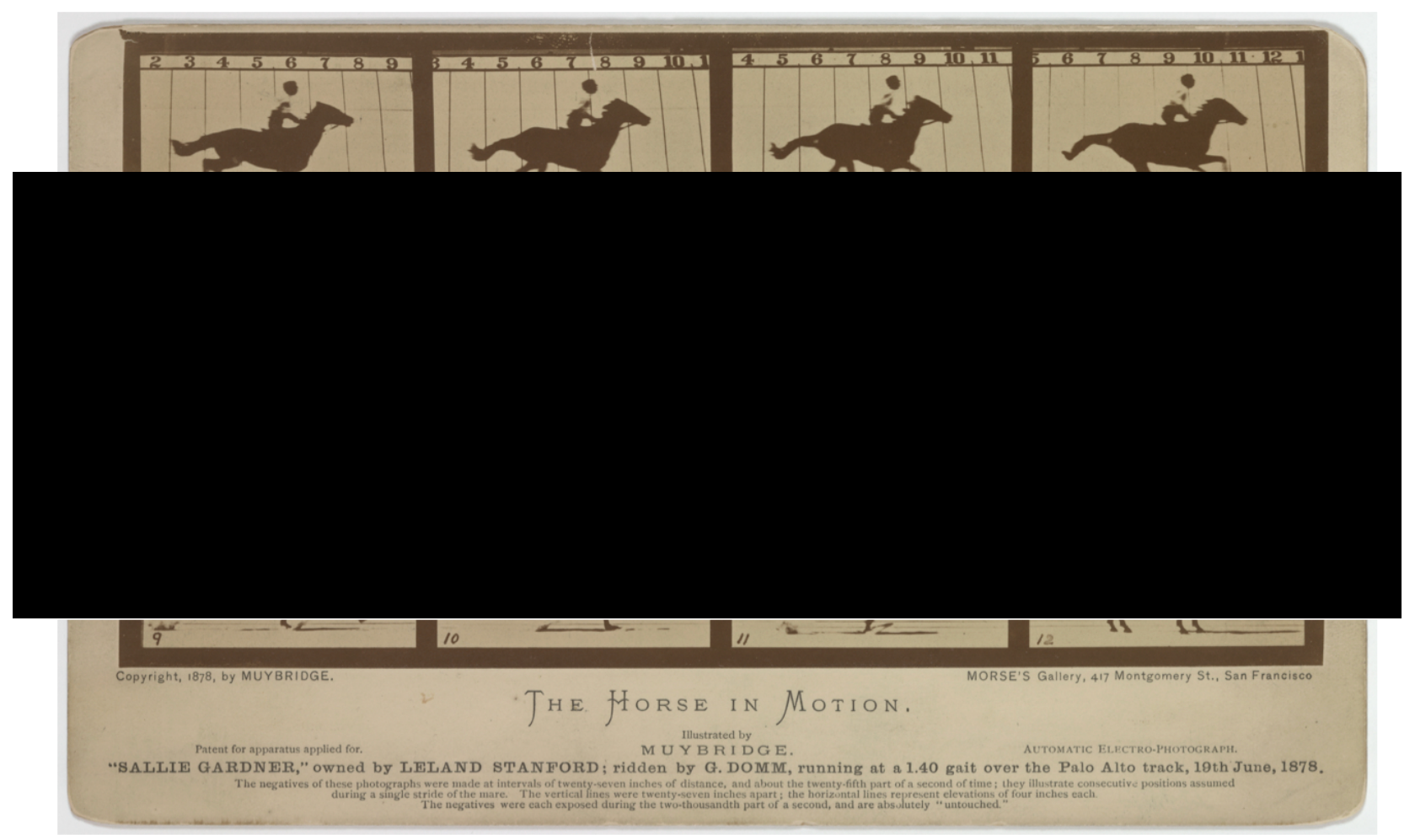

Figure 2. Eadweard Muybridge's The Horse in Motion (Library of Congress, Prints \& Photographic Division [reproduction number LC-DIG-PPMSCA-06607])

In signal processing, periodic sampling is the process of representing a continuous signal with a sequence of discrete data values (Lyons, 2011). Consequently, if the motion of the horse in Muybridge's images is the signal and the photographic images are discrete data values, his study can be considered to be an early example of periodic sampling of physical activity and certainly a very early, if not the first, example of modern experimental work in kinematics. 
Contemporary methods of collecting kinematic data include, but are not limited to, goniometers, linear position transducers, rotary position transducer, but the most common instrument is the high speed imaging system e.g. video cameras, that are able to collect successive images at equal time intervals. The number of images recorded a second is referred to as the frame rate or sample rate, having units of frames per second (fps) or frequency, hertz $(\mathrm{Hz})$. Imaging systems are used to collect linear and angular kinematic data and can be used with a calibrated plane of interest or at fixed intervals of known position. Such systems can be used independently of, and in conjunction with kinetic measurement systems.

Current examples of kinematic imaging systems are Quintic Biomechanics ("Quintic Biomechanics," n.d.) and VICON (VICON, n.d.) . Quintic Biomechanics represents a typical video based system, using conventional video images to generate data. VICON though, does not use video as its prime data source but uses video cameras to determine the position of markers in 3 dimensional space, based on the principle of geometric triangulation.

\subsubsection{Kinetics}

Kinetics is the branch of mechanics dealing with forces and torques and their effect on bodies at rest and in motion (Zatsiorsky \& Zaciorskij, 2002). Sir Isaac Newton's three laws of motion describe the effects of force in terms of motion and have been the cornerstone of kinetics since they were first reported in Newton's Principia (I. Newton, 1687). The theoretical determination of forces responsible for human motion have been a goal of biomechanists for many years. For example, Fenn (Fenn, 1957) reported Eduard Weber's erroneous attempts in 1846 to calculate the force produced by the triceps surae when raised on the toes.

Routine measurements of the force produced by humans during locomotion was not investigated until 1872 when Carlet of France (Carlet, 1872) used pneumatic bulbs attached to the the foot to measure pressure under the heel and metatarsal regions. Carlet's system, probably because it relied on pneumatic bulbs as force transducers (Sutherland, 2005), would be unlikely to represent force as vector quantity, which would require both direction and magnitude to fully describe it. Nevertheless, Carlet's device was able to record a force-time history of normal gait similar to that produced 
by a modern force platform measuring the vertical component of the ground reaction force (GRF), Figure 3.

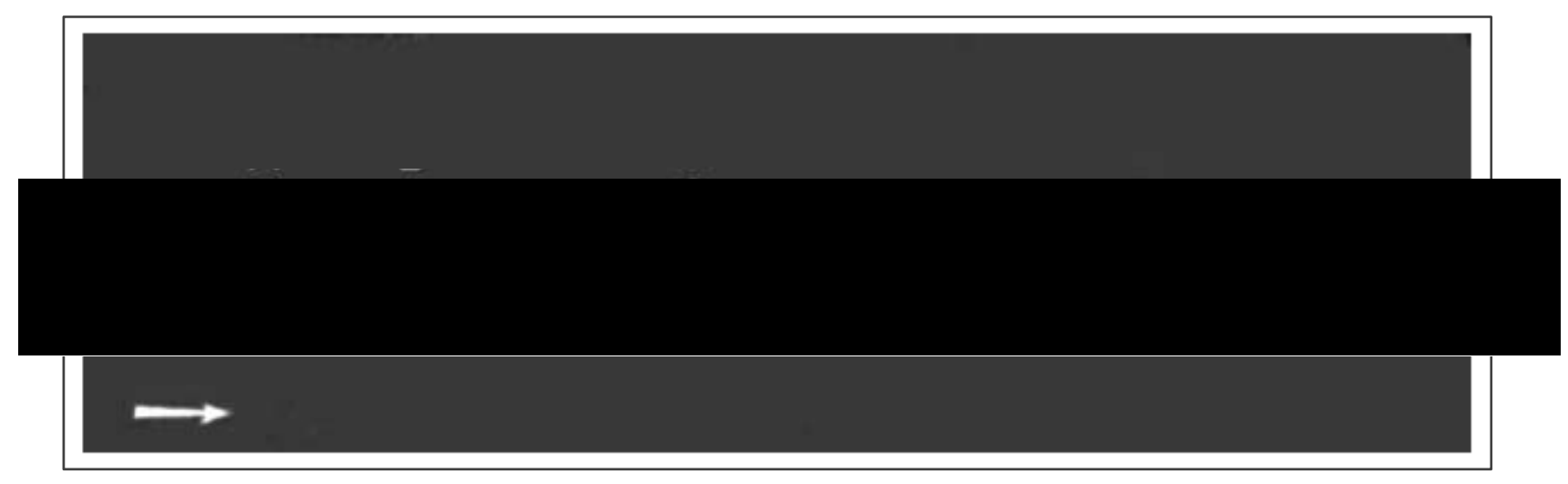

Figure 3. Time series trace produced from Carlet's pneumatic gait device representing the vertical component of the ground reaction force of normal gait (adapted from Sunderland, 2005)

It is interesting to note, and a testament to his vision, that Carlet's device has a direct contemporary equivalent in instruments that measure plantar pressure ("F-Scan System," n.d.; "pedar," n.d.).

The first instrument reported to be capable of measuring the GRF of human gait i.e. an instrument that was able to measure and record the vector quantity not just one component of the GRF, has been attributed to Jules Amar who reported his device, the Trottoir Dynamographique, in 1916 (Amar, 1916). Amar's device was an ingenious combination of steel and cast iron levers, springs and pillars that allowed pneumatic bladders to be activated but only in directions corresponding to the three planes of motion i.e. vertical, anterior-posterior and lateral-medial, Figure 4. 


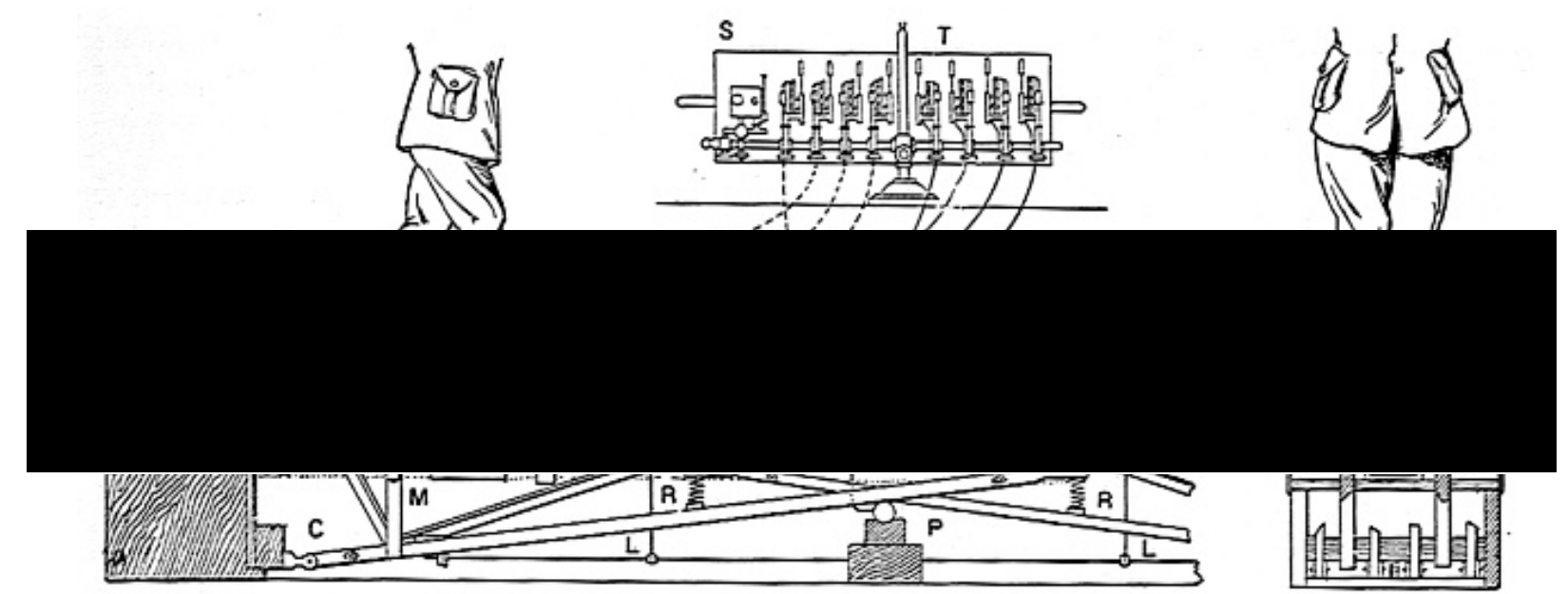

Figure 4. A schematic diagram of Amar's Trottoir Dynamographique.

1. Side elevation; 2. Transverse section; B. Platform for the wounded to walk; L, L. System of levers supporting the platform via part M; R. Coil springs; C. Clevis joint; P. Pneumatic bladder operating a diaphragm $\mathrm{T}$ and recorded on the cylinder S; A. Resting landing [figure adapted and translated from (Amar, 1917)]

The bulbs associated with each plane of motion, pneumatically activated an analogue device, the movement of which was in-turn was recorded on a "rapidly rotating cylinder" (Amar, 1916). The machine was used to aid in the design of prosthetics being used for amputees in the Great War (1914-1918) by attempting to mimic the gait pattern, in terms of GRF, of able-bodied controls.

Amar's device was, in effect, a double force platform (FP) with separate instrumentation for the left foot and the right foot, measuring $3 \mathrm{~m}$ long and $0.5 \mathrm{~m}$ wide. The design of current FPs can be traced directly back to Jules Amar's fundamental concepts. Although uniaxial force transducers are sometime s used in human movement kinetic analysis, the FP remains the most widely used instrument to collect kinetic data of human movement within a research environment. Modern force platforms can typically sample GRF at up to $2 \mathrm{kHz}$ with resolutions of ranging between 12 bits to 16 bits (“Bertec Corporation,” n.d.; Kistler, n.d.; Owen, Watkins, Kilduff, Bevan, \& Bennett, 2014). Force platforms have a very large dynamic range, in terms of magnitude of the force. At the lower end of the dynamic range, sub-newton accuracy is possible when postural sway is being measured in children (Geuze, 2003; Rose et al., 2002). At the higher end of the dynamic range, for example in drop jump landing studies, the vertical component of the ground reaction force (VGRF) can exceed 4 times body weight (BW) (Bates, Ford, Myer, \& Hewett, 2013; Brent \& Hewett, 2006). 


\subsubsection{Anthropometric science}

Modern principles of kinematic and kinetic measurements were established by Muybridge in 1878 and Amar in 1916 (Amar, 1916), respectively. However, it was not until 1939 when kinematics and kinetics were combined in a meaningful way. Thus enabling the systematic analyse of the forces and energy changes in the leg during walking using the process of inverse dynamics (Elftman, 1939) using a FP to collect kinetic data and cine film to measure kinematic data at a rate of 92 fps. Elftman (1939) can be considered the first person to use the methods of modern biomechanical analysis, which is dependent on a knowledge of the properties of the whole body, and body segment parameters (BSP), in terms of mass, centre of gravity (CoG) and moment of inertia. Elftman, described the process of inverse dynamics in a clear and instructive way and used a newly devised force platform capable of measuring GRF (Elftman, 1939) and anthropometric data from Otto Fischer (Fischer, 1906). Borelli appears to have been the first to have investigate the $\mathrm{CoG}$ of a human subject in 1679 . This was achieved by having the subject lay supine on a rigid board, supported by a movable pivot, and finding the balance point, thus enabling an estimation of the $\mathrm{CoG}$ of the whole body (Dempster, 1955). Borelli's work (1679), while creative and ground breaking, did not provide sufficient detail (i.e. data on BSP), for use in inverse dynamics studies.

There has been interest in, and several studies undertaken on, BSP since 3000 B.C. in Egypt (Drillis, Contini, \& Bluestein, 1969), however the first valid study of BSPs, in terms of usefulness to modern biomechanics, is attributed to Braune and Fischer (Braune \& Fischer, 1889) and the Fischer (Fischer, 1906) who produced meticulous data derived from the study of three males cadavers. They reported the masses and positions of $\mathrm{CoG}$, determined by the double suspension method, and moments of inertia for 12 body segments, namely, head, trunk without extremities, entire upper limb, arm, forearm plus hand, forearm, hand, entire lower limb, thigh, leg plus foot, leg and foot (Dempster, 1955; Drillis et al., 1969). These data were used extensively up until the 1950s (Clauser, McConville, \& Young, 1969) when Dempster engaged in a continuation of Braune and Fischer's work. The need for Dempster's work was stimulated by rapid improvements in aviation and the increasing importance of space 
flight in the 1950's. There was a need to provide more accurate data on the human body to the United States Airforce, because the pilot was now considered part of the aircraft, both in terms of operation and inertial properties (Dempster, 1955). Dempster's study reported extensive data of BSP, as well as other comprehensive human anthropometric data, derived from a thorough study of 8 cadavers. Figure 5, shows an example of body mass distribution reported in Dempster's study of 1955. More recently, BSP have been determined by scanning (X-ray and magnetic resonance imaging (MRI)) and other technique (Cheng, Chen, Chen, Lee, \& Chen, 2000; Durkin, Dowling, \& Andrews, 2002; Erdmann \& Kowalczyk, 2015). However, although the current techniques offer the potential of more accurate inverse dynamics studies, in practice access to scanning facilities is a limiting factor.

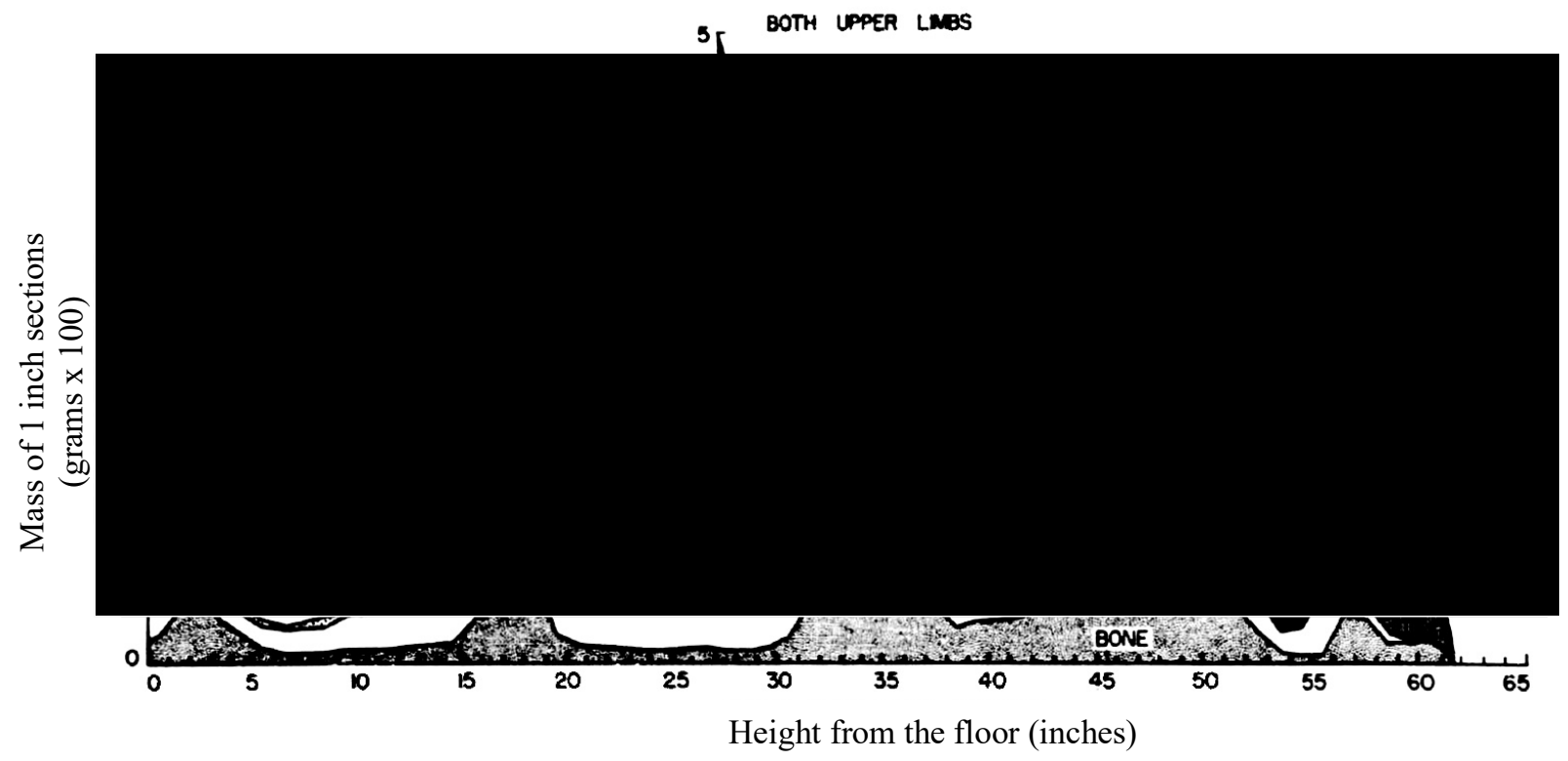

Figure 5. An example of Dempster's (1955) meticulous work, on human anthropometry and BSP, showing the distribution of body mass of a cadaver relative to its height. The weights (sic) of transverse saw-cut sections of one-inch thickness were plotted relative to height; the weights ( $\mathrm{sic}$ ) of bone, muscle, integument and organs in successive sections are shown also. Adapted from (Dempster, 1955) 


\subsubsection{The effect of loading on human tissue (bone)}

The previous sections have considered some methodologies used measure, infer or derive force (and kinematic variables), this section considers the effect of force on human tissue, namely bone. Bone have several functions within the human body including support and leverage, storage of minerals and lipids, blood cell production and protection of vital organs (Martini et al., 2012; Taichman, 2005; Watkins, 2009). However, the current section will be limited to the bone's function of transmitting and resisting loads (forces and torques) both external contact forces and internal muscles forces. Bones, in terms of load bearing structural functionality, consist of cortical (or compact) and trabecular (or spongy / cancellous) bone. Both types of bone are made from the same basic building blocks, osteons (Watkins, 2009), but differ in organisation, structural appearance and function. Bones can be considered to be a hybrid material whose specific properties are matched to function (Launey et al., 2010). Bones are able to adapt their shape, composition and structure, in response to timeaveraged mechanical conditions they experience.

The first documented interest in the connection between the structure of bone and functional mechanical properties is attributed to Julius Ward (Ward, 1838) and his observations of the structure of cortical and cancellous bone (Kivell, 2016). In Ward's book on human osteology he notes the similarity of the trabecular structure in the neck and shaft of a human femur to that of the mechanical structure of a street lamp bracket, Figure 6. Attention was drawn to the similarity of loading conditions for both structures. The area marked ' $G$ ' in Figure 6, is an area of low density trabecular bone and is commonly referred to as Ward's Triangle, after Julius Ward. 


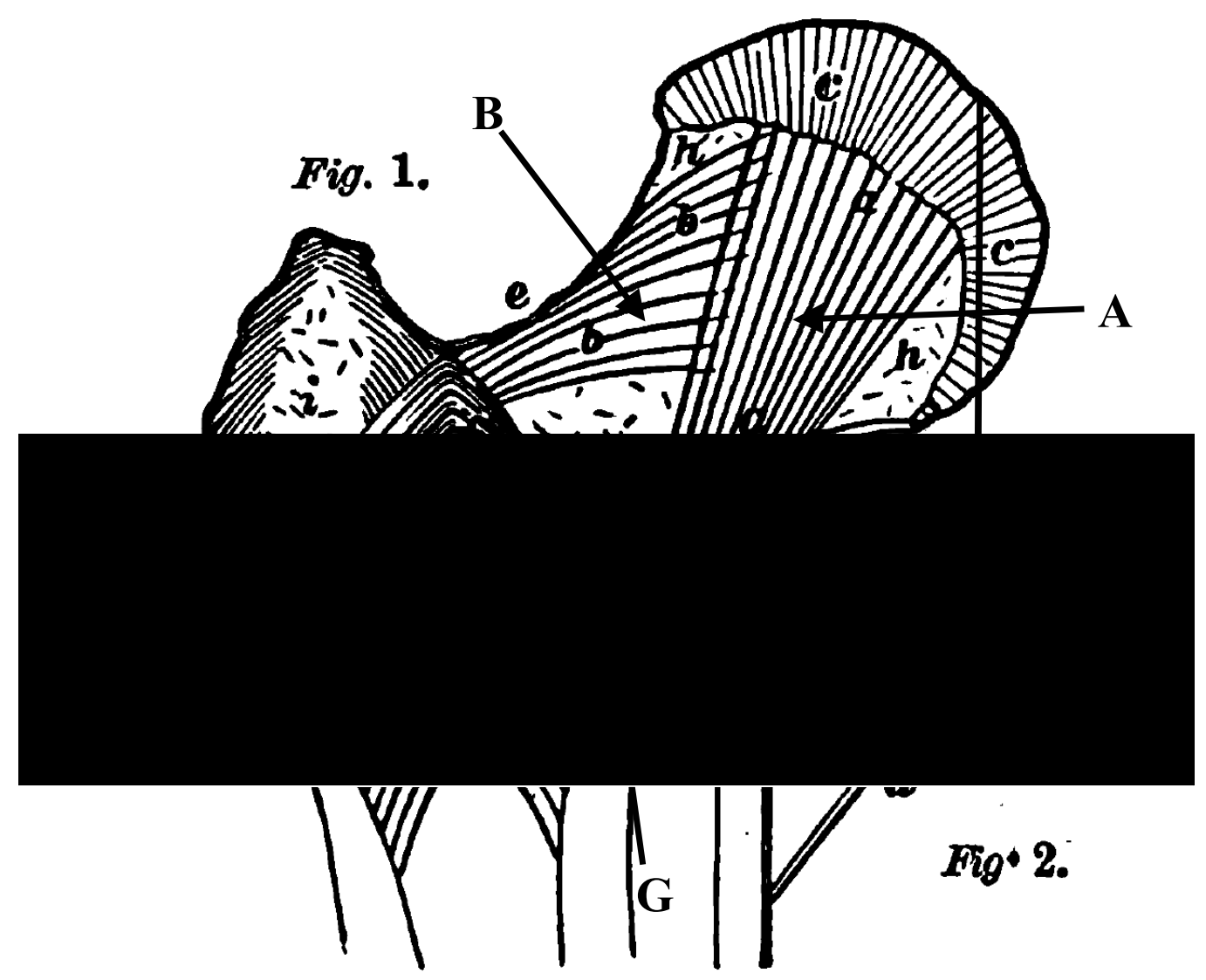

Figure 6. A schematic diagram comparing the internal structure of a human femur (Fig. 1.) with that of a lamp bracket (Fig. 2.). Ward (1938) observed that strut $a$ in Fig. 2., experiences compression and a bending moment about its base and that strut $b$, which is in tension, helps support $a$, the two elements providing a stable and strong structure. The analogous structures of the femur correspond to $\mathbf{A}, \mathbf{B}$. The region marked $\mathbf{G}$ (Ward's triangle), corresponds to the void g, in Fig. 2., and represents an area of low density trabecular bone in the femur. The femur supports the weight, m.g and the bracket supports the weight of the lamp, $\mathrm{m}_{\mathrm{L}} . \mathrm{g}$. Adapted from (Ward, 1838)

Nearly fifty years after Ward's keen observations, Julius Wolff (1892) proposed his law of bone adaptation:

"Thus the law of bone remodelling is the law according to which alterations of the internal architecture clearly observed and following mathematical rules, as well as secondary alterations of the external form of the bone following the same mathematical rules, occur as a consequence of primary changes in the shape and stressing or in the stressing of the bones."

(J. Wolff, 1892; Julius Wolff, 2012). 
Wolff's Law, in terms of functional adaptation over time due to external loading history, is still considered appropriate today, however elements of Wolff's mathematical explanation of adaptation are not correct (Ruff, Holt, \& Trinkaus, 2006). Current research paints a far more complex picture combining explanations of the process of mechanostat load sensing and biological processes to model and remodel bone (Frost, 1994, 2004; Hart et al., 2017)

\subsubsection{Methods of imaging bone}

Not long after Wolff's Law's publication, W. C. Röntgen (1895) discovered x-rays and their application to the study of bone (Mould, 1995), Figure 7. In the 1970s x-ray computed tomography (CT) was developed, where successive 'slices' of x-ray images were reconstructed to produce a 3-dimensional (3-D) image of bone, although

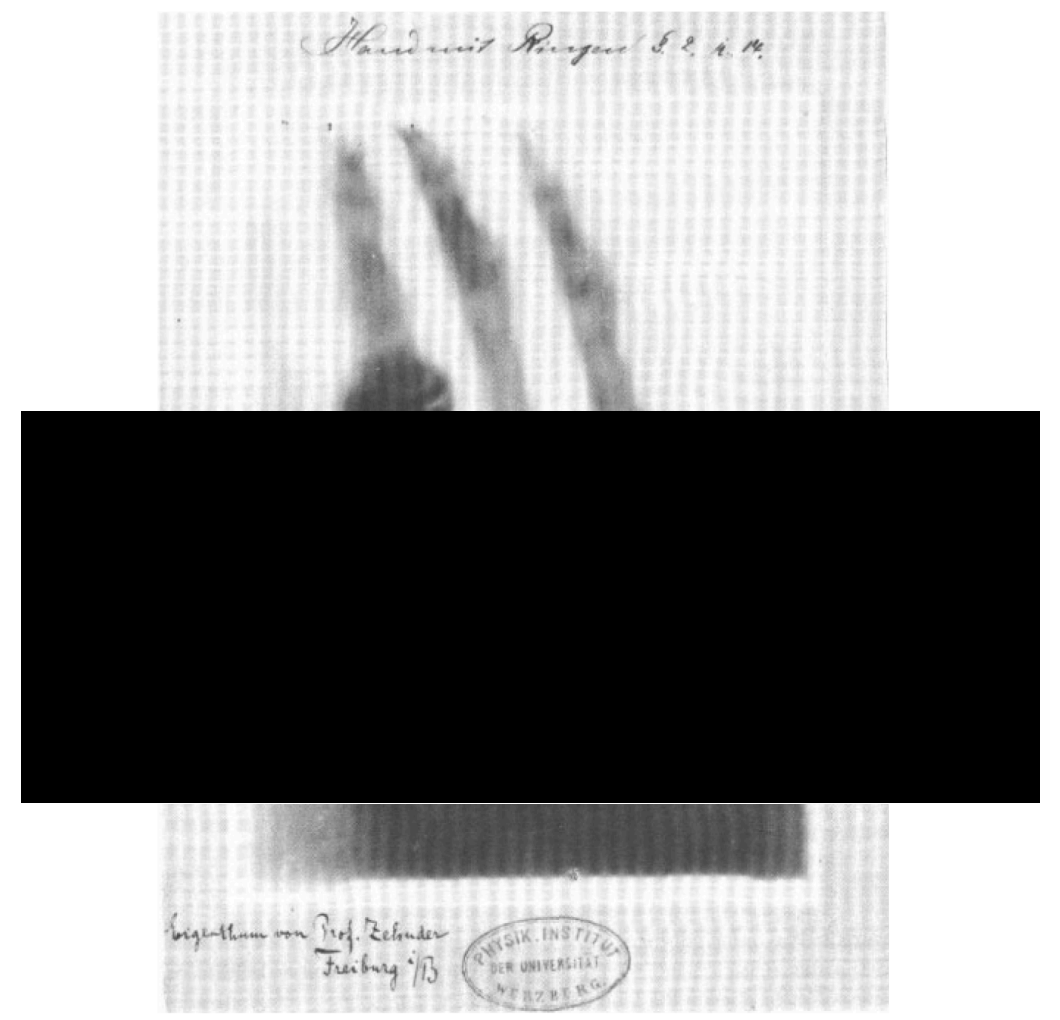

Figure 7. One of the first images produced using x-rays, Röntgen (1895). The image is of Frau Röntgen's hand. (Mould, 1995)

resolution was low (Bradley, 2008). At about the same time magnetic resonance imaging (MRI) was evolving, which used magnetic fields to produce 3-D images, not only of bone but also of soft tissue, far better than x-ray were able to and without the 
need for ionising radiation (Bradley, 2008). MRI scans are predominantly used for imaging soft tissue, however with appropriate optimisation, they are being increasingly used to study bone (Singh, Bray, \& Hall-Craggs, 2018). In the 1980s microCT ( $\mu$ CT) was developed

(Link, 2010) and in $1989 \mu \mathrm{CT}$ was first used to investigate bone architecture, with a resolution $\sim 10 \mu \mathrm{m}$ (Feldkamp, Goldstein, Parfitt, Jesion, \& Kleerekoper, 1989). More recently, laser surface scans have been used to model, with high resolution $(\sim 40 \mu \mathrm{m})$, the exterior surface of bones for both forensic osteology (Errickson, Thompson, \& Rankin, 2014) and anthropological purposes (Kuzminsky \& Gardiner, 2012). Figure 8., shows several examples of surface laser scans, $\mu \mathrm{CT}$ scans and MRI scans. Modern osteology and medical practice can now call on a battery of imaging techniques to study external and internal features of bone at a variety of resolutions.
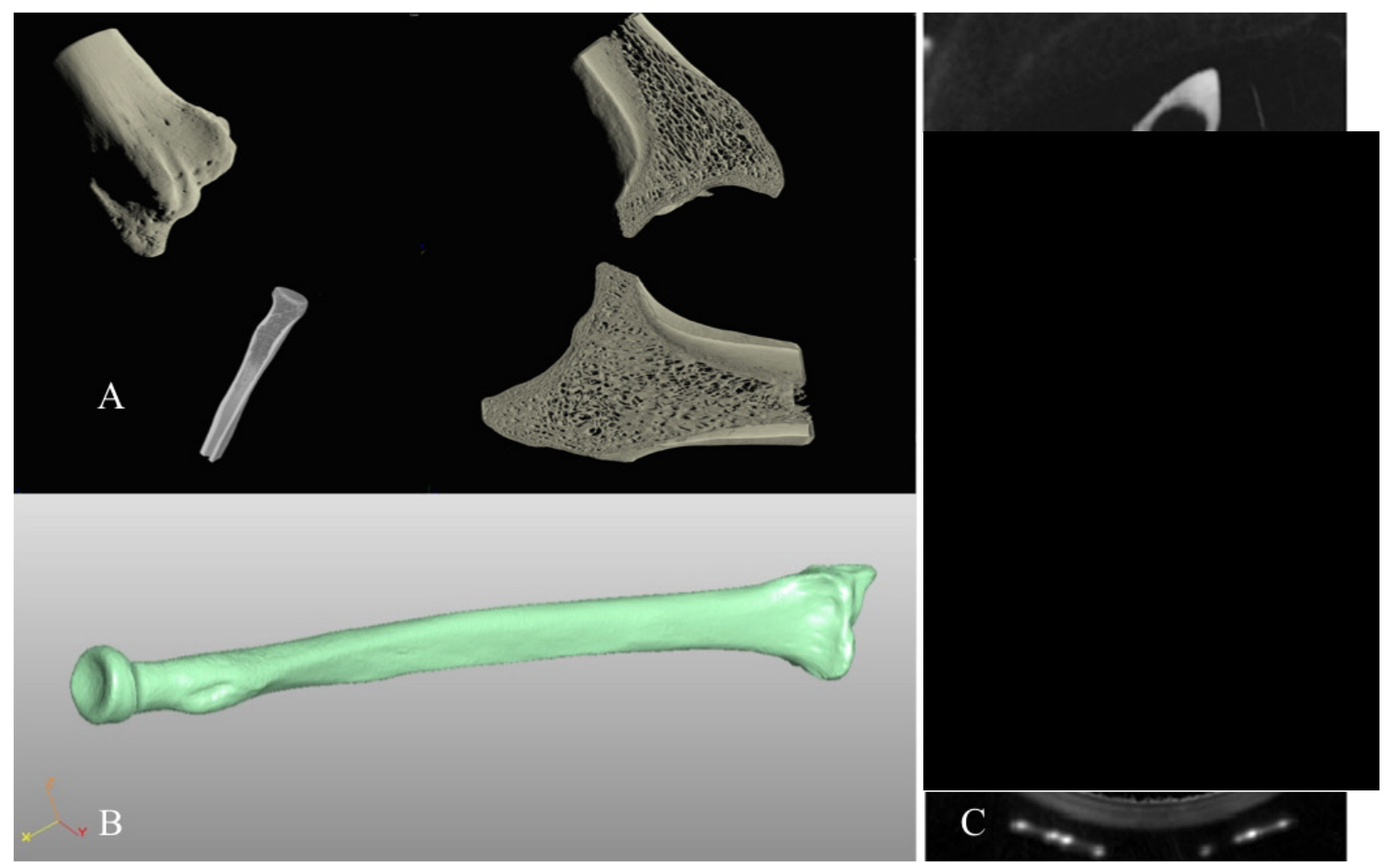

Figure 8. Examples of images produced by different scanning methods. Image A shows internal and external renders of a $\mu \mathrm{CT}$ scan of human remains (radius) from the warship Mary Rose (1545), resolution $30 \mu \mathrm{m}$. Image B shows a laser surface scan of the same radius as in $\mathrm{A}$, resolution $\sim 40 \mu \mathrm{m}$. Images $\mathrm{C}$ show a transvers plane view of a tibia and fibula using MRI scanning, optimised to render bone but not soft tissue. Image $\mathrm{C}$ adapted from (Singh et al., 2018). 


\subsection{Background to the papers presented in this corpus}

\subsubsection{Force and the process of forward dynamics}

Force is one common factor connecting the five papers in this corpus, it can be considered a complex variable, inasmuch as three base Système Internationale d'Unités (SI) units are needed to define the unit of force. Force can be defined in terms of its SI units as $\mathrm{Kg} \cdot \mathrm{m} \cdot \mathrm{s}^{-2}$ or generally as $[\mathrm{M}] \cdot[\mathrm{L}] \cdot\left[\mathrm{T}^{-2}\right]$ (where $\mathrm{M}=$ mass, $\mathrm{L}=$ length and $\mathrm{T}=$ time). It is a vector quantity requiring both direction and magnitude to be correctly described. It can also be defined as an influence which, if unopposed, causes a change in motion of an object (mass). The effect of force on a mass, in terms of linear kinematics was described by Sir Isaac Newton in his three laws of linear motion (I. Newton, 1687), commonly known as Newton's Laws (of linear) motion. Newton's three laws underpin classical mechanics and consequently biomechanics. They are:

$1^{\text {st }}$. An object's motion will be constant unless it experiences a net force. (N1)

$2^{\text {nd }}$. For a constant mass system, the rate of change of momentum is proportional to the applied force and is in the same direction as the force. (N2)

$3^{\text {rd }}$. If a body exerts a force on another body, the first body will experience the same force but in the opposite direction. This force is called a reaction force. (N3)

If the forces acting on a subject (which can be considered to act on the whole body centre of gravity (WCoG) of the subject) can be measured and the subject's body weight (BW) is known, Newton's laws can be used, in a process known as forward dynamics, to determine the kinematic variables (Hatze, 2002; Kerwin, 1997; Otten, 2003). The process of forward dynamics is explained below.

A FP is a device used to measure GRF, consequently, the mass of a subject can be determined if they stand still on the FP. The motion (velocity) of the subject will then be constant (zero), therefore the weight of the subject must be equal to the VGRF, as 
N1 states that if there is constant motion (i.e. zero velocity) there are no net forces acting. However, it is known that the subject has weight (due to their inertial mass and the effect of gravity), therefore the VGRF must be equal in magnitude, but opposite in its direction of action, to the weight of the subject due to N3.

If a subject performs a vertical jump off a PF and the subjects weight (and consequently mass) is known, at any point in time, the net vertical force acting on the subject can be determined by subtracting the weight of the subject from the VGRF. The acceleration can be determined using N2. The acceleration can then be used to determine the change in velocity of the subject. Similarly, if the change in velocity of the subject is known, the change in its position (of the WCoG) can be determined.

The above discussion details to the analysis of a subject at an instant. If the VGRFtime history of a vertical jump is collected and the initial conditions are arranged such that the velocity of the subject is known (zero) at the start of the jump. The corresponding velocity-time and displacement-time histories can be determined. This is the process of forward dynamics.

Instantaneous mechanical power of the $\mathrm{WGoG}(P)$ is determined using the relationship that instantaneous power is given by the product of instantaneous force and instantaneous velocity (C. T. M. Davies \& Rennie, 1968). $P$ can be determined using this relationship for a countermovement jump (CMJ), in which a jump is immediately preceded by a rapid dip, or a squat jump (SJ) in which a subject will squat down, rest briefly, then jump vertically upwards without any further dip or small countermovement. The ability to measure $\mathrm{P}$ in jumps allows strength and conditioning practitioners to assess and monitor athlete training status, as $\mathrm{P}$ is strongly correlated with successful performance in sports.

Whilst the above discussion details how the VGRF can be used with the mathematical process of forward dynamics to determine $\mathrm{P}$ in vertical jumping, it presupposes an instrument to measure VGRF to an appropriate level of accuracy and precision. A force platform (FP) is a device for measuring GRF, most commonly configured as a rigid plate with embedded force transducers symmetrically mounted, about the geometric centre of the plate, in each corner. The transducers are either of the strain 
gauge or piezoelectric type. All the studies in this thesis that used a FP, used the same model piezoelectric type (model number 92866AA, Kistler Instruments Ltd., Farnborough, United Kingdom) with data logging achieved using a 16 bit data acquisition system (model number 5691A, Kistler Instruments Ltd., Farnborough, United Kingdom). When using any piezoelectric force transducer there are several important considerations; some common to all digital data acquisition systems and others of specific importance to piezoelectric systems. Any digital system needs to be able to measure force to a high enough precision to be practical for its desired use. The precision of the instrument will depend primarily on two factors. The two factors are, the threshold of the instrument in terms of measuring force and size of the quantisation step of the analogue to digital converter (ADC). The threshold of the instrument is the minimum change in force that will result in a corresponding change in the instrument output. The quantisation step, $\Delta$, is the minimum change in the instrument's output that can be detected by the data acquisition system and is defined in Equation 1 .

$$
\Delta=\frac{\text { instrument output range }}{2^{n}}
$$

where $\Delta=$ quantisation step, $\mathrm{n}=$ number of binary bits used by the ADC

A further consideration is system noise which, for a piezoelectric FP originates from two main sources. The first is mechanical noise and can be caused by any vibration in the structure of the building / room where data is being collected. The vibration will cause the FP to move i.e. accelerate, and cause a consequent, unwanted force signal in the output. The second is electromagnetic noise, which piezoelectric systems are prone to. As piezoelectric transducers produce a charge, it is necessary to condition the raw signal by processing it through a charge amplifier in order to convert the signal to a voltage. A charge amplifier has a very high input impedance (by necessity) which, if cables are not routed with due consideration, can pick-up electromagnetic interference.

\subsubsection{Overview of papers}

Successful performance in sports is largely determined by the interaction of environmental, anthropometric and physiological factors. The main physiological 
factors are strength (peak muscle force), endurance, flexibility, speed, agility and power. Strength is usually assessed indirectly by measuring the external force that a muscle group or groups can generate in a prescribed movement such as a bench press or vertical jump. If the external ground reaction force (GRF)-time history of the movement is recorded, a number of neuromuscular performance variables can be assessed, in particular, peak force (strength, $S$ ), rate of force development $(R F D)$ and mechanical power $(P)$. The papers presented here describe a series of studies concerning (i) the reliability and validity of $S, R F D$ and $P$ in elite athletes based on $G R F$-time histories, measured by a FP and (ii) the utilisation of $P$ derived in this way in the study of the development of coordination and bone health and (iii) the development of a valid and reliable measure of bone morphology.

Paper 1 (Liam P. Kilduff, Dan J. Cunningham, Nick J. Owen, Daniel J. West, Richard M. Bracken and Christian J. Cook, 2001) investigates the effect of postactivation potentiation $(P A P)$ on the peak power output. PAP is a technique that may briefly increase peak power by prior activation of muscles, on start performance in elite swimmers. It assesses the effectiveness of $P A P$ by measuring power as an outcome. The increase in $P$ due to $P A P$ was of the order of $5 \%$ which highlighted the need for a reliable and valid method of assessing power output.

Paper 2 (Daniel J. West, Nick J. Owen, Marc R. Jones, Richard M. Bracken, Christian J Cook, Dan J. Cunningham, David A. Shearer, Charlotte V. Finn, Robert U. Newton and Liam P, Kilduff., 2011) investigates the relationships between isometric force capacity and dynamic performance. The outcome variables from an isometric midthigh pull (IMTP) included $S$ at different time points and $R F D$. Whilst $S$ is relatively simple to determine, force at different time points is dependent on identifying the instant of initiation of the pull. This is a non-trivial problem. A new method of determining pull initiation was described that could detect an initiation even when considerable variation in $G R F$ was present in the 'quite' period before the onset of muscular contraction.

Papers 1 and 2 highlighted the need for a reliable and valid methods of assessing of $S, R F D$ and $P$. Paper 3 (Nick J. Owen, James Watkins, Liam P. Kilduff, Huw R. Bevan and Mark A. Bennett, 2014) describes the development of a reliable and valid criterion method of assessing peak instantaneous power output $(P p)$ in a 
countermovement jump $(C M J)$. The paper is the first to fully investigate all variables needed to confidently define a criterion method.

Paper 4 (Owen, N J, Griffiths, W, \& Watkins, J, 2015) describes the collection and presentation of normative values of $P p$ for children aged 7 to 11 years old. This paper is the first to describe valid, reliable normative measures of power in children.

The analysis of $P p$ in a $C M J$ has been proposed and as a marker for bone health in children (Baptista, Mil-Homens, Carita, Janz, \& Sardinha, 2016a). However, as bones are not regular shaped objects, some existing methods of measuring bones' dimensions, in order to determine bone health, are not suitable e.g. cross-sectional area. Paper 5 (Mahmoodi, P, Annan, S, \& Owen, N, 2015) describes a new method for determining a valid and reliable measure of cross-sectional area of long bones, specifically a radius bone. The measurements are derived from laser scans of bones. 
1.3 Review of the Papers. 


\subsubsection{Paper 1. Effect of postactivation potentiation on swimming starts in international sprint swimmers}

Paper 1 investigated the potential benefit of $P A P$ with two outcome measures, peak forces produced at the start of a swim by means of an instrumented starting block and time to $15 \mathrm{~m}$. A FP mounted at an angle of elevation of $10^{0}$ to horizontal on the starting block, was used to collect force data for the dive and a simple kinematic video based system was used to determine $15 \mathrm{~m}$ times. Both these measurements were straightforward to implement and data required minimal manipulation. The time to 15 $\mathrm{m}$ was measured by means of a video camera, the time base (frame rate) of the video camera $(50 \mathrm{~Hz})$ and the camera was placed orthogonal to the direction of swimming, on the $15 \mathrm{~m}$ line, to provide time with a resolution of $1 / 50^{\text {th }} \mathrm{s}$ i.e. $50 \mathrm{~Hz}$ or $1 / 50^{\text {th }} \mathrm{s}$. The FP, as it was inclined, needed a simple rotational transform applied to the force components in order to align them with vertical and horizontal (in the direction of the swim). However, the method used to determine if PAP was working i.e. if it was providing a potentiating effect, required the measurement of peak mechanical power of the whole body centre of gravity $(P p)$ from a countermovement jump $(C M J)$ taken several times, starting just prior to the $P A P$ stimulus being applied.

At the time of the study, there was no published criterion method to determine $P p$ of a $C M J$ performed off a FP by means of analysis of the vertical component of the ground reaction force $(V G R F)$. The specification needed to determine a valid and reliable measure $P p$ had been identified in several studies (Hatze, 1998; Kibele, 1998; Street, McMillan, Board, Rasmussen, \& Heneghan, 2001; Vanrenterghem, Clercq, \& Cleven, 2001). However, no single study reported all variables that needed to be controlled to obtain such a measurement. Namely, sampling frequency of the PF and integration, resolution of the FP, force range of the FP, method of determining body weight and identification of the instant the CMJ starts and consequently the start point for integration. Examples of contemporary specifications reported for the determination of $P p$ (Table 1) illustrates the lack of an agreed method and specification as well as a lack of clear reporting as exemplified by the reporting of the determination of the initiation of jump as "determined by software" (Hatze, 1998; Kibele, 1998). 
Table 1. Illustrates the specification for collecting and analysing $P p$ utilising the VGRF collected from a FP. Adapted from Owen, 2008

\begin{tabular}{|c|c|c|c|}
\hline & \multicolumn{3}{|c|}{ Recommended variable value or method of determining variable } \\
\hline Variable & Kibele (1998) & Hatze (1998) & Vanrenterghem (2001) \\
\hline $\begin{array}{l}\text { Sample frequency } \\
\text { and resolution }\end{array}$ & $1000 \mathrm{~Hz}$ at 12 bits & $\begin{array}{l}2000 \mathrm{~Hz}, \\
\text { resolution not } \\
\text { considered }\end{array}$ & $\begin{array}{l}100 \text { to } 1000 \mathrm{~Hz} \text { no single } \\
\text { frequency was identified as } \\
\text { recommended, resolution not } \\
\text { considered }\end{array}$ \\
\hline Integration frequency & Not stated & $2000 \mathrm{~Hz}$ & $\begin{array}{l}100 \text { to } 1000 \mathrm{~Hz} \text { no single } \\
\text { frequency was identified as } \\
\text { recommended }\end{array}$ \\
\hline $\begin{array}{l}\text { Method of } \\
\text { integration }\end{array}$ & Trapezoidal rule & Not stated & Not stated \\
\hline $\begin{array}{l}\text { Determination of } \\
\text { body weight }\end{array}$ & $\begin{array}{l}\text { Difference between } \\
\text { stance phase and } \\
\text { airborne phase of } \\
\text { jump's force values }\end{array}$ & Not stated & $\begin{array}{l}\text { By adjusting the value of BW } \\
\text { during the stance phase until } \\
\text { the displacement of the } C G \text { at } \\
\text { the end of the stance phase } \\
\text { equalled its value at the } \\
\text { beginning. }\end{array}$ \\
\hline $\begin{array}{l}\text { Determination of } \\
\text { initiation of jump }\end{array}$ & $\begin{array}{l}\text { Determined by } \\
\text { software - methods } \\
\text { not stated }\end{array}$ & $\begin{array}{l}\text { Determined by } \\
\text { software - } \\
\text { methods not } \\
\text { stated }\end{array}$ & $\begin{array}{l}\text { Time, after stance phase, when } \\
\text { force value exceeded the } \\
\text { preceding five force samples' } \\
\text { mean by a set multiple of } \pm \\
\text { SD's. }\end{array}$ \\
\hline $\begin{array}{l}\text { Determination of } \\
\text { instant of take-off }\end{array}$ & $\begin{array}{l}\text { Determined by } \\
\text { software - methods } \\
\text { not stated }\end{array}$ & $\begin{array}{l}\text { Determined by } \\
\text { software - } \\
\text { methods not } \\
\text { stated }\end{array}$ & Not stated \\
\hline
\end{tabular}

Further, contemporary studies using $P p$ measured in a CMJ as an outcome measure in regression studies (Canavan \& Vescovi, 2004; Harman, Rosenstein, Frykman, Rosenstein, \& Kraemer, 1991; Johnson \& Bahamonde, 1996; Sayers, Harackiewicz, Harman, Frykman, \& Rosenstein, 1999; Shetty, 2002) reported very little information with regard to the specification and methods for determining $P p$ produced in a CMJ (Table 2). 
Table 2. An example of the specifications reported in the literature for the determination of $P p$ of a $C M J$ by analysing the $V G R F$. Adapted from (Owen, 2008)

\begin{tabular}{|c|c|c|c|c|c|c|}
\hline & \multicolumn{6}{|c|}{$\begin{array}{c}\text { Author/s } \\
\text { (type of jump) }\end{array}$} \\
\hline variable & $\begin{array}{l}\text { Harman et } \\
\text { al. } 1991 \\
\text { (SJ) }\end{array}$ & $\begin{array}{c}\text { Johnson } \\
\text { and } \\
\text { Bahamond } \\
\text { e } 1996 \\
(\mathrm{CMJ}) \\
\end{array}$ & $\begin{array}{l}\text { Sayers et } \\
\text { al. } \\
1999 \\
(\mathrm{CMJ})\end{array}$ & $\begin{array}{l}\text { Shetty } \\
2002 \\
(\mathrm{CMJ})\end{array}$ & $\begin{array}{c}\text { Canavan } \\
\text { and } \\
\text { Vescovi } \\
2003 \\
(\mathrm{CMJ}) \\
\end{array}$ & $\begin{array}{c}\text { Lara et al. } \\
2006 \\
(\mathrm{CMJ})\end{array}$ \\
\hline $\begin{array}{l}\text { Method of } \\
\text { integration }\end{array}$ & $\begin{array}{c}\text { Not } \\
\text { reported }\end{array}$ & $\begin{array}{c}\text { Not } \\
\text { reported }\end{array}$ & $\begin{array}{c}\text { Not } \\
\text { reported }\end{array}$ & $\begin{array}{c}\text { Not } \\
\text { reported }\end{array}$ & $\begin{array}{c}\text { Not } \\
\text { reported }\end{array}$ & $\begin{array}{c}\text { Not } \\
\text { reported }\end{array}$ \\
\hline $\begin{array}{c}\text { Sampling } \\
\text { frequency }(\mathrm{Hz})\end{array}$ & 500 & 500 & 500 & 100 & 500 & 500 \\
\hline $\begin{array}{l}\text { Resolution of } \mathrm{A} \\
\text { to D converter }\end{array}$ & 12 bits & $\begin{array}{c}\text { Not } \\
\text { reported }\end{array}$ & $\begin{array}{c}\text { Not } \\
\text { reported }\end{array}$ & $\begin{array}{c}\text { Not } \\
\text { reported }\end{array}$ & $\begin{array}{c}\text { Not } \\
\text { reported }\end{array}$ & $\begin{array}{c}\text { Not } \\
\text { reported }\end{array}$ \\
\hline $\begin{array}{c}\text { Frequency of } \\
\text { integration }\end{array}$ & $20 \mathrm{~Hz}$ & $\begin{array}{c}\text { Not } \\
\text { reported }\end{array}$ & $\begin{array}{c}\text { Not } \\
\text { reported }\end{array}$ & $\begin{array}{c}\text { Not } \\
\text { reported }\end{array}$ & $\begin{array}{c}\text { Not } \\
\text { reported }\end{array}$ & $\begin{array}{c}\text { Not } \\
\text { reported }\end{array}$ \\
\hline $\begin{array}{c}\text { Definition of } \\
\text { time of the start } \\
\text { of jump }\end{array}$ & $\begin{array}{l}\text { Not } \\
\text { reported }\end{array}$ & $\begin{array}{c}\text { Not } \\
\text { reported }\end{array}$ & $\begin{array}{c}\text { Not } \\
\text { reported }\end{array}$ & $\begin{array}{c}\text { Not } \\
\text { reported }\end{array}$ & $\begin{array}{c}\text { Not } \\
\text { reported }\end{array}$ & $\begin{array}{c}\text { Not } \\
\text { reported }\end{array}$ \\
\hline $\begin{array}{c}\text { Jump with arms } \\
\text { immobilised }\end{array}$ & No & No & $\begin{array}{c}\text { Not } \\
\text { reported }\end{array}$ & No & Yes & Yes \\
\hline Force range & $\begin{array}{c}\text { Not } \\
\text { reported }\end{array}$ & $\begin{array}{c}\text { Not } \\
\text { reported }\end{array}$ & $\begin{array}{c}\text { Not } \\
\text { reported }\end{array}$ & $\begin{array}{c}\text { Not } \\
\text { reported }\end{array}$ & $\begin{array}{c}\text { Not } \\
\text { reported }\end{array}$ & $\begin{array}{c}\text { Not } \\
\text { reported }\end{array}$ \\
\hline
\end{tabular}

$\mathrm{CMJ}=$ countermovement jump, $\mathrm{SJ}=$ squat jump

Critically, as shown in Table 2, none reported how the determination of the jump start time $\left(t_{s}\right)$ was identified which is essential for reliable determination of $P p$ (Owen, 2008). Incorrect identification of $t_{s}$ can cause a velocity drift, due to incorrect impulse calculations, which will increase throughout the jump. Therefore, the studies should be interpreted with caution.

In contrast to these earlier studies, Paper 1, reports a definition for $t_{s}$, although it did not report force range of the FP or resolution of the A to D converter. Although the omissions may affect the validity of the $P p$, the reliability would not be affected. Therefore, within study comparisons remain valid. However, caution should be exercised when comparing paper 1 study values of absolute force against those of other studies. It should also be noted that $P A P$ is reported to increase $P p$ by $\sim 4 \%$, consequently it is important to establish the absolute error in the determination of $P p$ in a $C M J$ off a FP in order to make valid conclusions about study outcomes involving the measurement of $P p$. Future research should investigate a robust specification for the determination of $P p$ in a CMJ performed off a FP. 
Paper 1 citations. Since publication (2011) this paper has been cited by 68 times. Average $=9.7$ citations per year (source Google Scholar accessed 26/9/2018) 


\subsubsection{Paper 2. Relationship between force-time characteristics of the isometric midthigh pull and dynamic performance in professional rugby league players}

Paper 2 investigated the relationships between force/time neuromuscular variables derived from performance in an isometric mid-thigh pull (IMTP) and dynamic performance in jumping and sprinting. An IMTP consists an athlete pulling vertically upwards on a horizontal, fixed bar, at mid-thigh height, attached to a power rack (or equivalent), whilst standing on a FP, (Figure 9). After the command to pull is given, the athlete pulls as 'hard and as fast' as they can and the resulting force/time history is collected (Haff, Ruben, Lider, Twine, \& Cormie, 2015; Stone et al., 2004).

Neuromuscular variables are determined from analysis of the force/time history. Peak strength (Fp) is defined as the highest value of force produced during a period of $5 \mathrm{~s}$ and, as such, is straightforward to determine (Haff et al., 2005; McGuigan, Winchester, \& Erickson, 2006). Other variables are dependent on the identification of a start time i.e. an instant that is the start of the athlete pulling. For example, force at $100 \mathrm{~ms}$ (F100) after the pull started i.e. pull initiation time (Tp), force at $250 \mathrm{~ms}$ (F250) after

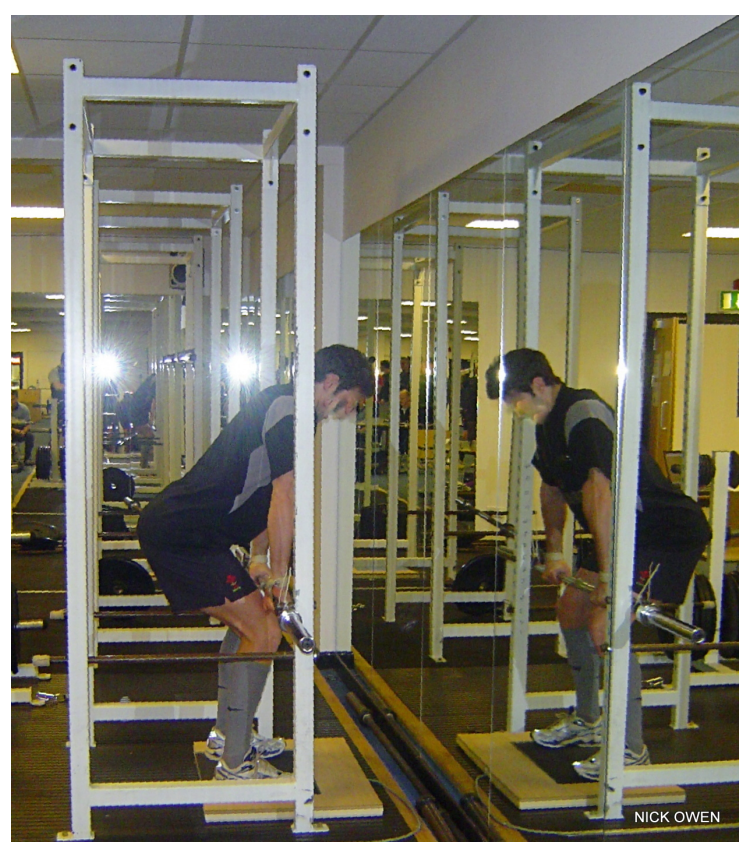

Figure 9. Example of an isometric mid-thigh pull set-up showing the athlete standing on a force platform and pulling on a bar, fixed to a power rack.

Tp and time to Fp (Aagaard, Simonsen, Andersen, Magnusson, \& Dyhre-Poulsen, 2002; Brady, Harrison, \& Comyns, 2018; Dos'Santos, Jones, Comfort, \& Thomas, 2017). Figure 10, illustrates a typical force/time history of an IMTP and defines key 


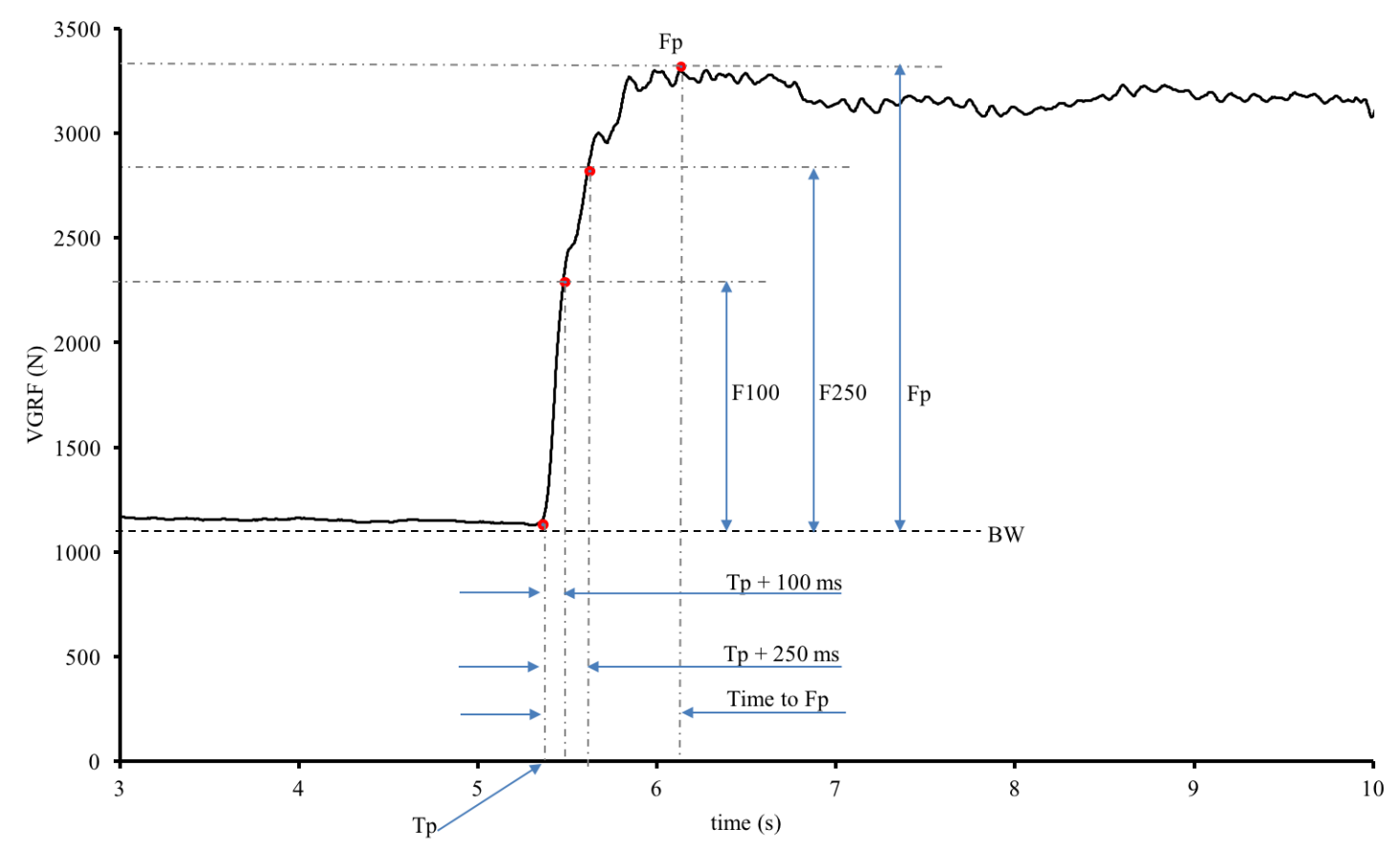

Figure 10. An example of a force/time history derived from an athlete performing an IMTP on a force platform. $\mathrm{BW}=$ body weight, $\mathrm{Fp}=$ maximum value of force during the pull (expressed as force above $\mathrm{BW}$ ), $\mathrm{Tp}=$ pull initiation time, $\mathrm{F} 100=$ force $100 \mathrm{~ms}$ after Tp (above BW), F250 = force at $250 \mathrm{~ms}$ after Tp (above BW)

variables. However, when an IMTP is performed, due to the position the athlete assumes, there is in some athletes, a tendency to push and/or pull on the bar prior to commencement of the pull. As the athlete is standing on a FP, there is a corresponding variation of the force/time history of the period just prior to the pull being executed, in the region prior to $\mathrm{Tp}$. It is difficult, without affecting the ecological validity of the test, to avoid this situation. Consequently, it is normal to collect data for an IMTP where the period prior to initiation of the pull, from which statistics used to define Tp are derived, vary considerably in terms of force stability (Figure 11A). It is therefore difficult to define thresholds, based on a mean and standard deviations of force values, in a similar manner to that described in paper 1. Papers contemporary to Paper 2, whilst reporting variables which necessitated determining $\mathrm{Tp}$, did not report the 


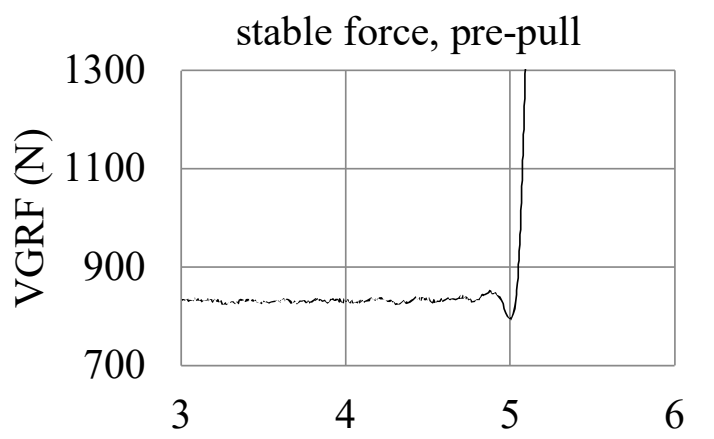

A

unstable force, pre-pull

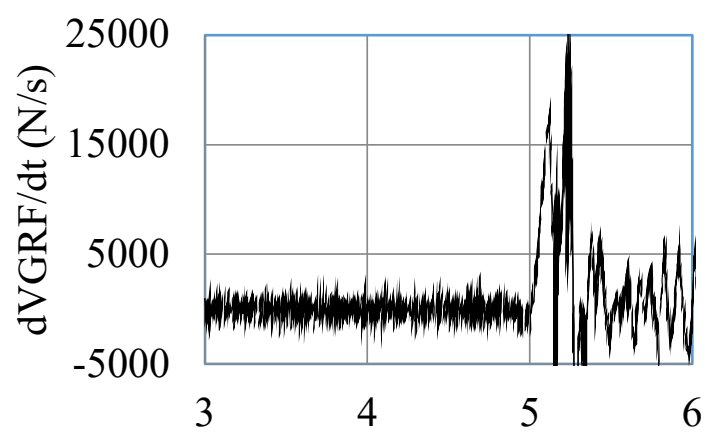

$\mathrm{B}$
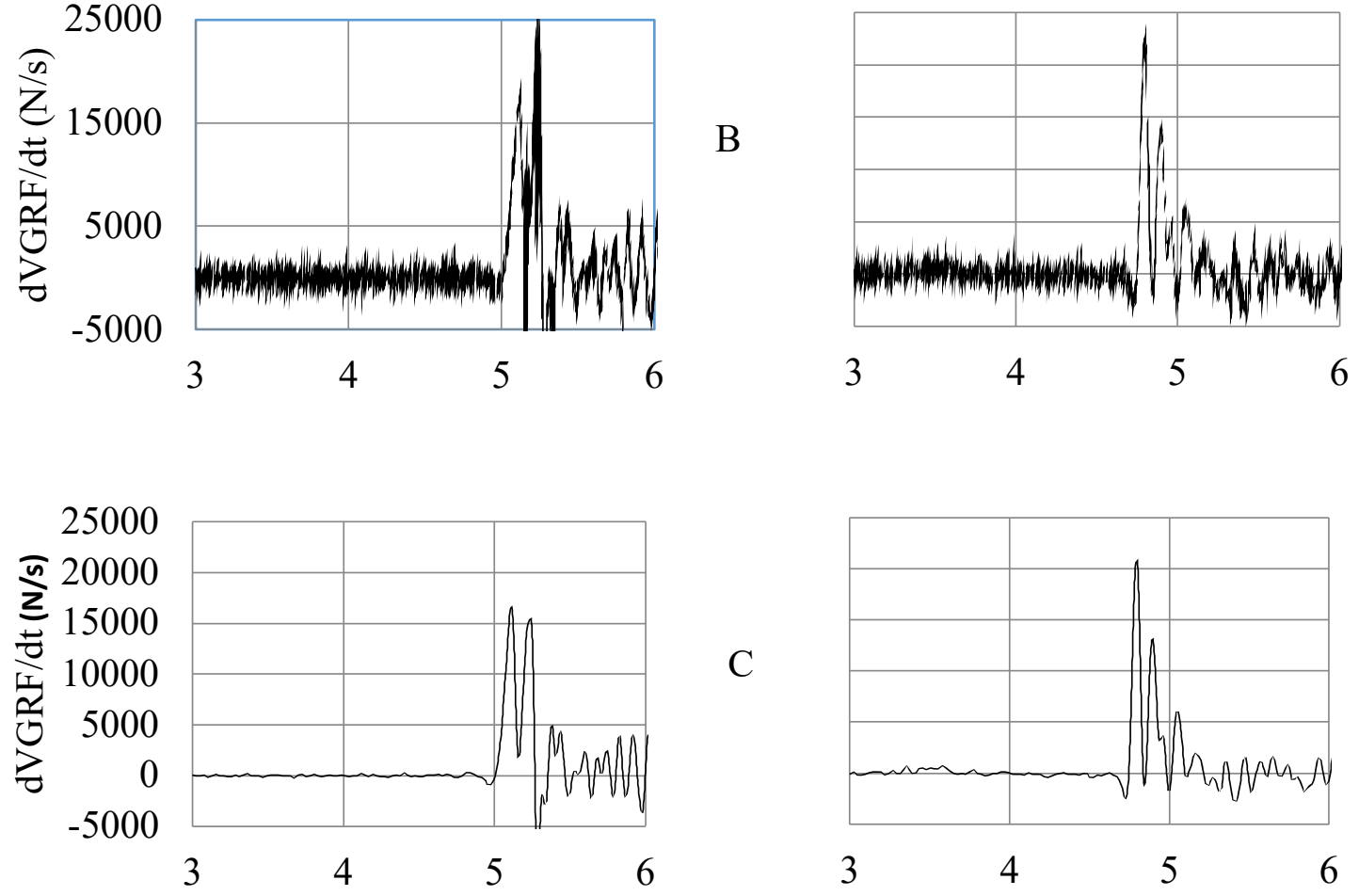

time (s)

Figure 11. Two typical force/time histories of IMTP, showing the period prior to initiation of the pull and the start of the pull. 10A, illustrates examples of a stable period and an unstable period, prior to the initiation of the pull. 10B shows the corresponding $1^{\text {st }}$ derivative of $10 \mathrm{~A}$ determined from raw data. $10 \mathrm{C}$ shows the corresponding $1^{\text {st }}$ derivative of $10 \mathrm{~A}$ but determined from data filtered with a dual pass Butterworth low pass filter cut-off frequency $20 \mathrm{~Hz}$.

methods used to determine a value for Tp (Beckham et al., 2013; Haff et al., 2015, 1997; Stone et al., 2004) or reported determination by subjective measures or arbitrary values e.g. $40 \mathrm{~N}$ change in force. Biases of between $20 \mathrm{~ms}$ to $330 \mathrm{~ms}$ in Tp have been 
reported as a result (Dos'Santos et al., 2017). Clearly, this is unacceptable as even at the lower end of the biases, a $20 \mathrm{~ms}$ error in identifying Tp would cause a 20\% (time) error in the determination of F100. Given that the gradient of the force/time history is at its steepest at this time, such an error would render the data unusable. Paper 2 sought to develop an objective method of determining Tp which was robust in terms discriminating between variation of pre-pull force/time history and the start of the pull.

It was reasoned that the purpose of an IMTP was to increase force (i.e. a change in force) when the pull was initiated. Also, as force is being continuously, there might also be a change in force during the period prior to $\mathrm{Tp}$, it was reasonable to assume though, that the magnitude of the change of force after Tp would be considerably larger than before Tp. It followed that, using the $1^{\text {st }}$ derivative of the force/time history might provide a stable metric from which to set thresholds to determine Tp. All real world signals have some degree of noise associated with them, including force/time histories derived a PF. The noise is evident in (Figure 11A) on both traces. It is well understood that the process of differentiation amplifies noise (Chartrand, 2011), consequently the $1^{\text {st }}$ derivative of the raw force/time history an IMTP was unusable (Figure 11B) as the noise resulting from the process of differentiation swamped the signal. Therefore, the signal was low pass filtered using a Butterworth filter with a cut-off frequency of 20 Hz. The cut-off frequency was determined by inspection of the fast Fourier transform of the raw force/time history and also inspection of the filtered signal. It was clear that the $1^{\text {st }}$ derivative of the filtered signal (Figure 11C) shows little sensitivity to the large (but slow) force changes seen in the unstable force (Figure 11A). Both $1^{\text {st }}$ derivatives of the filtered data look very similar to each other, even though their parent data (Figure 11A) is very different. As such, setting thresholds based on the mean and standard deviation of the $1^{\text {st }}$ derivative of the filtered raw signal, prior to the pull, was successful in identifying a consistent value for Ts. The method showed no sensitivity to large force variation, prior to the initiation of the pull, which were common with this type of test. Although this method has been applied successfully to thousands of athletes, and, as such, can be considered to be valid form an applied perspective, it is challenging to validate it to an output variable, as was the case in paper 1. Nevertheless, given the robust nature of the method reported in paper 2, it is recommended that all future research use this method for the identification of Tp. Also, future research should investigate confirming the theoretical validity of the reported method. 
Paper 2 citations. Since publication (2011) this paper has been cited by 93 times. Average $=13.2$ citations per year (source Google Scholar accessed 26/9/2018) 


\subsubsection{Paper 3. Development of a criterion method to determine peak mechanical power output in a countermovement jump}

Paper 3 can be considered a progression, in terms of methodology, from paper 1. Paper 3 reported the development of a criterion method to determine peak mechanical power $(P p)$ output, of the whole body centre of gravity (WGoG), in a countermovement jump (CMJ). Paper 1 specified some variables to measure reliable $P p$ in a CMJ, Paper 3 specifies all the variables necessary to measure to measure valid and reliable $P p$ in a CMJ performed off a FP

Movement is initiated by the conversion of potential chemical energy, stored in the muscles, into mechanical energy in the form of mechanical work. Work (W) is done when one or more body segments are moved a distance $(\mathrm{d})$ by muscle forces $(\mathrm{F})$ and can be represented algebraically (equation 1). In a vertical CMJ, work is done, by the muscle tendon units of the lower limbs, against gravity, on the athlete's WCoG.

$$
\mathrm{W}=\mathrm{F} . \mathrm{d}
$$

The rate of doing work is referred to as mechanical power (P) (equation 2).

$$
\begin{aligned}
& \mathrm{P}=\mathrm{F} . \mathrm{d} / \mathrm{t}=\mathrm{F} . \mathrm{v} \\
& \text { where } \mathrm{v}=\text { velocity, } \mathrm{t}=\text { time }
\end{aligned}
$$

The first reported use of equation 2, to measure mechanical $\mathrm{P}$ in vertical jumping was by Davies and Rennie (1968). They used a FP to investigate power in jumping. Their FP output an analogue voltage, that was proportional VGRF of a subject jumping, and it was recorded on an electromechanical data logging device with an effective sample frequency of $50 \mathrm{~Hz}$ (Davies \& Rennie, 1968). Instantaneous mechanical power was then determined by first calculating the vertical acceleration of the subject's WCoG (N2) and then integrating it, with respect to time, to obtain instantaneous velocity. Instantaneous $\mathrm{P}$ was then calculated by determining the product of VGRF and vertical velocity (equation 2). 
The method used by Davies and Rennie (1968) has become the accepted method to determine $P p$ form a VGRF/time history collected from a FP. Modern FPs collect discrete data and thus numerical methods of integration are used to determine velocity from the time-sampled force/time history (equation 3 ).

$$
v_{t}=v_{t-1}+\int_{t-1}^{t} \frac{F-g}{m} d t
$$

where $v_{t}=$ vertical velocity of the WCoG at time $t, v_{t-1}=$ velocity one sample before time, $t, \mathrm{~F}=\mathrm{VGRF}, g=$ acceleration due to gravity, $m=$ mass of the subject.

It is important to know the absolute velocity at the start of a CMJ as numerical integration of the force/time history is only able to determine the change in velocity. As CMJs start with a quiet standing phase (also called weighing period) i.e. where the athlete stands still on the FP, the velocity of the athlete's WCoG, at this point, is zero. Consequently, changes to the velocity of the $\mathrm{WCoG}$ can be added to zero to determine the absolute velocity.

A typical example of a force/time history of a CMJ and the corresponding velocity and power/time histories can be seen in Figure 12.

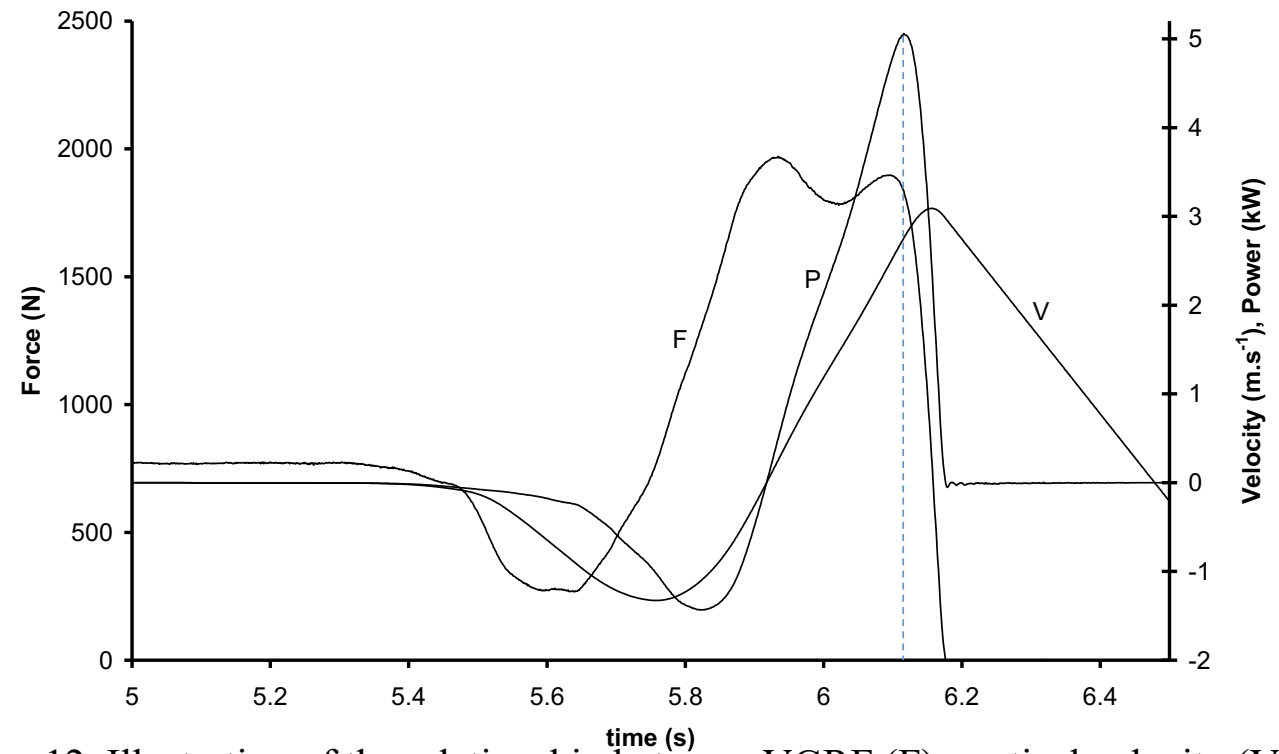

Figure 12. Illustration of the relationship between VGRF (F), vertical velocity (V) and mechanical power $(\mathrm{P})$ for a subject performing a CMJ. The dotted line indicates $P p$ and its relationship with $\mathrm{V}$ and $\mathrm{F}$.

The ability to produce high levels of $P p$ is generally considered to be a key determinant in athletic performance (Bevan et al., 2010; Cronin \& Hansen, 2005; R. U. Newton \& 
Dugan, 2002; Sleivert \& Taingahue, 2004), therefore it is important to use a valid criterion method to minimise errors and consequent uncertainty, such that maximum benefit to athletes is achieved. The above method is one such approach

Table 1, highlighted the 6 variables that need to be controlled in order to determine a valid and reliable measure of $P p$ in jumping. Paper 1 reported a reliable method to determine $P p$ in jumping by specifying $\mathrm{t}_{\mathrm{s}}$ and reporting the sample frequency, integration frequency and BW measurement used in the method. It did not, however, justify the selection of these specification nor did it consider force range. Thus, the need for Paper 3.

Previous research reported that the vertical force range of a FP should be 3 to 3.5 times BW (Kibele, 1998). Although this is true for the net VGRF, in practice a FP determines the arithmetic sum of each of four transducers (one in each corner). An athlete performing a CMJ will transfer their weight, within their base support, from a posterior position, anteriorly towards the distal metatarsals (ball of the foot). Consequently, the front two force transducers will experience proportionately higher force values than the back. Thus, requiring the gross force range to be higher at 5.6 times BW. This is an important finding of Paper 3 as exceeding the force range on two force transducers would not be obvious from the force/time history as the sum of all four transducers is normally displayed on FP systems. This summed value would mask the forces values that exceed the range and allow potentially significant errors to go undetected. Clearly, if athlete programmes where developed using such potential flawed data, there would be a consequent uncertainty in the training prescription and potential efficacy of such training.

Another important finding of Paper 3 was the necessity to deem a jump to had been initiated $\left(t_{s}\right)$ if, after the weighing period, the VGRF increased or decreased beyond threshold value. Figure 13, illustrates the need for the specification. In a sample of 15 elite rugby players, 7 players initiated a CMJ by dropping their WGoG (VGRF decreasing beyond the threshold) and 8 players initiated a CMJ by elevating their WCoG (VGRF increasing beyond the threshold). 


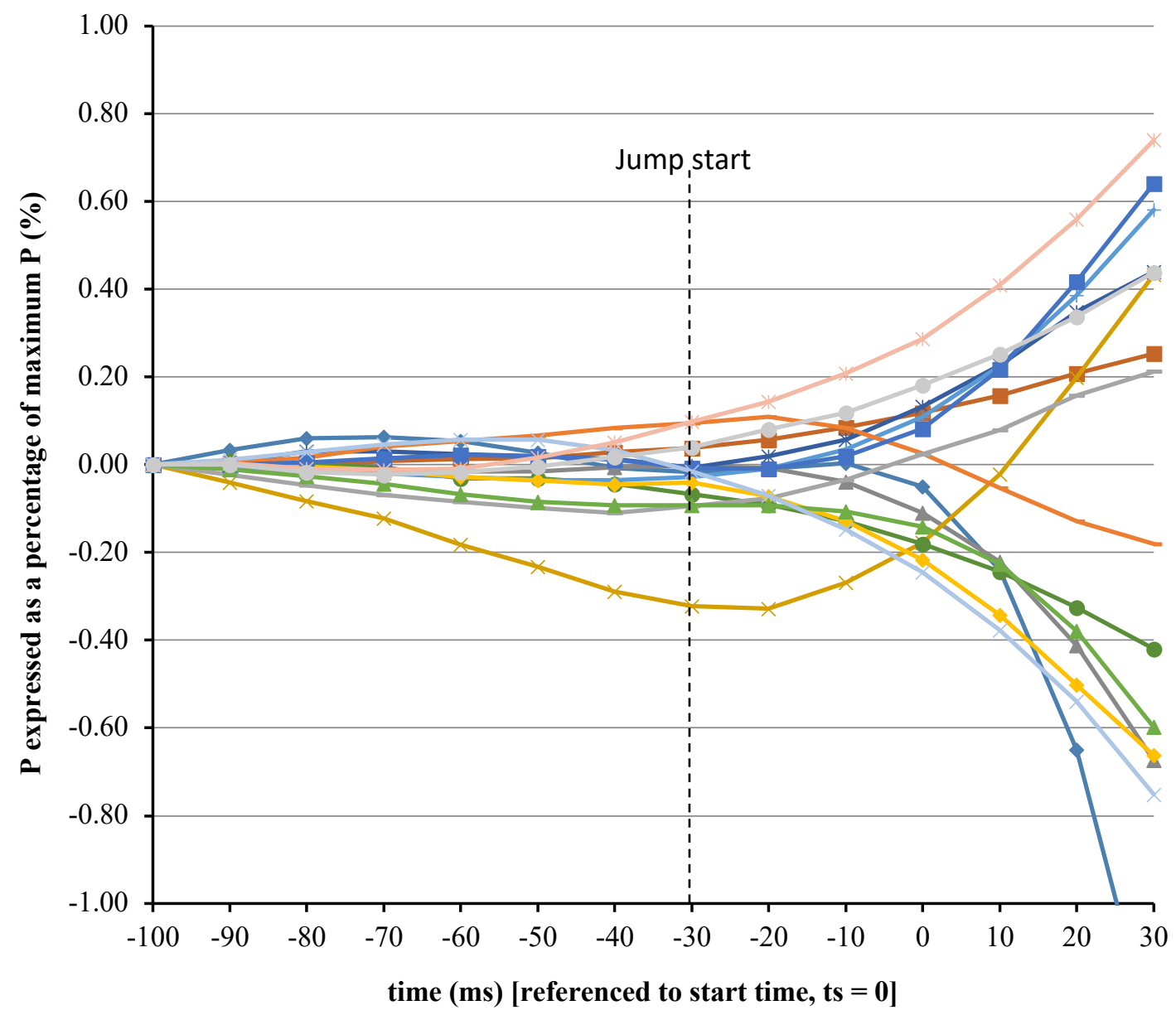

Figure 13. Power/time histories for 15 elite rugby players at the start of a CMJ. Positive power indicates an elevation of the $\mathrm{WCoG}$ and negative power indicates a lowering of the WCoG.

Many studies reporting $P p$ in a CMJ use methodologies that deem a jump to have been initiated only if the VGRF reduces after the weighing period, i.e. a lowering of the WCoG (Eagles, Sayers, Bousson, \& Lovell, 2015; J. J. McMahon, Murphy, Rej, \& Comfort, 2016; J. McMahon et al., 2017). Unpublished results from the work undertaken for Paper 3 (due to journal space restrictions) determined that methodologies using this approach to identifying the jump start (and more importantly the point from which to start the integration of the force/time history) can produce errors of around $1 \%$ in the value of $P p$, a significant error in term of overall accuracy of the method. 
Other systems measure mechanical energy in humans, for example motion capture systems using the principles of inverse dynamics. However, due to average values used for BSP and errors propagated through multiple calculations, the kinetic outputs of such systems is prone to significant error (Hatze, 2002; Rao, Amarantini, Berton, \& Favier, 2006). The use of a FP and the methodology reported in Paper 3 can be currently be considered as the most valid and reliable method of determining mechanical power output of a human being.

The ability to accurately measure human power output offers unique opportunities to investigate human performance as it is a measure of a person's ability to convert potential chemical energy (stored in the muscles) into kinetic energy used for locomotion, in the form of mechanical work. Measuring $P p$ in a CMJ has potential applications in sports and clinical setting, many of which have yet to be explored. Paper 3 is currently the only published criterion method to measure $P p$ in a CMJ.

Paper 3 citations. Since publication (2014) this paper has been cited by 60 times. Average $=15$ citations per year $($ source Google Scholar accessed 26/9/2018) 


\subsubsection{Paper 4. Normative data for lower limb peak mechanical power in children aged 7 to 11 years old}

Paper 4, used the published criterion method for measuring $P p$ in a CMJ from Paper 3, to evaluate normative lower limb $P p$ data for children aged 7 to 11 years old (school years 3 to 6). Even though the paper was a brief communication, it represented a significant collaboration with a local education authority, in terms of gaining access to large populations of school children in a relatively short period of time. The output of this study resulted in new data being published that will form the basis of a new generation of tests for coordination deficits and bone health.

The vertical jump, as an assessment of athletic ability, was first proposed in 1921 (Sargent, 1921) and has been used extensively ever since. However, the methods of assessing the outcome measure (jump height, in the case of Sargent) have changed significantly. It is not uncommon for jump height, as measured and defined in a various different ways, to be reported as power (Patterson \& Peterson, 2004) or estimates of power, derived from jump height, to be reported as power (Baptista, MilHomens, Carita, Janz, \& Sardinha, 2016b; Janz, Letuchy, Burns, Francis, \& Levy, 2015). However, such reports are misleading and incorrect. Mechanical power has an agreed scientific definition within the SI system (rate of change of energy or Watts $\left[\mathrm{kg} \cdot \mathrm{m}^{2} \cdot \mathrm{s}^{-3}\right]$ ) and although jump height, in a vertical jump, and estimates of power derived from regression equations, clearly correlate with power they are not measures of power (Knudson, 2009; Winter et al., 2016). If valid conclusions are to be drawn from the studies measuring power it is important that the measurements are valid (mechanical power is being measured, rate of change of energy or rate of doing mechanical work) and reliable (in terms of the participants' ability to repeatedly produce the same measures to a required agreement level). However, it is common for power to be incorrectly measured and/or methodology to be lacking in detail to the extent that results might be compromised.

There are several studies in the literature reporting normative "power" values for children. For instance, a study of, $n=1845$, English school children aged 10 to 15.9 years old (Taylor, Cohen, Voss, \& Sandercock, 2010) reported normative values of leg power. However, the methods used did not measure power but estimated it with a 
regression equation that used body mass and jump height as predictors of power. Estimates of leg power, based on regression equations, are generally recognised as being an invalid method of assessing power in an individual due to large errors (Tessier, Basset, Simoneau, \& Teasdale, 2013). Further, the study used a regression equation, the Sayers' equation, developed for 18 to 21 year olds (Sayers et al., 1999) and, as such, is invalid for use with children. Given such methodological limitations, the results of the study and further studies that have replicated this methodology (e.g. Ramírez-Vélez et al., 2017) need to be interpreted with caution.

In 2006 a study entitled "Mechanography - A New Device for the Assessment of Muscle Function in Pediatrics" was published (Fricke, Weidler, Tutlewski, \& Schoenau, 2006). In it the authors describe a so called "new device" for measuring kinetic variables, including lower limb $P p$, and also report normative values for, $\mathrm{n}=$ 517 , school boys and girls, aged 6 to 21 years old. The device they describe was in fact a FP and the methods used, which were briefly described, are those first reported by Davies and Rennie (1968). There was only one reference (Cavagna, 1975) to the very large body of work on that has accumulated since 1968 on the measurement of lower body $P p$ using a FP within the sports science literature. Surprisingly, there were no references to key papers on the subject of measurement of mechanical power in jumping by analysis of the corresponding force/time history, as measured by a FP (C. T. M. Davies \& Rennie, 1968; Hatze, 1998; Kibele, 1998; Street et al., 2001).

Expanding on the 2006 paper, Mechanography was used by Veileux and Rauch (2010) to report the reproducibility (reliability) of kinetic variables in children as well as adults (Veilleux \& Rauch, 2010) and a further three studies reported normative values for lower limb Pp in children (Busche, Rawer, Rakhimi, Lang, \& Martin, 2013; Gabel, Macdonald, Nettlefold, Race, \& McKay, 2016; Sumnik et al., 2013). Unfortunately, none of the studies using Mechanography reported all the specifications needed to measure valid and reliable lower body $P p$ as reported in the criterion method (Owen et al., 2014). A summary of the specifications reported by these studies, in terms of lower body $P p$ measurement, can be found in Table 3. The studies had large overall sample sizes, $\mathrm{n}=868$, age range 3 to 19 years old (Busche et al., 2013), $\mathrm{n}=769$, age range 6 to 19 years old (Sumnik et al., 2013) and $n=715$, age range 7 to 21 years old (Gabel et al., 2016). However the wide age ranges meant that for some ages there were small 
sample sizes (e.g. only 9 males aged 5 year old and 14 females aged 19 years old).

Although the Mechanography studies are well designed and have large sample sizes, the lack of methodological detail limits the extent to which researchers can be confident in the results.

Table 3. Specifications, for the measurement of lower limb $P p$ in children, reported for studies using “Mechanography” adapted from Jones (2018)

\begin{tabular}{|c|c|c|c|c|c|c|}
\hline Author & $\begin{array}{c}\text { Sample } \\
\text { Frequency } \\
\text { (Hz) }\end{array}$ & $\begin{array}{c}\text { Force } \\
\text { Range } \\
\text { (N) }\end{array}$ & $\begin{array}{c}\text { Jump start } \\
\text { Initiation } \\
\text { identification }\end{array}$ & $\begin{array}{c}\text { A/D } \\
\text { Resolution }\end{array}$ & $\begin{array}{c}\text { Determination } \\
\text { of BW }\end{array}$ & $\begin{array}{c}\text { Methods of } \\
\text { Integration }\end{array}$ \\
\hline $\begin{array}{c}\text { Fricke } \\
\text { et al } \\
2005\end{array}$ & NR & 7200 & NR & NR & NR & NR \\
\hline $\begin{array}{c}\text { Busche } \\
\text { et al } \\
2013\end{array}$ & NR & 12000 & NR & NR & NR & NR \\
\hline $\begin{array}{c}\text { Sumnik } \\
\text { et al, } \\
2013\end{array}$ & 800 & NR & NR & NR & NR & NR \\
\hline $\begin{array}{c}\text { Gabel } \\
\text { et al } \\
2016\end{array}$ & 800 & NR & NR & NR & NR & NR \\
\hline
\end{tabular}

Paper 4, appears to be the only paper to report normative values of lower body $P p$ for a paediatric population, based on a published criterion method.

The data from Paper 4, is presented in Figure 13, as a normalised probability function. It is interesting to note that, although the average $P p$ output increases with school year from $905 \mathrm{~W}$ in $\mathrm{Y} 3$ to $1367 \mathrm{~W}$ in $\mathrm{Y} 6$ and at the upper end of the distribution, $1500 \mathrm{~W}$ in $\mathrm{Y} 3$ to $2300 \mathrm{~W}$ in $\mathrm{Y} 6$, the lower end of the distribution hardly changes from $350 \mathrm{~W}$ for all school years. The implication is stark, if a child in Y3 is in the bottom $5^{\text {th }}$ 
percentile, in terms of lower limb $P p$, they cannot be expected to improve, to any appreciable extent, in the next 4 years and possibly beyond. It is important to be able to measure $P p$ accurately in order to identify, and help, children at the lower end of the distribution.

The measurement of lower limb $P p$ in children has potential to aid in the identification and diagnosis of several diseases (Fricke et al., 2006) and conditions e.g. developmental coordination disorder. However, without an agreed method and standard of reporting neuromuscular variables, collaboration between groups, and consequent benefits, will be compromised.

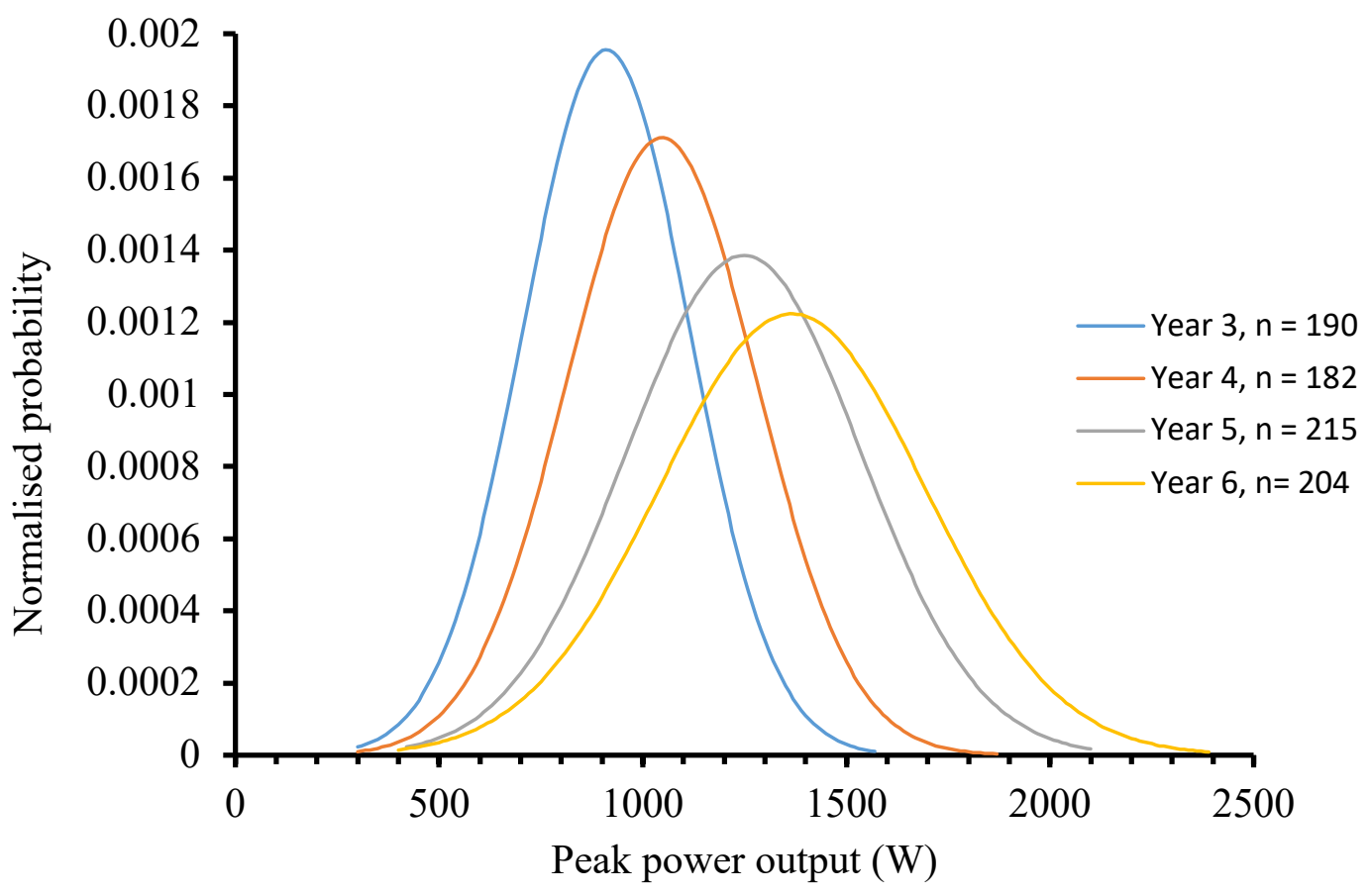

Figure 14. Distribution of $P p$ output in children in school years 3 to 6.

Given the need for an appropriate method for measuring $P p$ in children to facilitate such support, the aim of paper 4 was to identify and apply such a method. It was reasonable to assume that a specification for measuring lower limb $P p$ in elite athletes (Owen et al., 2014) would produce valid and reliable results in children or other populations, hence the results reported can be considered valid and reliable. However, it is also reasonable to assume that a specification for measuring lower limb $P p$ children would be lower than that for elite athletes. Consequently, future research 
should investigate the need for population specific specifications for lower limb $P p$. If valid and reliable results are achievable with a lower specification for a paediatric population, the cost of manufacturing of measurement equipment could decrease and hence the equipment's availability. 


\subsubsection{Paper 5. A computational method of obtaining reliable measurement of periosteal cross-sectional area of human radii from laser scans}

Henry VIII's warship Mary Rose was built in 1409 and was in service as a flagship when she sank on July $19^{\text {th }}, 1545$ whilst engaging a French invasion fleet in the Battle of the Solent (Rule, M \& Charles (principe di Galles), 1982; Stirland, 2000). Five hundred men were on board when she sank (Hildred A, 2018). After sinking and due to prevailing currents in the Solent, a large section of the ship became buried under silt creating anaerobic conditions (Stirland, 1993). As a result bones were particularly well preserved, from which 97 fairly complete skeletons (FCS), 170 skull and many other bones are curated by the Mary Rose Trust (MRT) in Portsmouth (Hildred A, 2018).

It has been assumed that there were archers on board, due to the large amount of archery equipment listed on the ship's inventory (250 longbows and 9600 arrows) and also recovered from the wreck. If indeed there were archers on board, it would provide a unique opportunity to study impact of a lifetime of archery on bone development. Bones respond to loading both from external sources and from internal muscle forces by remodelling such that they are better adapted to cope with the loads they experience (Frost, 1994, 2004; Hart et al., 2017; Wolff, 1870). Work by Stirland (1993) had proposed variation in humeral heads as a marker of using a medieval longbow and a possible way of identifying the skeletal remains of archer. However, a study in 2014 determined that, due to differential loading, the radii bones were more likely to exhibit bi-lateral variation (Annan, 2014). The human remains from the Mary Rose present a unique opportunity to study the effects of occupational activity. Specifically, identifying archers from quantifying bilateral variation of paired radii.

In order to accurately measure the morphology of ancient bones it is necessary to use appropriate instruments, both in terms of validity and reliability while also being minimally invasive. There are several techniques that could be termed appropriate for this task, for example, $\mu \mathrm{CT}$ or peripheral qualitative computed tomography (pQCT) (Chirchir et al., 2015; Feldkamp et al., 1989; Sievänen et al., 1998), laser scanning ( Davies, Shaw, \& Stock, 2012; Kuzminsky \& Gardiner, 2012) or MRI (Singh et al., 2018). All of these scanning technologies have strengths and weakness in terms of 
specific applications, for example, surface morphology measurements. For an initial investigation into bilateral variation in paired radii, it was appropriate to start by investigate external features. Although both $\mu \mathrm{CT}$ and MRI would be able to provide high resolution data on surface morphology, a laser scanner was chosen as the preferred instrument. The choice was made based on its relative simplicity of operation, high spatial resolution and comparatively small file sizes, which would facilitate computational speed without compromising accuracy.

Although most scanning technologies are capable of producing acceptable levels of resolution, there exists a common problem of validity and reliability, in terms of measuring the cross-sectional area (XSA) of long bones, due to their irregularities. When a cross sectional area is determined from a scan, the bone needs to be aligned to a reference surface (real or virtual), but due to the bone's morphological irregularity, this can introduce misalignments and the consequent errors (Louis, Soykens, Willnecker, Van den Winkel, \& Osteaux, 1996; Sievänen et al., 1998).

Paper 5 details a computational method that overcomes these problems) by systematically measuring multiple XSAs at varying orientations and choosing the minimum value as being valid and reliable. The principle is the same as determining the true CSA of a cylinder (i.e. orthogonal to the cylinder). Consider, if an infinite number of CSAs, at varying of angles, of a cylinder were taken and the angles were not known. The true CSA could be determined by selecting the one CSA with the minimum value, which would also be a perfect circle, as opposed to an ellipse. Figure 14 is a graphical representation of all the XSAs, for a single bone, measured in order to produce one, final value (lowest). 


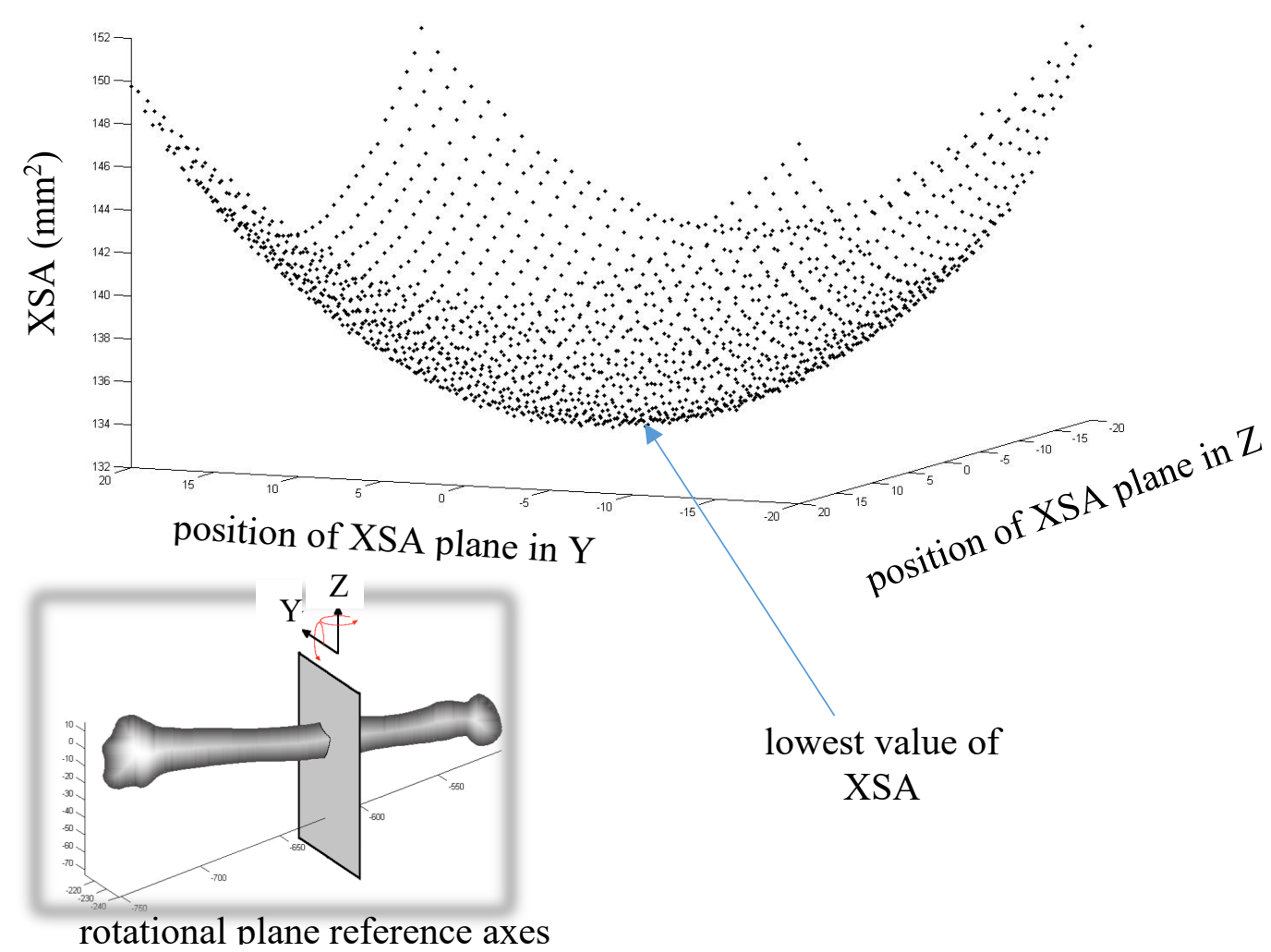

Figure 15. Cross sectional area bowl. Each dot represents one measure of XSA, the lowest value of XSA is chosen as the correct value.

The results reported in Paper 5 were a sub-set $(n=10)$ of the 20 pairs of radii bones $(\mathrm{n}=40)$ in the MRT collection. Since publication, further analysis has been carried out on all 40 bones. The process of studying the bones was extensive. First, they were scanned and then the bony land marks were identified by rater 1, and the program for CSA measurement was run to determine the lowest value of CSA for that bone. The process was repeated for all bones. The laser scan files were then randomised and the same process was repeated by rater 1 . The laser scan files were randomised again and then a second rater repeated the process. Intra and inter-rater comparisons were carried out using limits of agreement (Martin Bland \& Altman, 1986). The results are presented in Figure 15. 

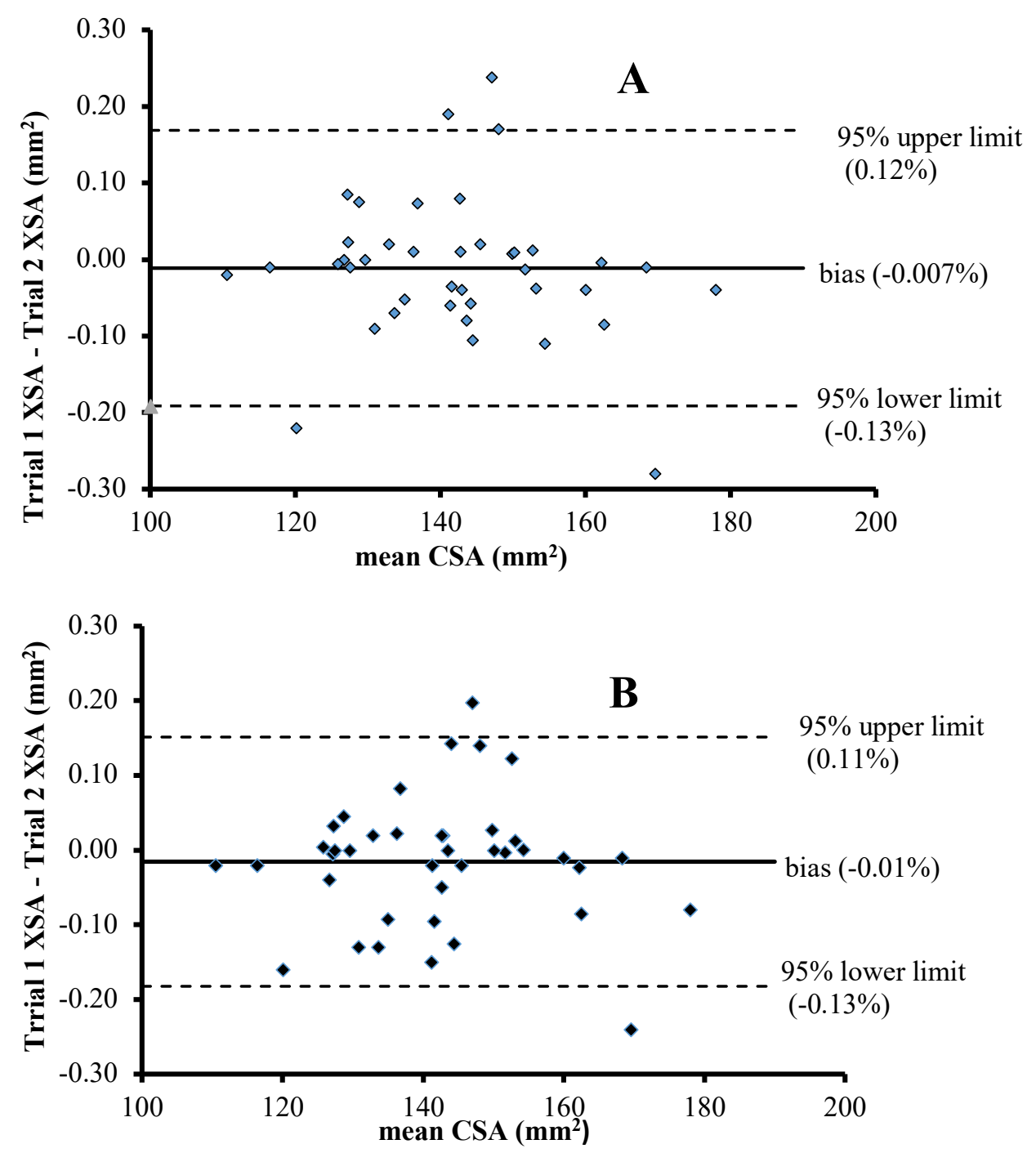

Figure 16. Limit of agreement plots for intra-rater reliability A, and inter-rater reliability $\mathrm{B}$, of CSA of 40 radii.

Through an extensive process of scanning and and computational and error analysis, Paper 5 reports a valid and reliable method of measuring periosteal CSA of radii, with $95 \%$ limits of agreement (LOA) less than $0.2 \%$. The methods used in the study can be easily adapted for use with other long bones. Bilateral differences in long bone CSA. due to occupational activity, have been reported to be an order of magnitude larger than 
LOA of Paper 5's method. Bilateral CSA differences in tennis players has been reported as $14.8 \%$ (Haapasalo et al., 2000) and 7\% (Kontulainen, Sievänen, Kannus, Pasanen, \& Vuori, 2003), therefore the LOA associated with Paper 5's methods could be confidently used to differentiate differences in bones due to occupational activity. The measurement of bone morphology (as well as mineral density) is becoming an important area of research, in terms of bone health in children (Baptista et al., 2016b; McKay, 2005; Riddell, Solis-Trapala, Prentice, \& Ward, 2015). The methodology reported here could benefit this research by providing bone CSA measurements with much lower errors than any other reported methodology. Future research should determine optimal setting for this method of measuring CSA, in terms of the minimal number of cross sections need to produce an acceptable level of LOA. Procedures should be developed for applying this method to other human long bones and scanning technologies. 


\subsection{Discussion}

"I often say that when you can measure what you are speaking about, and express it in numbers, you know something about it; but when you cannot measure it, when you cannot express it in numbers, your knowledge is of a meagre and unsatisfactory kind; it may be the beginning of knowledge, but you have scarcely, in your thoughts, advanced to the stage of science, whatever the matter may be." (Kelvin, 1891).

Lord Kelvin's quote seems most appropriate for this collection of papers. The ability to measure a physical quantity to limits of accuracy and precision that make it practical for its applied use is fundamental to scientific endeavour. If the physical quantity, force and power in papers 1 to 4 , cannot be guaranteed to be within reasonable limits it is not worth measuring them. For example, regression studies that estimate power never achieve an accuracy better than $\pm 15 \%$ for an individual. Although this level of accuracy might find use in determining group means, its use for measuring an individual is limited in the extreme. Paper 3 has been published for 4 years and has been cited over 60 times as a criterion method for measuring Pp in a CMJ and its rate of citation is increasing.

The use of the criterion method of measuring Pp to produce valid, reliable and accurate normative values for $\mathrm{Pp}$ in a paediatric population, provides the basis for many other studies. For example, it is reasonable to assume, given $\mathrm{Pp}$ in a CMJ measures a subject's ability to utilise energy, that it could be used as a measure of obesity. Power output decreases as a subject's weight increased above normal values (Dugan, Doyle, Humphries, Hasson, \& Newton, 2004). Dyspraxia is a challenging condition to diagnose, one reason being that gross motor coordination is difficult to measure. There are over 45 tests used for assessing coordination in children, however all lack evidence of validity and reliability (Brown \& Lalor, 2009). In order to produce power in a jump, intricate coordination between body segments is necessary, it is therefore feasible that measuring power jumping could be developed into a coordination test.

There is evidence emerging that $\mathrm{Pp}$ in a $\mathrm{CMJ}$ can predict poor bone health in children (Baptista et al., 2016b; Janz et al., 2015). However, the methods that currently used in 
such studies to estimate power, are flawed. There exists potential for the methodology reported in Page 3 and normative values of Pp in children, reported in Paper 4, to great improve the validity of such studies. Similarly, as studies of bone health require measurements of bone morphology, Paper 5 could also have an important role in the progression of this area of study.

Paper 5 allows very accurate quantification of bone CSA, which it turn will enable osteologists to better identify which of the skeletons in the MRT's collection were those of archers. Identifying the skeletons of archers will present a unique opportunity to study the effects of a lifetime of, very specific, physical activity had on the skeleton. Such skeletons could be examined by $\mu \mathrm{CT}$ to help understand the internal structure of the bones, in a way that would be impossible for living subjects due to the large doses of ionising radiation produced by $\mu \mathrm{CT}$ scanners.

The Papers presented in this thesis provides new, valid and reliable methods and data for use in sports science, clinical science and archaeological sciences. 
Appendix 1. Substantiation of applicant contribution to submitted papers. 
To who so ever it may concern.

I confirm that Nicholas Owen's input to:

\section{Normative data for lower limb peak mechanical power in children} aged 7 to 11 years old

N.J. Owen, W. Griffiths \& J. Watkins. Journal of Comorbidity 2015; 5: 93.

is as stated in the document "substantiation of publications for PhD Nick Owen 20-9-18"

Yours sincerely,

Wynne Griffiths B.A.

\section{Substantiation}

HB Huw Bevan

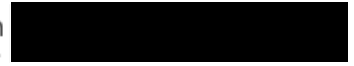

I confirm that Nicholas Owen's input to:

Development of a criterion method to determine peak mechanical power output in a countermovement jump Nick J. Owen, James Watkins, Liam P. Kilduff, Huw R. Bevan and Mark A. Bennett.

Journal of Strength and Conditioning Research. 2014. 28(6)/1552-1558 is as stated in the document "substantiation of publications for PhD Nick Owen 20-9-18"

Regards

Huw Bevan 


\section{To whom it may concern}

Date : September 28th 2018

From: James Watkins PhD

Emeritus Professor of Biomechanics

College of Engineering

Swansea University

Re: Contribution of Nicholas Owen to published research papers

I confirm that Nicholas Owen's input to:

Development of a criterion method to determine peak mechanical power output in a countermovement jump

Nick J. Owen, James Watkins, Liam P. Kilduff, Huw R. Bevan and Mark A. Bennett. Journal of Strength and Conditioning Research. 2014. 28(6)/1552-1558

and

Normative data for lower limb peak mechanical power in children aged 7 to 11 years old N.J. Owen, W. Griffiths \& J. Watkins. Journal of Comorbidity 2015; 5: 93.

is as stated in the document "substantiation of publications for PhD Nick Owen 20-9-18" $\ldots$

Mark Bennett

Fri 28/09, 13:23

Owen NJ. $\leftleftarrows$

To whom it may concern;

I confirm that Nicholas Owen's input to:

Development of a criterion method to determine peak mechanical power output in a countermovement jump Nick J. Owen, James Watkins, Liam P. Kilduff, Huw R. Bevan and Mark A. Bennett.

Journal of Strength and Conditioning Research. 2014. 28(6)/1552-1558

is as stated in the document "substantiation of publications for PhD Nick Owen 20-9-18"

Yours sincerely,

Mark Bennett 
Owen N.J. $\approx$

Hi Nick,

I confirm that Nicholas Owen's input to:

A computational method of obtaining reliable measurement of periosteal cross-sectional area of human radii from laser scans

P. Mahmoodi, S. Annan and N. Owen. Proceedings of the 23rd UK Conference of the Association for Computational Mechanics in Engineering 2015, Swansea. 73-76.

is as stated in the document "substantiation of publications for PhD Nick Owen 20-9-18"

Kind Regards,

Pooya

Dr Pooya Mahmoodi (PhD)

Project Officer

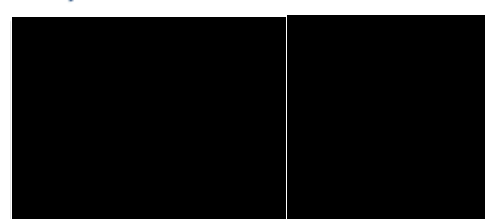

David Shearer

Fri 28/09, 10:38

Owen N.. $\approx$

To Whom It May Concern:

I confirm that the Nicholas Owen's input to:

Relationship between force-time characteristics of the isometric midthigh pull and dynamic performance in professional rugby league players

Daniel J. West, Nick J. Owen, Marc R. Jones, Richard M. Bracken, Christian J Cook, Dan J. Cunningham, David A.

Shearer, Charlotte V. Finn, Robert U. Newton and Liam P, Kilduff.

Journal of Strength and Conditioning Research. 2011. 25(11)/3070-3075

is as stated in the document "substantiation of publications for PhD Nick Owen 20-9-18"

Kindest Regards

David Shearer

Professor David Shearer

Athro mewn Seicoleg Perfformiad Elît | Professor in Elite Performance Psychology

Cyfadran Gwyddorau Bywyd ac Addysg | Faculty of Life Science and Education

Drifucanl na Cumru I I Inivareitu of Cnuth W/aloc 
Christian Cook

Fri 28/09, 10:56

Owen NJ. $\approx$

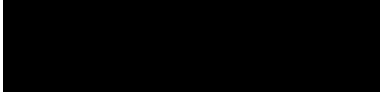

I, Christian John Cook, confirm that Nicholas Owen's input to:

Effect of postativation potentiation on swimming starts in international sprint swimmers

Liam P. Kilduff, Dan J. Cunningham, Nick J. Owen, Daniel J. West, Richard M. Bracken and Christian J. Cook. Journal of Strength and Conditioning Research. 2011. 25(9)/2418-2423

and

Relationship between force-time characteristics of the isometric midthigh pull and dynamic performance in professional rugby league players

Daniel J. West, Nick J. Owen, Marc R. Jones, Richard M. Bracken, Christian J Cook, Dan J. Cunningham, David A. Shearer, Charlotte V. Finn, Robert U. Newton and Liam P, Kilduff.

Journal of Strength and Conditioning Research. 2011. 25(11)/3070-3075

is as stated in the document "substantiation of publications for PhD Nick Owen 20-9-18"

Christian Cook

\section{Substantiation}

Charlie Fin Fri 28/09, 09:3

Owen N.J. $\approx$

I confirm that the Nicholas Owen's input to:

Relationship between force-time characteristics of the isometric midthigh pull and dynamic performance in professional rugby league players

Daniel J. West, Nick J. Owen, Marc R. Jones, Richard M. Bracken, Christian J Cook, Dan J. Cunningham, David A. Shearer, Charlotte V. Finn, Robert U. Newton and Liam P, Kilduff.

Journal of Strength and Conditioning Research. 2011. 25(11)/3070-3075

is as stated in the document "substantiation of publications for PhD Nick Owen 20-9-18"

Charlie Finn MPhil, BSc (Hons) 
(No subject)

BR Bracken R.M

- S Reply all |

Fri 28/09, 09:04

Owen N.J. $\approx$

Good Morning Nick,

In relation to your query, I can confirm that the your input to:

Effect of postativation potentiation on swimming starts in international sprint swimmers. Liam P. Kilduff, Dan J. Cunningham, Nick J. Owen, Daniel J. West, Richard M. Bracken and Christian J. Cook. Journal of Strength and Conditioning Research. 2011. 25(9)/2418-2423

and

Relationship between force-time characteristics of the isometric midthigh pull and dynamic performance in professional rugby league players. Daniel J. West, Nick J. Owen, Marc R. Jones, Richard M. Bracken, Christian J Cook, Dan J. Cunningham, David A. Shearer, Charlotte V. Finn, Robert U. Newton and Liam P, Kilduff. Journal of Strength and Conditioning Research. 2011. 25(11)/3070-3075

is as stated in the document "substantiation of publications for PhD Nick Owen 20-9-18"

I hope this helps,

Kind regards,

Richard

Dr Richard M. Bracken

Associate Professor in Exercise Physiology and Biochemistry 
$\mathrm{KL}$ Kilduff $\mathrm{L}$.

Fri 28/09, 08:21

Owen N.J. $\approx$

Dear Nick

I confirm that the Nicholas Owen's input to:

Effect of postativation potentiation on swimming starts in international sprint swimmers

Liam P. Kilduff, Dan J. Cunningham, Nick J. Owen, Daniel J. West, Richard M. Bracken and Christian J. Cook. Journal of Strength and Conditioning Research. 2011. 25(9)/2418-2423

and

Relationship between force-time characteristics of the isometric midthigh pull and dynamic performance in professional rugby league players

Daniel J. West, Nick J. Owen, Marc R. Jones, Richard M. Bracken, Christian J Cook, Dan J. Cunningham, David A. Shearer, Charlotte V. Finn, Robert U. Newton and Liam P, Kilduff.

Journal of Strength and Conditioning Research. 2011. 25(11)/3070-3075

and

Development of a criterion method to determine peak mechanical power output in a countermovement jump Nick J. Owen, James Watkins, Liam P. Kilduff, Huw R. Bevan and Mark A. Bennett. Journal of Strength and Conditioning Research. 2014. 28(6)/1552-1558

is as stated in the document "substantiation of publications for PhD Nick Owen 20-9-18"

BW

Liam

Liam Kilduff

Professor of Performance Science / Athro Gwyddor Perfformio 
Thu $27 / 09,20: 40$

Owen NJ. $:$

Hi Nick,

No problem:

I confirm that the Nicholas Owen's input to:

Effect of postativation potentiation on swimming starts in international sprint swimmers

Liam P. Kilduff, Dan J. Cunningham, Nick J. Owen, Daniel J. West, Richard M. Bracken and Christian J.

Cook

Journal of Strength and Conditioning Research. 2011. 25(9)/2418-2423

and

Relationship between force-time characteristics of the isometric midthigh pull and dynamic performance in professional rugby league players

Daniel J. West, Nick J. Owen, Marc R. Jones, Richard M. Bracken, Christian J Cook, Dan J.

Cunningham, David A. Shearer, Charlotte V. Finn, Robert U. Newton and Liam P, Kilduff,

Journal of Strength and Conditioning Research. 2011. 25(11)/3070-3075

is as stated in the document "substantiation of publications for PhD Nick Owen 20-9-18"

Cheers

Dan

Sent from my iPhone

Daniel West

Thu 27/09, 19:02

Owen N. $\approx$

To whom it may concern

I confirm that the Nicholas Owen's input to:

Effect of postativation potentiation on swimming starts in international sprint swimmers

Liam P. Kilduff, Dan J. Cunningham, Nick J. Owen, Daniel J. West, Richard M. Bracken and Christian J. Cook. Journal of Strength and Conditioning Research. 2011. 25(9)/2418-2423

and

Relationship between force-time characteristics of the isometric midthigh pull and dynamic performance in professional rugby league players

Daniel J. West, Nick J. Owen, Marc R. Jones, Richard M. Bracken, Christian J Cook, Dan J. Cunningham, David A Shearer, Charlotte V. Finn, Robert U. Newton and Liam P, Kilduff. Journal of Strength and Conditioning Research. 2011. 25(11)/3070-3075

is as stated in the document "substantiation of publications for PhD Nick Owen 20-9-18

Regards,

Daniel

Dr Daniel West

Newcastle University Research Fellow

Institute of Cellular Medicine

Newcastle University

UK 


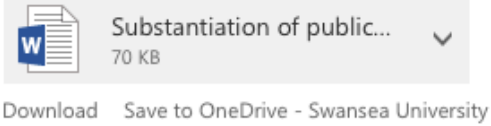

Dear Nick,

\section{RE: Substantiation of Publications for PhD}

I confirm that Nicholas Owen's input to the following publication:

A computational method of obtaining reliable measurement of periosteal cross-sectional area of human radii from laser scans

P. Mahmoodi, S. Annan and N. Owen. Proceedings of the 23rd UK Conference of the Association for Computational Mechanics in Engineering 2015, Swansea. 73-76.

is as stated in the document "Substantiation of publications for PHD Nick Owen 20-9-18".

Kind regards,

Simon Annan

Substantiation of publications for PhD Nick Owen

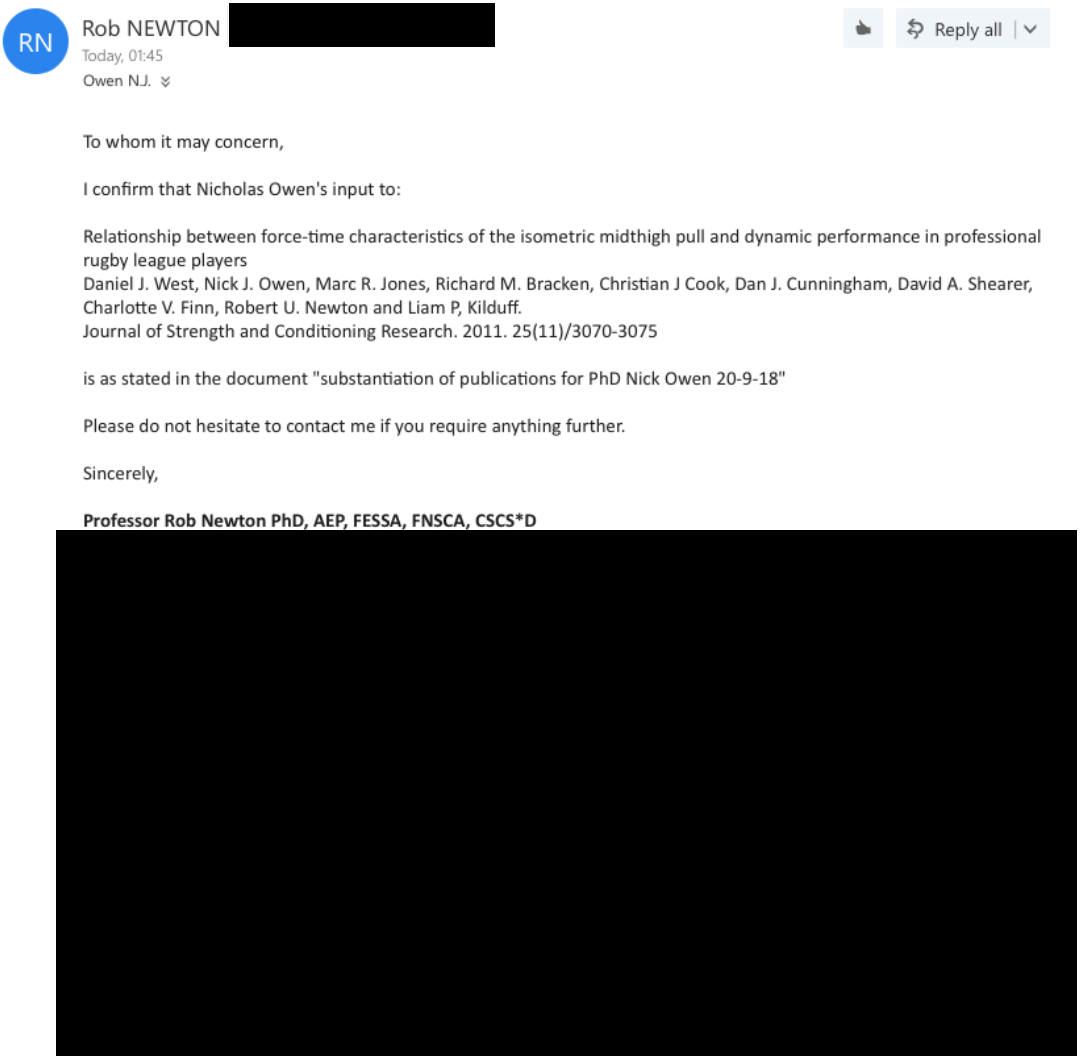


References 
Aagaard, P., Simonsen, E. B., Andersen, J. L., Magnusson, P., \& Dyhre-Poulsen, P. (2002). Increased rate of force development and neural drive of human skeletal muscle following resistance training. Journal of Applied Physiology, 93(4), 1318-1326. https://doi.org/10.1152/japplphysiol.00283.2002

Amar, J. (1916). Trottoir dynamographique. Comptes Rendus Hebdomadaires Des Séances de l'Académie Des Sciences, 163, 130-133.

Amar, Jules. (1917). Trottoir Dynamographique du prof. Amar. Larousse Médical Illustré de Guerre, 319-320.

Annan, S. (2014). Bi-lateral asymetry as a measure of occupational activity in human remains from the Mary Rose (MSc). Swansea University.

Baptista, F., Mil-Homens, P., Carita, A., Janz, K., \& Sardinha, L. (2016a). Peak Vertical Jump Power as a Marker of Bone Health in Children. International Journal of Sports Medicine, 37(08), 653-658. https://doi.org/10.1055/s-0042105290

Baptista, F., Mil-Homens, P., Carita, A., Janz, K., \& Sardinha, L. (2016b). Peak Vertical Jump Power as a Marker of Bone Health in Children. International Journal of Sports Medicine, 37(08), 653-658. https://doi.org/10.1055/s-0042105290

Bates, N. A., Ford, K. R., Myer, G. D., \& Hewett, T. E. (2013). Impact Differences in Ground Reaction Force and Center of Mass Between the First and Second Landing Phases of a Drop Vertical Jump and their Implications for Injury Risk Assessment. Journal of Biomechanics, 46(7), 1237-1241.

https://doi.org/10.1016/j.jbiomech.2013.02.024 
Beckham, G., Mizuguchi, S., Carter, C., Sato, K., Ramsey, M., Lamont, H., ... Stone, M. (2013). Relationships of isometric mid-thigh pull variables to weightlifting performance. THE JOURNAL OF SPORTS MEDICINE AND PHYSICAL FITNESS, 53(5), 10.

Bertec Corporation. (n.d.). Retrieved September 17, 2018, from https://bertec.com/products/force-plates/standard-packages/

Bevan, H. R., Bunce, P. J., Owen, N. J., Bennett, M. A., Cook, C. J., Cunningham, D. J., ... Kilduff, L. P. (2010). Optimal Loading for the Development of Peak Power Output in Professional Rugby Players: Journal of Strength and Conditioning Research, 24(1), 43-47. https://doi.org/10.1519/JSC.0b013e3181c63c64

Bradley, W. G. (2008). History of Medical Imaging. Proceedings of the American Philosophical Society, 152(3), 349-361. Retrieved from https://www.jstor.org/stable/40541591

Brady, C. J., Harrison, A. J., \& Comyns, T. M. (2018). A review of the reliability of biomechanical variables produced during the isometric mid-thigh pull and isometric squat and the reporting of normative data. Sports Biomechanics, 1-25. https://doi.org/10.1080/14763141.2018.1452968

Braune, W., \& Fischer, O. (1889). The center of gravity of the human body as related to the German infantryman. ATI, 138,452 .

Brent, J. L., \& Hewett, T. E. (2006). The Effects of Plyometric Vs. Dynamic Stabilization and Balance Training on Power, Balance, and Landing Force in Female Athletes. Journal of Strength and Conditioning Research, 20(2), 345353. 
Brown, T., \& Lalor, A. (2009). The movement assessment battery for children-second edition (MABC-2): a review and critique. Physical \& Occupational Therapy in Pediatrics, 29(1), 86-103.

Busche, P., Rawer, R., Rakhimi, N., Lang, I., \& Martin, D. D. (2013). Mechanography in childhood: references for force and power in counter movement jumps and chair rising tests. Journal of Musculoskeletal \& Neuronal Interactions, 13(2), 213-226.

Canavan, P. K., \& Vescovi, J. D. (2004). Evaluation of Power Prediction Equations: Peak Vertical Jumping Power in Women: Medicine \& Science in Sports \& Exercise, 36(9), 1589-1593. https://doi.org/10.1249/01.MSS.0000139802.96395.AC

Carlet, M. G. (1872). Essai expérimental sur la locomotion humaine. Etude de la marche. Ann Sci Nat (Zool), 16, 1-92.

Cavagna, G. A. (1975). Force platforms as ergometers. Journal of Applied Physiology, 39(1), 174-179. https://doi.org/10.1152/jappl.1975.39.1.174

Cave, A. J. E. (1950). Ancient Egypt and the origin of anatomical science. SAGE Publications.

Chartrand, R. (2011). Numerical Differentiation of Noisy, Nonsmooth Data. International Scholarly Research Notices, Applied Mathematics. https://doi.org/10.5402/2011/164564

Cheng, C.-K., Chen, H.-H., Chen, C.-S., Lee, C.-L., \& Chen, C.-Y. (2000). Segment inertial properties of Chinese adults determined from magnetic resonance imaging. Clinical Biomechanics, 15(8), 559-566. https://doi.org/10.1016/S0268-0033(00)00016-4 
Chirchir, H., Kivell, T. L., Ruff, C. B., Hublin, J.-J., Carlson, K. J., Zipfel, B., \& Richmond, B. G. (2015). Recent origin of low trabecular bone density in modern humans. Proceedings of the National Academy of Sciences, 112(2), 366-371. https://doi.org/10.1073/pnas.1411696112

Clauser, C. E., McConville, J. T., \& Young, J. W. (1969). WEIGHT, VOLUME, AND CENTER OF MASS OF SEGMENTS OF THE HUMAN BODY: Fort Belvoir, VA: Defense Technical Information Center. https://doi.org/10.21236/AD0710622

Cooper, J. M. (1983). Historical Overview of Biomechanics. In ISBS-Conference Proceedings Archive (Vol. 1).

Cronin, J. B., \& Hansen, K. T. (2005). Strength and power predictors of sports speed. $J$ Strength Cond Res, 19(2), 349-357.

Davies, C. T. M., \& Rennie, R. (1968). Human Power Output. Nature, 217(5130), 770771. https://doi.org/10.1038/217770a0

Davies, T. G., Shaw, C. N., \& Stock, J. T. (2012). A test of a new method and software for the rapid estimation of cross-sectional geometric properties of long bone diaphyses from 3D laser surface scans. Archaeological and Anthropological Sciences, 4(4), 277-290. https://doi.org/10.1007/s12520-012-0101-8

Dempster, W. T. (1955). Space requirements of the seated operator, geometrical, kinematic, and mechanical aspects of the body with special reference to the limbs. Michigan State Univ East Lansing.

Dos'Santos, T., Jones, P. A., Comfort, P., \& Thomas, C. (2017). Effect of Different Onset Thresholds on Isometric Midthigh Pull Force-Time Variables: Journal of Strength and Conditioning Research, 31(12), 3463-3473. https://doi.org/10.1519/JSC.0000000000001765 
Drillis, R., Contini, R., \& Bluestein, M. (1969). Body segment parameters. New York University, School of Engineering and Science.

Dugan, E. L., Doyle, T. L. A., Humphries, B., Hasson, C. J., \& Newton, R. U. (2004). DETERMINING THE OPTIMAL LOAD FOR JUMP SQUATS: A REVIEW OF METHODS AND CALCULATIONS. Journal of Strength and Conditioning Research, 18(3), 668-674.

Durkin, J. L., Dowling, J. J., \& Andrews, D. M. (2002). The measurement of body segment inertial parameters using dual energy X-ray absorptiometry. Journal of Biomechanics, 35(12), 1575-1580. https://doi.org/10.1016/S00219290(02)00227-0

Eagles, A. N., Sayers, M. G. L., Bousson, M., \& Lovell, D. I. (2015). Current Methodologies and Implications of Phase Identification of the Vertical Jump: A Systematic Review and Meta-analysis. Sports Medicine, 45(9), 1311-1323. https://doi.org/10.1007/s40279-015-0350-7

Elftman, H. (1939). FORCES AND ENERGY CHANGES IN THE LEG DURING WALKING. American Journal of Physiology-Legacy Content, 125(2), 339356. https://doi.org/10.1152/ajplegacy.1939.125.2.339

Elhadi, A. M., Kalb, S., Perez-Orribo, L., Little, A. S., Spetzler, R. F., \& Preul, M. C. (2012). The journey of discovering skull base anatomy in ancient Egypt and the special influence of Alexandria. Neurosurgical Focus, 33(2), E2.

Erdmann, W. S., \& Kowalczyk, R. (2015). A personalized method for estimating centre of mass location of the whole body based on differentiation of tissues of a multi-divided trunk. Journal of Biomechanics, 48(1), 65-72. https://doi.org/10.1016/j.jbiomech.2014.11.001 
Errickson, D., Thompson, T. J. U., \& Rankin, B. W. J. (2014). The application of 3D visualization of osteological trauma for the courtroom: A critical review. Journal of Forensic Radiology and Imaging, 2(3), 132-137. https://doi.org/10.1016/j.jofri.2014.04.002

Feldkamp, L. A., Goldstein, S. A., Parfitt, M. A., Jesion, G., \& Kleerekoper, M. (1989). The direct examination of three-dimensional bone architecture in vitro by computed tomography. Journal of Bone and Mineral Research, 4(1), 3-11. https://doi.org/10.1002/jbmr.5650040103

Fenn, W. O. (1957). THE MECHANICS OF STANDING ON THE TOES1. American Journal of Physical Medicine \& Rehabilitation, 36(3), 153. Retrieved from https://journals.lww.com/ajpmr/Citation/1957/06000/THE_MECHANICS_OF_ STANDING_ON_THE_TOES1.3.aspx

Fischer, O. (1906). Theoretical fundamentals for a mechanics of living bodies with special applications to man as well as to some processes of motion in machines (in German). BG Teubner, Berlin.

Fricke, O., Weidler, J., Tutlewski, B., \& Schoenau, E. (2006). Mechanography-A New Device for the Assessment of Muscle Function in Pediatrics. Pediatric Research, 59(1), 46-49. https://doi.org/10.1203/01.pdr.0000191580.07644.1c

Frost, H. M. (1994). Wolff's Law and bone's structural adaptations to mechanical usage: an overview for clinicians. The Angle Orthodontist, 64(3), 175-188.

Frost, H. M. (2004). A 2003 Update of Bone Physiology and Wolff's Law for Clinicians. Angle Orthodontist, 74(1), 13.

F-Scan System. (n.d.). Retrieved September 1, 2018, from https://www.tekscan.com/products-solutions/systems/f-scan-system 
Gabel, L., Macdonald, H. M., Nettlefold, L., Race, D., \& McKay, H. A. (2016). Reference data for jumping mechanography in Canadian children, adolescents and young adults. Journal of Musculoskeletal \& Neuronal Interactions, 16(4), $283-295$.

Geuze, R. H. (2003). Static balance and developmental coordination disorder. Human Movement Science, 22(4-5), 527-548.

https://doi.org/10.1016/j.humov.2003.09.008

Haapasalo, H., Kontulainen, S., Sievänen, H., Kannus, P., Järvinen, M., \& Vuori, I. (2000). Exercise-induced bone gain is due to enlargement in bone size without a change in volumetric bone density: a peripheral quantitative computed tomography study of the upper arms of male tennis players. Bone, 27(3), 351357. https://doi.org/10.1016/S8756-3282(00)00331-8

Haff, G. G., Carlock, J. M., Hartman, M. J., Kilgore, J. L., Kawamori, N., Jackson, J. R., ... Stone, M. H. (2005). FORCE-TIME CURVE CHARACTERISTICS OF DYNAMIC AND ISOMETRIC MUSCLE ACTIONS OF ELITE WOMEN OLYMPIC WEIGHTLIFTERS. Journal of Strength and Conditioning Research, 19(4), 741-748.

Haff, G. G., Ruben, R. P., Lider, J., Twine, C., \& Cormie, P. (2015). A Comparison of Methods for Determining the Rate of Force Development During Isometric Midthigh Clean Pulls. The Journal of Strength \& Conditioning Research, 29(2), 386. https://doi.org/10.1519/JSC.0000000000000705

Haff, G. G., Stone, M., O’Bryant, H. S., Harman, E., Dinan, C., Johnson, R., \& Han, K.-H. (1997). Force-Time Dependent Characteristics of Dynamic and Isometric Muscle Actions. The Journal of Strength \& Conditioning Research, 11(4), 269. Retrieved from https://journals.lww.com/nsca- 
jscr/abstract/1997/11000/force_time_dependent_characteristics_of_dynamic.14. $\operatorname{aspx}$

Harman, E. A., Rosenstein, M. T., Frykman, P. N., Rosenstein, R. M., \& Kraemer, W. J. (1991). Estimation of human power output from vertical jump. The Journal of Strength \& Conditioning Research, 5(3), 116-120.

Hart, N. H., Nimphius, S., Rantalainen, T., Ireland, A., Siafarikas, A., \& Newton, R. U. (2017). Mechanical basis of bone strength: influence of bone material, bone structure and muscle action. Journal of Musculoskeletal \& Neuronal Interactions, 17(3), 114-139. Retrieved from https://www.ncbi.nlm.nih.gov/pmc/articles/PMC5601257/

Hatze, H. (1974). The meaning of the term" biomechanics". Journal of Biomechanics, $7(2), 189$.

Hatze, H. (1998). Validity and reliability of methods for testing vertical jumping performance. Journal of Applied Biomechanics, 14(2), 127-140.

Hatze, H. (2002). The fundamental problem of myoskeletal inverse dynamics and its implications. Journal of Biomechanics, 35(1), 109-115. https://doi.org/10.1016/S0021-9290(01)00158-0

Hildred A. (2018, August 15). Mary Rose skeletal remains.

Janz, K. F., Letuchy, E. M., Burns, T. L., Francis, S. L., \& Levy, S. M. (2015). Muscle Power Predicts Adolescent Bone Strength: Iowa Bone Development Study. Medicine \& Science in Sports \& Exercise, 47(10), 2201-2206. https://doi.org/10.1249/MSS.0000000000000648

Johnson, D. L., \& Bahamonde, R. (1996). Power output estimate in university athletes. Journal of Strength and Conditioning Research, 10, 161-166. 
Kelvin, W. T. B. (1891). Popular Lectures and Addresses (Vol. 1). Macmillan and Company.

Kerwin, D., G. (1997). Force Plate Analysis of human jumping. Loughborough.

Kibele, A. (1998). Possibilities and Limitations in the Biomechanical Analysis of Countermovement Jumps: A Methodological Study. Journal of Applied Biomechanics, 14(1), 105-117. https://doi.org/10.1123/jab.14.1.105

Kistler. (n.d.). Standard Force Plate for Research and Sports. Retrieved September 17, 2018, from https://www.kistler.com/en/product/type-9281e/

Kivell, T. L. (2016). A review of trabecular bone functional adaptation: what have we learned from trabecular analyses in extant hominoids and what can we apply to fossils? Journal of Anatomy, 228(4), 569-594. https://doi.org/10.1111/joa.12446

Knudson, D. V. (2009). Correcting the Use of the Term "Power" in the Strength and Conditioning Literature: Journal of Strength and Conditioning Research, 23(6), 1902-1908. https://doi.org/10.1519/JSC.0b013e3181b7f5e5

Kontulainen, S., Sievänen, H., Kannus, P., Pasanen, M., \& Vuori, I. (2003). Effect of Long-Term Impact-Loading on Mass, Size, and Estimated Strength of Humerus and Radius of Female Racquet-Sports Players: A Peripheral Quantitative Computed Tomography Study Between Young and Old Starters and Controls. Journal of Bone and Mineral Research, 18(2), 352-359. https://doi.org/10.1359/jbmr.2003.18.2.352

Kuzminsky, S. C., \& Gardiner, M. S. (2012). Three-dimensional laser scanning: potential uses for museum conservation and scientific research. Journal of Archaeological Science, 39(8), 2744-2751. https://doi.org/10.1016/j.jas.2012.04.020 
Launey, M. E., Buehler, M. J., \& Ritchie, R. O. (2010). On the mechanistic origins of toughness in bone. Annual Review of Materials Research, 40, 25-53.

Link, T. M. (2010). The Founder's Lecture 2009: advances in imaging of osteoporosis and osteoarthritis. Skeletal Radiology, 39(10), 943-955.

Louis, O., Soykens, S., Willnecker, J., Van den Winkel, P., \& Osteaux, M. (1996). Cortical and total bone mineral content of the radius: accuracy of peripheral computed tomography. Bone, 18(5), 467-472.

Lyons, R. G. (2011). Understanding Digital Signal Processing, 3/E. Pearson Education India.

Mahmoodi, P, Annan, S, \& Owen, N. (2015). A computational method of obtaining reliable measurement of periosteal cross-sectional area of human radii from laser scans. In Proceedings of the 23rd UK Conference of the Association for Computational Mechanics in Engineering (pp. 73-76).

Maquet, P. (1989). [Borelli: De Motu Animalium. A first treatise on biomechanics]. Acta Orthopaedica Belgica, 55(4), 541-546.

Martin Bland, J., \& Altman, D. (1986). STATISTICAL METHODS FOR ASSESSING AGREEMENT BETWEEN TWO METHODS OF CLINICAL MEASUREMENT. The Lancet, 327(8476), 307-310. https://doi.org/10.1016/S0140-6736(86)90837-8

Martini, F., Bartholomew, E. F., Garrison, C. W., Hutchings, R. T., Nath, J. L., Ober, W. C., \& Welch, K. (2012). Fundamentals of anatomy \& physiology (7th ed.). Pearson.

McGuigan, M. R., Winchester, J. B., \& Erickson, T. (2006). THE IMPORTANCE OF ISOMETRIC MAXIMUM STRENGTH IN COLLEGE WRESTLERS. Journal of Sports Science and Medicine, (CSSI1). 
McKay, H. A. (2005). "Bounce at the Bell": a novel program of short bouts of exercise improves proximal femur bone mass in early pubertal children. British Journal of Sports Medicine, 39(8), 521-526. https://doi.org/10.1136/bjsm.2004.014266

McMahon, J. J., Murphy, S., Rej, S. J. E., \& Comfort, P. (2016). CountermovementJump-Phase Characteristics of Senior and Academy Rugby League Players. International Journal of Sports Physiology and Performance, 12(6), 803-811. https://doi.org/10.1123/ijspp.2016-0467

McMahon, J., Rej, S., Comfort, P., McMahon, J. J., Rej, S. J. E., \& Comfort, P. (2017). Sex Differences in Countermovement Jump Phase Characteristics. Sports, 5(1), 8. https://doi.org/10.3390/sports5010008

Mould, R. F. (1995). The early history of X-ray diagnosis with emphasis on the contributions of physics 1895-1915. Physics in Medicine \& Biology, 40(11), 1741. https://doi.org/10.1088/0031-9155/40/11/001

Newton, I. (1687). Philosophiae naturalis principia mathematica. Londini: Jussu Societatis Regiæ ac Typis Josephi Streater. Prostat apud plures Bibliopolas.

Newton, R. U., \& Dugan, E. (2002). Application of Strength Diagnosis. Strength and Conditioning Journal, 10.

Otten, E. (2003). Inverse and forward dynamics: models of multi-body systems. Philosophical Transactions of the Royal Society B: Biological Sciences, 358(1437), 1493-1500. https://doi.org/10.1098/rstb.2003.1354

Owen. (2008). Development of a field test to estimate peak vertical mechanical power of elite male rugby union players (MPhil). Swansea University.

Owen, N J, Griffiths, W, \& Watkins, J. (2015). Normative data for lower limb peak mechanical power in children aged 7 to 11 years old. Journal of Comorbidity, 5(2), 93. https://doi.org/10.15256/joc.2015.5.52 
Owen, N. J., Watkins, J., Kilduff, L. P., Bevan, H. R., \& Bennett, M. A. (2014). Development of a Criterion Method to Determine Peak Mechanical Power Output in a Countermovement Jump: Journal of Strength and Conditioning Research, 28(6), 1552-1558. https://doi.org/10.1519/JSC.0000000000000311

Patterson, D. D., \& Peterson, D. F. (2004). Vertical Jump and Leg Power Norms for Young Adults. Measurement in Physical Education and Exercise Science, 8(1), 33-41. https://doi.org/10.1207/s15327841mpee0801_3

pedar. (n.d.). Retrieved September 1, 2018, from http://www.novel.de/novelcontent/pedar

Pope, M. H. (2005). Giovanni Alfonso Borelli--the father of biomechanics. Spine, 30(20), 2350-2355.

Quintic Biomechanics. (n.d.). Retrieved September 1, 2018, from https://www.quinticsports.com/quintic-biomechanics/

Ramírez-Vélez, R., Correa-Bautista, J. E., Lobelo, F., Cadore, E. L., Alonso-Martinez, A. M., \& Izquierdo, M. (2017). Vertical Jump and Leg Power Normative Data for Colombian Schoolchildren Aged 9-17.9 Years: The FUPRECOL Study. Journal of Strength and Conditioning Research, 31(4), 990-998.

https://doi.org/10.1519/JSC.0000000000001550

Rao, G., Amarantini, D., Berton, E., \& Favier, D. (2006). Influence of body segments' parameters estimation models on inverse dynamics solutions during gait. Journal of Biomechanics, 39(8), 1531-1536. https://doi.org/10.1016/j.jbiomech.2005.04.014

Riddell, A., Solis-Trapala, I., Prentice, A., \& Ward, K. (2015). Muscle power and force are predictors of bone microarchitecture and strength in healthy children and adolescents measured by high resolution peripheral quantitative computed 
tomography and jumping mechanography. Presented at the 7th International Conference on Children, BioScientifica. https://doi.org/10.1530/boneabs.4.P167

Rose, J., Wolff, D. R., Jones, V. K., Bloch, D. A., Oehlert, J. W., \& Gamble, J. G. (2002). Postural balance in children with cerebral palsy. Developmental Medicine \& Child Neurology, 44, 58-63.

Ruff, C., Holt, B., \& Trinkaus, E. (2006). Who's afraid of the big bad Wolff?: “Wolff's law" and bone functional adaptation. American Journal of Physical Anthropology, 129(4), 484-498. https://doi.org/10.1002/ajpa.20371

Rule, M, \& Charles (principe di Galles). (1982). The Mary Rose: the excavation and raising of Henry VIII's flagship. London: Conway Maritime Press.

Sargent, D. A. (1921). The Physical Test of a Man. American Physical Education Review, 26(4), 188-194. https://doi.org/10.1080/23267224.1921.10650486

Sayers, S. P., Harackiewicz, D. V., Harman, E. A., Frykman, P. N., \& Rosenstein, M. T. (1999). Cross-validation of three jump power equations. Medicine and Science in Sports and Exercise, 31(4), 572-577.

Shetty, A. B. (2002). Leg Power: Estimation of leg power: a two-variable model. Sports Biomechanics, 1(2), 147-155.

https://doi.org/10.1080/14763140208522793

Sievänen, H., Koskue, V., Rauhio, A., Kannus, P., Heinonen, A., \& Vuori, I. (1998). Peripheral Quantitative Computed Tomography in Human Long Bones: Evaluation of In Vitro and In Vivo Precision. Journal of Bone and Mineral Research, 13(5), 871-882. https://doi.org/10.1359/jbmr.1998.13.5.871

Singh, S., Bray, T. J. P., \& Hall-Craggs, M. A. (2018). Quantifying bone structure, micro-architecture, and pathophysiology with MRI. Clinical Radiology, 73(3), 221-230. https://doi.org/10.1016/j.crad.2017.12.010 
Sleivert, G., \& Taingahue, M. (2004). The relationship between maximal jump-squat power and sprint acceleration in athletes. European Journal of Applied Physiology, 91(1), 46-52. https://doi.org/10.1007/s00421-003-0941-0

Stirland, A. (1993). Asymmetry and activity-related change in the male humerus. International Journal of Osteoarchaeology, 3(2), 105-113. https://doi.org/10.1002/oa.1390030207

Stirland, A. (2000). Raising the dead: the skeleton crew of Henry VIII's great ship, the Mary Rose. John Wiley \& Sons Incorporated.

Stone, M. H., Sands, W. A., Carlock, J., Callan, S., Dickie, D., Daigle, K., ... Hartman, M. (2004). THE IMPORTANCE OF ISOMETRIC MAXIMUM STRENGTH AND PEAK RATE-OF-FORCE DEVELOPMENT IN SPRINT CYCLING. Journal of Strength and Conditioning Research, 18(4).

Street, G., McMillan, S., Board, W., Rasmussen, M., \& Heneghan, J. M. (2001). Sources of Error in Determining Countermovement Jump Height with the Impulse Method. Journal of Applied Biomechanics, 17(1), 43-54. https://doi.org/10.1123/jab.17.1.43

Sumnik, Z., Matyskova, J., Hlavka, Z., Durdilova, L., Soucek, O., \& Zemkova, D. (2013). Reference data for jumping mechanography in healthy children and adolescents aged 6-18 years, 13(3), 297-311.

Sutherland, D. H. (2005). The evolution of clinical gait analysis part III-kinetics and energy assessment. Gait \& Posture, 21(4), 447-461.

Taichman, R. S. (2005). Blood and bone: two tissues whose fates are intertwined to create the hematopoietic stem-cell niche. Blood, 105(7), 2631-2639. https://doi.org/10.1182/blood-2004-06-2480 
Taylor, M. J. D., Cohen, D., Voss, C., \& Sandercock, G. R. H. (2010). Vertical jumping and leg power normative data for English school children aged 10-15 years. Journal of Sports Sciences, 28(8), 867-872.

https://doi.org/10.1080/02640411003770212

Tessier, J.-F., Basset, F.-A., Simoneau, M., \& Teasdale, N. (2013). Lower-Limb Power cannot be Estimated Accurately from Vertical Jump Tests. Journal of Human Kinetics, 38, 5-13. https://doi.org/10.2478/hukin-2013-0040

Thurston, A. J. (1999). Giovanni Borelli and the study of human movement: An historical review. Australian and New Zealand Journal of Surgery, 69(4), 276288.

Vanrenterghem, J., Clercq, D. D., \& Cleven, P. V. (2001). Necessary precautions in measuring correct vertical jumping height by means of force plate measurements. Ergonomics, 44(8), 814-818.

https://doi.org/10.1080/00140130118100

Veilleux, L.-N., \& Rauch, F. (2010). Reproducibility of jumping mechanography in healthy children and adults. Journal of Musculoskeletal \& Neuronal Interactions, 10(4), 256-266.

VICON. (n.d.). Motion Capture for Biomechanics and Sports Science. Retrieved September 1, 2018, from http://www.vicon.com/motion-capture/biomechanicsand-sport

Ward, F. (1838). Outlines of human osteology (first). London: Henry Renshaw.

Watkins, J. (2009). Structure and Function of the Musculoskeletal System-2E. Human Kinetics.

Watkins, J. (2014). Fundamental biomechanics of sport and exercise. Routledge. 
Winter, E. M., Abt, G., Brookes, F. C., Challis, J. H., Fowler, N. E., Knudson, D. V., ... Van Mechelen, W. (2016). Misuse of "power" and other mechanical terms in sport and exercise science research. The Journal of Strength \& Conditioning Research, 30(1), 292-300.

Wolff, J. (1892). Das Gesetz der Transformation der Knochen. Berlin: A. Hirschwald.

Wolff, Julius. (1870). Ueber die innere Architectur der Knochen und ihre Bedeutung für die Frage vom Knochenwachsthum. Archiv Für Pathologische Anatomie Und Physiologie Und Für Klinische Medicin, 50(3), 389-450.

Wolff, Julius. (2012). The Law of Bone Remodelling. Springer Science \& Business Media.

Zatsiorsky, V. M., \& Zaciorskij, V. M. (2002). Kinetics of human motion. Human Kinetics. 